\title{
The Diseases of the Sweet Pea
}

\section{THESIS}

PRESENTED TO THE FACULTY OF THE GRADUATE SCHOOL OF THE UNIVERSITY OF PENNSYLVANIA IN PARTIAL FUL-

FILMENT OF THE REQUIREMENTS FOR THE

DEGREE OF DOCTOR OF PHILOSOPHY

\section{J. J. TAUBENHAUS}

PHILADELPHIA

1914 


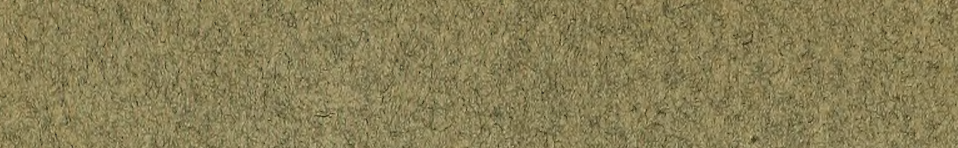

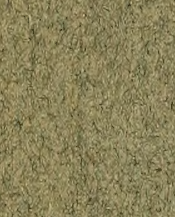

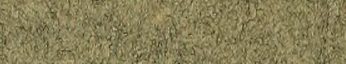 \\ (1)

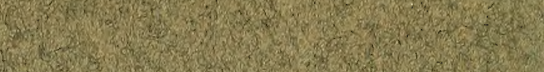

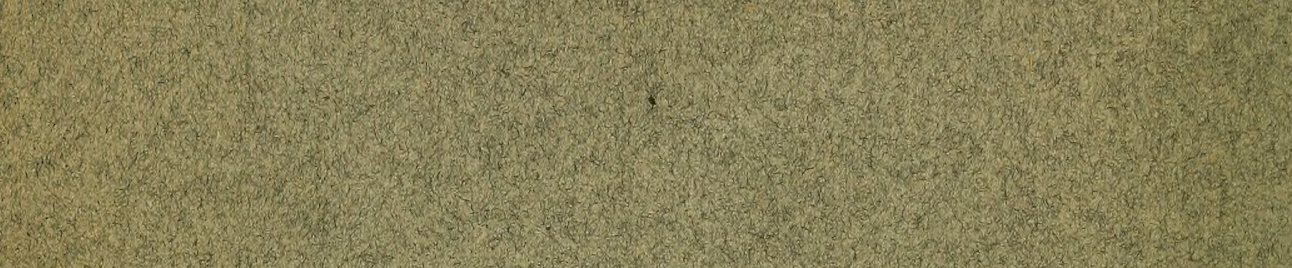

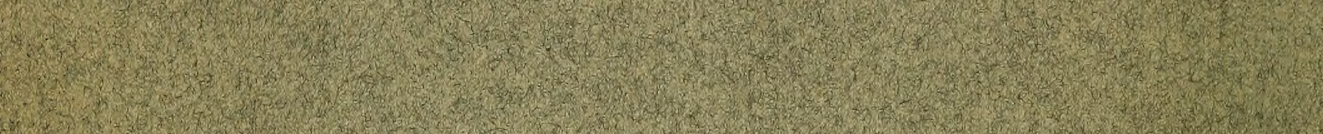

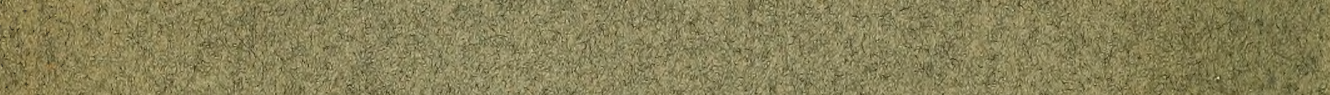
(2)

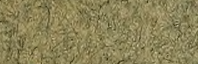

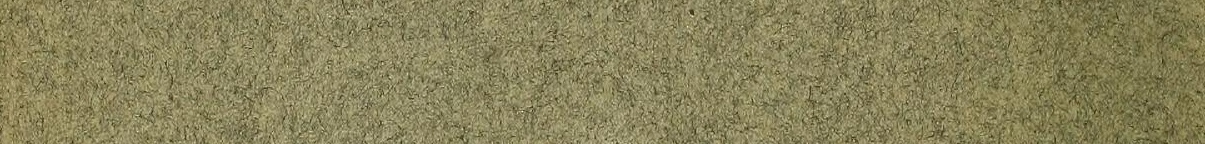

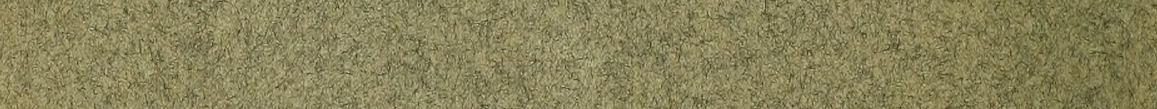

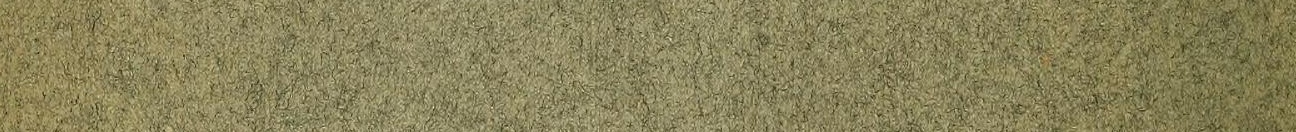

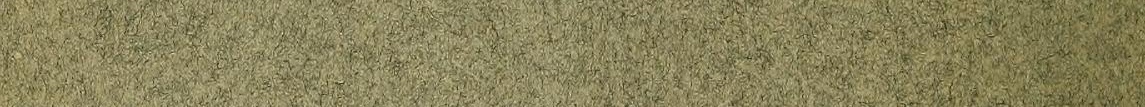
2. (6) 1.7.

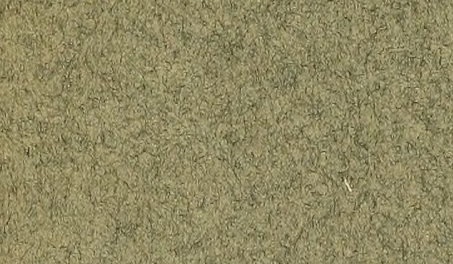

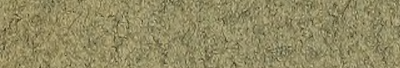

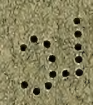

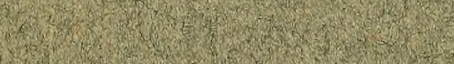

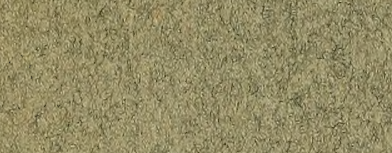

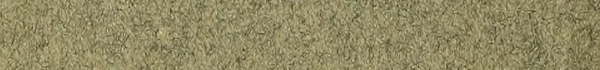

(2)

(A)

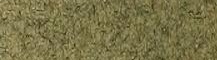

(15)

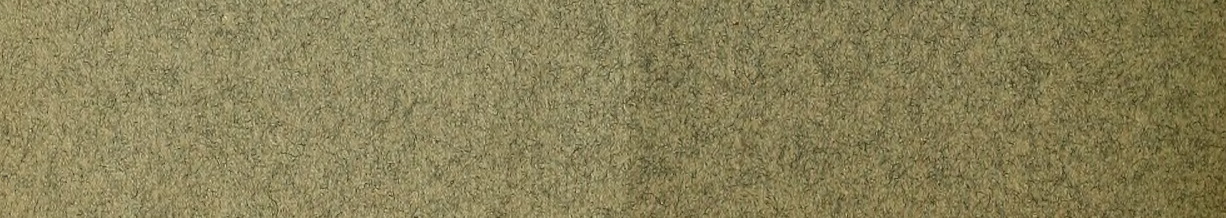

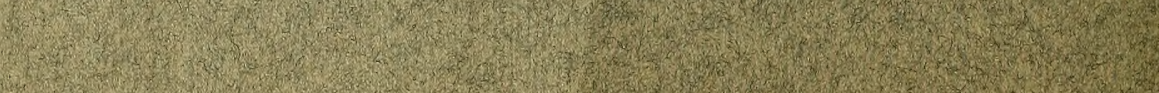




\section{The Diseases of the Sweet Pea}

\section{THESIS}

PRESENTED TO THE FACULTY OF THE GRADUATE SCHOOL OF THE UNIVERSITY OF PENNSYLVANIA IN PARTIAL FULFILMENT OF THE REQUIREMENTS FOR THE DEGREE OF DOCTOR OF PHILOSOPHY

$$
\text { J. J. TAUBENHAUS }
$$

PHILADELPHIA 


$$
\frac{S B 608}{595 T^{3}}
$$

$$
\text { Tho Uairosily }
$$

$\therefore \vdots$ 


\title{
Delaware College
}

\author{
Agricultural
}

\section{Experiment Station}

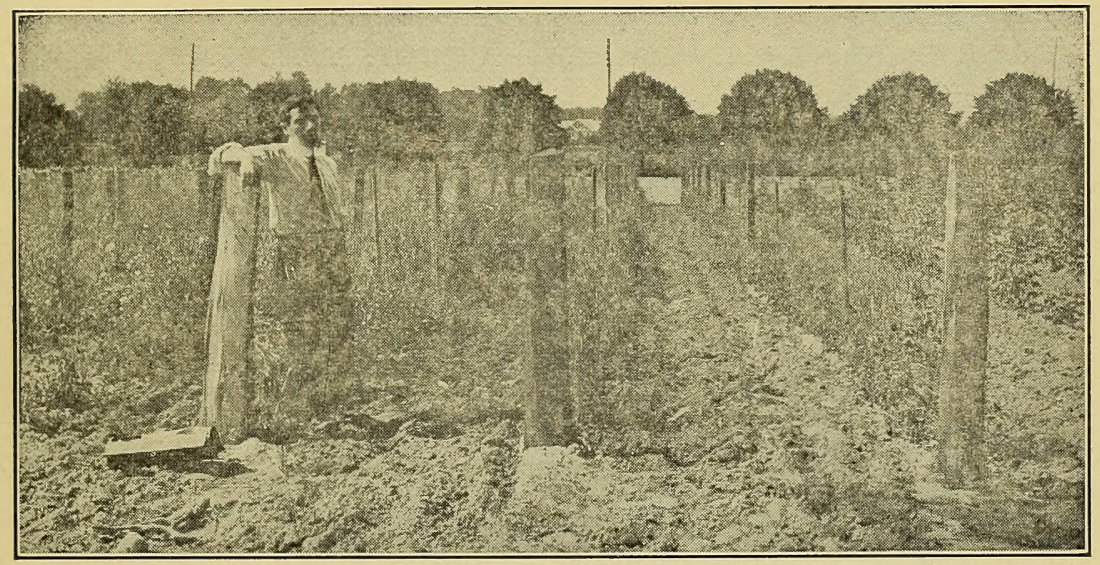

The Diseases of the Sweet Pea

\author{
BY J. J. TAUBENHAUS
}

Newark, Delaware 


\section{INDEX}

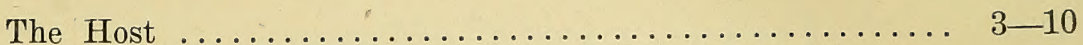

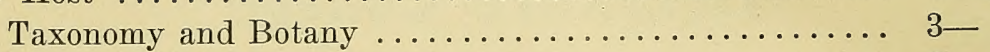

History of the Sweet Pea ................. $5-6$

Economic Importance .................... $5-6$

Cultivation and Care ........................ $6-8$

Sweet Peas Under Glass .................. 8-10

Diseases of the Sweet Pea .................. 10-74

I. Fungous Diseases . . . . . . . . . . . . . 12-68

II. Bacterial Diseases . . . . . . . . . . . . . . 68 72

III. Physiological Diseases $\ldots \ldots \ldots \ldots \ldots \ldots \ldots \ldots .72-74$

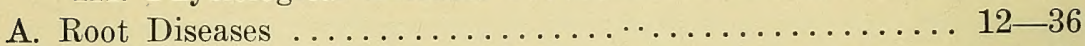

B. Diseases of the Aerial Parts of the Plants......... 36-65

C. Diseased Seeds ........................ 65-68

Root rot (Thielavia basicola Zopf) ........... 12-21

Rhizoctonia root rot (Corticium vagum B. \& C.) .... 21-27

Chaetomium root rot (Chaetomium spirochaete Patt.) . 27-30

Fusarium root rot (Fusarium lathyri Taub.)....... 31-34

Root Knot (Heterodera radicicola [Greef] Muller)..... 35-36

Stem or collar rot (S. libertiana Fckl.) . ......... 36-41

Powdery mildew (Oiduim sp.) . ............. 41-43

Anthracnose (Glomerella rufomaculans) ........ 43-55

Mosaic disease ........................... 56-64

Diseases not known to be present in this country..... $64-65$

Pea blight (Peronospora trifoliorum De By.) .... 64-65

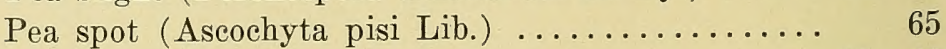

Diseased seeds ........................ 65-68

Streak disease (Bacillus lathyri M. \& T.) . ...... 68-72

Bud drop ................................ 72-73

Arrested development .................. 73-74

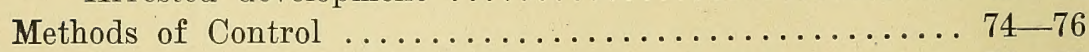

Resistant varieties ..................... 76-80

Seed treatment $\ldots \ldots \ldots \ldots \ldots \ldots \ldots \ldots \ldots \ldots \ldots \ldots 76-80$

Treatment of Soil with Chemicals ............ 80-82

Studies of the Fungicidial value of some chemical poisons $82-85$

Soil treatment in the greenhouse ............ 85-87

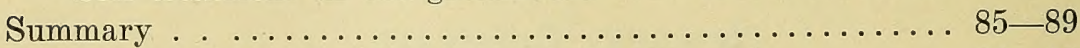

References . . . . . . . . . . . . . . . . . . . . 88-93 


\section{THE DISEASES OF THE SWEET PEA BY J. J. TAUBENHAUS}

\section{THE HOST \\ TAXONOMY AND BOTANY}

The sweet pea (Lathyrus odoratus L.) belongs to the family Leguminosae, the sub family Papilionaceae, the tribe Vicieae. The sweet pea (Lathyrus odoratus L.) is a herbaceous vine with rough stems, hairy and winged. The leaves are alternate, pinnately compound with terminal tendriliform leaflets. The leaflets are oval or oblong, mucronate. Peduncles 2-4 flowered, much longer than the leaves. The calyx teeth are broad, longer than the tube. The flowers are large, and showy in shades of blue, red, yellow and white. The standard is large, expanded, hooded, or wavy. The legumes are compressed, linear, 1-3 inches, hairy. The seeds are round, sometimes angled, black, white or mottled.

\section{HISTORY OF THE SWEET PEA}

Origin, Improvement and Distribution ${ }_{1}^{* *}$. The word "Lathyrus" is from the Greek La. la (augmentative) and thouros, anything exciting, having reference to the qualities of seeds of certain species. In Europe the species of Lathyrus are known as "Gesse," the sweet pea being known as Gesse odorante. The French know the plant under this name, or as Pois Odorante, or Pois de Senteur."

The earliest mention of the sweet pea is found in "Sillabus Plantarum Sicillæ-nuper detectarum a P. F. Franciscus Cupani", (Panormi, 1695). The sweet pea is spoken of as "Lathyrus distoplatyphyllos hirsutis mollis, magno et peramoeno flore odore." Father

*Also presented to the Faculty of the Graduate School of the University of Pennsylvania, June 1913, as a major thesis in partial fulfillment of the requirements for the degree of Doctor of Philosophy.

Acknowledgements. - The writer is indebted to Dr. John W. Harshberger, under whose direction the work was conducted, for helpful suggestions and criticisms. Acknowledgements are also due to Dr. T. F. Manns for helpful suggestions and advice. Thanks are also due to the many American seedsmen for financial support in carrying out the field experiments.

**All references will be found on pp. 84to 93 . 
Cupani was very enthusiastic about this flower and in 1699 sent seed to Dr. Uvedale at Enfield, England, and to Caspar Commelin at Amsterdam, Holland. Commelin described and illustrated the plant in his "Hort.-Medici Amsıelodamensis" (1697-1701). Commelin also adopted Cupani's name for the plant.

In his "Almagesti Botanici Mantissa" (1700) Dr. Leonard Plukenet also gives a description of the sweet pea. A dried specimen preserved in Plukenet's Herbarium, which now forms part of Sir Hans Sloane collection, is the oldest specimen of the sweet pea in existence.

Mention is made of the sweet pea by Petiver in the "Botanicum Hortense III" (1713). Petiver calls the plant Lathyrus Siculus, a native of Sicily which has large broad sweet smelling flowers. H. B. Ruppii in "Flora Jenensis" (Frankfort, 1718) places Lathyrus Siculus Ravini in a class of plants with irregular flowers. It is thus seen that all authorities place Sicily as the home of the sweet pea.

Linnæus, 1753, in his great "Systema Plantarum Europæ," classifies the sweet pea as follows:

"Odoratus II. Lathyrus pedunculis bifloris, eirrhis diphyllis, foliis ovato-oblongis, leguminibus hirsu'is. Hort. Cliff. 368, Hort. Upsal. 216, Roy. lugd. 363.

"Siculus a. La'thyrus Siculus. Rupp. jen., 210

Lathyrus distoplatyphyllos hirsuitis mollis, magno et peramœno flore odoro. Comm. Hort. 2, p. 219, t. 80.

"Zeylanicus b. Lathyrus Zeylanicus. Odorato flore amœne ex albo et rubro vario. Burm. Zeyl., 138.

"Habitat: a. in Sicilia; b. in Zeylona."

Here then is the first use of the term "odoratus" as a distinctive name.

Kniphof in his "Botanico in originali" (1757-1763) gives a colored illustration of Painted Lady sweet pea. In the catalog of W. Malcolm (1778), seedsman of Kensington Turnpike, we find offered for sale, white, purple and Painted Lady sweet peas. The first evidence of improvement is noticed in the catalog of John Mason (1793). He offered black, purple, scarlet, white and Pain'ted Lady sweet peas. Between 1845 and 1849 the firm of Messrs. J. Carter \& Co. introduced a new striped sweet pea and a new large purple sweet pea. In 1850 Messrs. Nobel, Cooper and Bolton introduced a new large dark purple variety. In $1860 \mathrm{Mr}$. Carter offered several new varieties of sweet 
peas. In James Vick's "Illustrated Catalog and Flower Guide" (1870), nine varieties of sweet peas are mentioned.

Beginning with 1880 , great strides have been made in the improvement of the sweet pea in England. Thomas Laxton and Henry Eckford (about 1880) were the moving spirits. Mr. Laxton introduced several new varieties obtained by crossing. Mr. Eckford was responsible for one hundred and fifteen new varieties. In America, Edward Sayers in his book "The American Flower Garden Companion" Boston, 1838), gives a list of five varieties of sweet peas. Of the American pioneers and breeders of the sweet pea, those who should be mentioned are D. M. Ferry \& Co. who in 1889 introdued the Blanche Ferry; W. Atlee Burpee \& Co., Messrs. C. C. Morse \& Co., J. C. Vaughn and Peter Henderson.

During the first one hundred years of sweet pea culture only three varieties, or colors, were known, i. e., purple with blue wings, pale red with white wings (Painted Lady) and white. The black and the scarlet appeared in the last years of the eighteenth century. At the present time there are more than a hundred and fifty varieties in cultivation with promising new ones appearing every year. This shows the grea' popularity of the sweet pea and the extent to which it is grown. Whenever a crop is grown extensively and for a long time under certain soil and climatic conditions, as is the sweet pea, diseases are sure to appear, making it difficult for the crop to succeed unless precautionary measures are taken. The cultivation of the sweet pea in England is at a crisis, the disease factor being the one obstacle to its cultivation. In America sweet pea growers are confronted with several important diseases.

\section{ECONOMIC IMPORTANCE}

I have been unable to obtain statistical data concerning the sweet pea crop. Messrs. C. C. Morse \& Co. fuınished us with the following information :

"Your favor of the 8th inst. was duly received and I shall be very glad to answer the questions you have asked, as well as I can.

"However, our Sweet Peas will be practically a failure this year and my statistics will apply only to past seasons, probably more accurately 'to the crop of 1911, which was the best we have had in recent times. Even last year's crop was very poor. 
1. So far as seed is concerned, the Sweet Pea crop is worth about $\$ 250,000$ annually to the grower.

2. There are about 1700 acres of land planted to Sweet Peas for seed in California annually. I have no knowledge of what acreage is devoted to flowers for market.

3. Practically no Sweet Pea seed is imported and about one-half of the California acreage is exported.

4. Fully 90 per cent. of the export business is done with Great Britain; the balance with Holland, Germany and France.

5. No other country, so far as we know, produces Sweet Pea seed to amount to anything.

Respectfully yours,

C. C. MORSE \& CO."

According to Bailey $_{2}$, California, in 1902, supplied the world's market with 125 tons of sweet pea seeds. As a cut flower the sweet pea is a great favorite and is extensively grown for that purpose.

\section{CULTIVATION AND CARE}

In this connection we will consider only those points of culture which directly influence the disease factor.

Climate. The sweet pea does best in a temperate region. It will not stand too warm a climate, as the plants there soon dry up and die, or they are so weakened as to succumb readily to all sorts of fungous diseases. California seems to be its ideal home, nevertheless the sweet pea is known to thrive under various elimatic conditions. It is less susceptible to cold than to heat and in hot dry climates irrigation is essential.

Site. The sweet pea requires an open, sunny location so as to get plenty of light and air. Plants grown in too shady a place will be spindly, weak, and open to the attacks of diseases.

Soil. All light sandy soils should be avoided for the reason already referred to above. A good loamy soil is preferred provided, of course, its subsoil is well underdrained, otherwise the plants will grow poorly and be consitantly open to the attacks of disease.

Fertilizer. In order to be at their best, sweet peas must be provided with sufficient available plant food in the soil. However, 
fertilizers should be used very judiciously. The aim should be to apply a food that is well balanced, i. e., it should contain the proper amount of nitrogen, phosphorus, potash and lime. Too much of one of these elements and too little of the other will produce disturbances in the metabolism of the plant as will be seen later under the discussion of physiological diseases. For an ordinary garden land, the following is a well balanced fertilizer devised by Prof. T. F. Manns of the Del. Expt. Station. Before plowing a surface application of well rotted manure at the rate of 6 tons per acre is first applied to the soil. After plowing and harrowing the soil, it is furrowed and 5 tons of rotted manure per acre is applied in the furrows. The manure is worked in deep with a spade and the following fertilizer is applied in the furrows :

*Sodium nitrate
Dried blood
Acid phosphate
Potassium sulphate
Rock phosphate
Hydrated lime
Carbonate of lime

200 lbs. per acre

250 lbs. " " "

1200 lbs. " " "

240 lbs. " " "

400 lbs. " " "

200 lbs. " " "

600 lbs. " “

The fertilizer is well mixed up with the soil and the seeds are planted on top and covered to a depth of about two to three inches.

Care of the Seeds and Depth of Sowing. Most of the whiteseeded varieties are subject to decay in the soil. Most of the blackseeded varieties are more resistant to soil decay but 'they do not germinate evenly. In order, therefore, to hasten germination, it is advisable to place the seed in tepid water over night. With this treatment the seeds swell and are ready to be sown the next day. The Rev. W. T. Hutchins, a well-known sweet peas specialist in America, advises the placing of the seed in moist earth for seven or eight days. They are then taken out and examined. The swollen seeds are plan'ted and the hard seeds eut with a knife to hasten germination. Whatever method is used the aim should be to hasien germination in order to prevent the seed from laying too long in the ground and thereby causing decay. The depth of sowing the seeds varies from two to three inches according to the nature of the soil. As to distance, five feet

*This mixture was recommended for a very heavy acid soil deficient in organic matter. 
apart between the rows and three inches in the row will insure the desired amount of air and light.

Care of the Growing Plants. Frequent cultivations with the hoe or with the cultivator will provide sufficient aeration of the roots to insure a vigorous growth of the vine. It is in baked and ill-drained soils that saprophytic fungi assume the nature of semi parasites, since it is in these soils that the plants are often weak and consequently yicld readily to the attacks of disease. Moreover, frequent cultivations destroy the weeds which may act as disease carriers or disease trans-

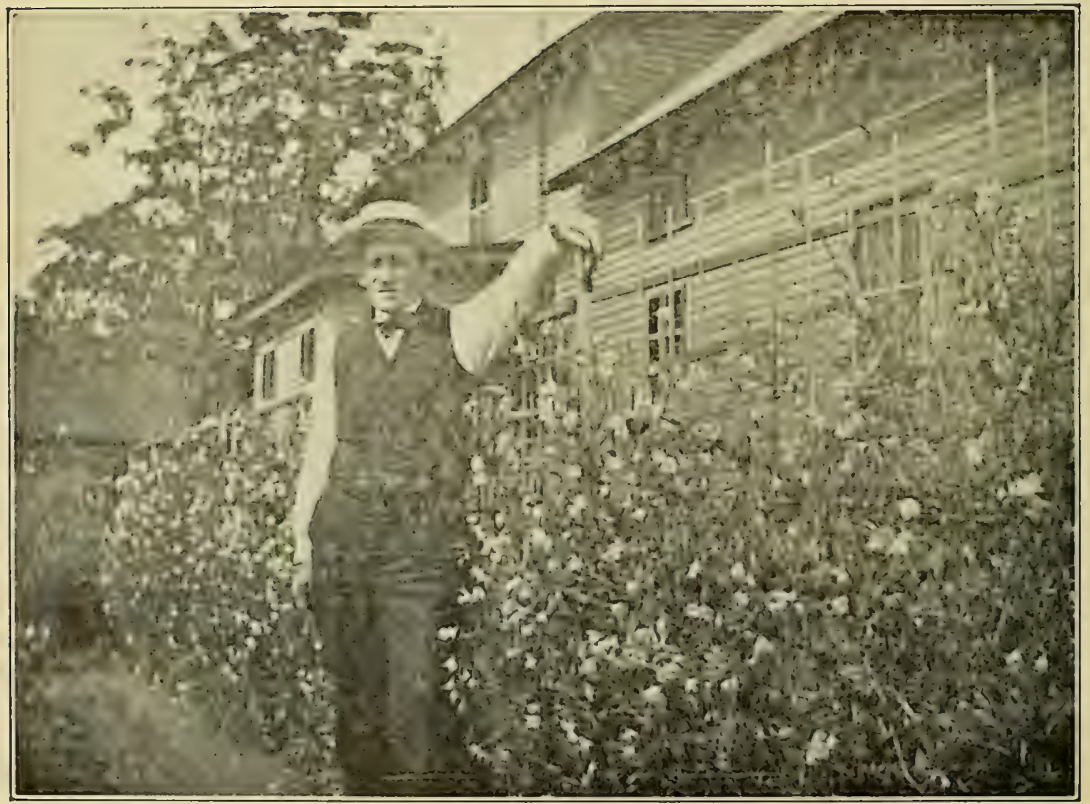

A convenient way of trailing sweet peas

mitiers. Irrigation wherever possible will no doubt benefit the plants, but irrigation should not replace cultivation. The plants should be kept free from the insect and the fungus pests. This will be discussed under methods of control. With the sweet pea, contrary to many other flowering plants, the blooms should be gathered freely as the more we do this the longer the vines will continue to flower. 


\section{SWEET PEAS UNDER GLASS}

The following notes on cultivation are by Mr. William Sim, Cliftondale, Mass., and are extracted from a paper read by him before the Gardeners' and Florists' Club of Boston on April 21, 1908:

"To grow the sweet pea to perfection under glass you must have a greenhouse suitable for the purpose. It should be at least eight feet high on the sides, four and a half feet being glass. My houses are seven feet, and I find the side rows sirike the glass when the vines are about half grown, thereby giving me half a crop. My center rows are about right; they are twelve to fifteen feet high. The higher the vines grow the more and better flowers you get. We plant the rows five feet apart and in a line with the supports of the greenhouse. The uprights are twelve feet apart, so in supporting we run twine from one support to the other on each side of the row. This I have found the best method of supporting. I have tried wire netiting; it is only a nuisance, as the vines do not cling to the wire, which causes just as much tying as if it were not there. It also causes injury many times to the vines, as a sweet pea stretches many times more than a foot in developing; if held back by anything in growing the growth looks like a spiral spring, and the picking of the blooms is made very difficult. The side rows are planted five feet from the sides of the house; and all the heating pipes are on the sides. The vines are very susceptible to red spider and as they will not stand syringing, the further you can afford economically to have them from the pipes the better.

"We have not changed the soil in the houses since they were built four and five years ago, and we find the vines are getting more vigorous each year. In the same soil a crop of tomatoes and of violets is harvested each year. The soil was originally eighteen inches deep, but by the application of manure each year the depth is now 'two and a half feet. The tomato crop is on the wane the middle of August. When these are cleaned ou' we trench the house over as deep as the soil, bringing the bottom soil to the surface. In the bottom of the trench we put three inches of decomposed cow manure; one foot from the surface we put on three inches more of the same material. The house is allowed to remain in this state until nearly itime for sowing the seed. The soil is then usually very dry, so we dampen it down enough to cling together while the house gets another forking over. This time we go down one foot and mix the top layer of manure with the surface soil. We then make the surface as nearly level as pos- 
sible and thoroughly water the soil, giving enough to penetrate the entire mass, with a strong dose of liquid horse manure. In about three days, depending on the weather, the house will be ready to plant. We sow the seeds about one and a half inches apart. We make the drills one inch deep and do not allow more than one inch of soil over them. We do not pull any more soil toward the roots, as is often recommended, but let it remain level. If more soil is pulled around the base of the plant, stem rot is sure to follow. We do not water the plants again until they are up about three inches.

"Of course, you can grow them on a bench with a few inches of soil, but the results will be just what you make them-a weak growth and a crop of short-stemmed flowers. These soon play out, as there is not enough soil or food for the vines to live on.

"They may be made to flower any time you wish by increasing the temperature, but the best results are obtained by growing at a temperature just above freezing until the buds can be felt in the crowns of the plants. Then the temperature should be gradually increased, say one degree a night, until you reach 48 degrees. This, I think, is about right, although in midwin'ter I think they move a little better at 50 . As the days lengthen a little cooler tempera'ture seems to suit better. A rise of 10 to 15 degrees should be given during the day in sunny weather. In spells of cloudy weather 55 degrees is high enough during the day. If a high temperature is given in dark weather the growth gets soft and wilts when the sun comes out bright again. While the plants are young they should be regularly fumiga'ted so there will not be a sign of lice when the plants commence to flower. If they are clean at this stage it will not be necessary to fumigate while they are in bloom. It is impossible to sell sweet peas that smell of 'tobacco. Tobacco also bleaches the flowers of some varieties, and makes them look like some other variety.

"We sometimes hear of someone having trouble with the buds dropping. This is more the case in midwinter than at any other time, and is caused by a too cool temperature or a sudden chill, or too much water. Should a house be allowed to go near the freezing point in midwniter the wholesale dropping of buds will be sure to follow." 


\section{DISEASES OF THE SWEET PEA HISTORICAL}

The literature on the subject of sweet pea disease previous to 1906 is mostly of a fragmentary nature. In 1896 Cuthbertson $_{3}$ first recoris a bud and blossom drop of the Cupid sweet pea in Scotland attributing the cause to cold and damp weather at that time.

In 1906, $\mathrm{Massee}_{4}$ gave the first brief scientific account of some sweet pea diseases, mentioning the following fungi: Peronospora trifoliorum, P. viciae, Erysiphe polygoni, and Ascochyta pisi.

In 1906, Weston 5 was first to describe the "Streak" as a new disease of 'the sweet pea in England (the cause not given). In 1907, Weston $_{6}$ again calls attention to the serious nature of the "Streak."

In 1907, an anonymous note ${ }_{6}$ mentions the following diseases: eelworm (Tylenchus devastatrix and obiusa), Peronospora trifoliorum,, sclerotia of some species of Sclerotinia, Erysiphe martii, and Botrytis cinerea.

In 1909, in a brief note, $\mathrm{Massee}_{7}$ also mentions the "Streak" disease which he thinks is induced by an excess of manure in the soil. This excess produces a deleterious effect on the soil flora which in turn brings about physiological disturbances resulting in the "streak." In 1912, Massee $_{8}$ again mentions a disease of sweet pea seedlings and of other plants as due to Thielavia.

In the same year (1912) Chittenden ${ }_{9}$, before the London Sweet Pea Society and in an article in the Royal Horticultural Society Journal reports on the "Streak" disease, which according to him, was found to be due to Thielavia basicola.

In 1912, W. Dyke ${ }_{10}$, an amateur scientist and gardener, calls attention to the "streak" disease which he believes is induced by a species of Fusarium and Macrosporium. It will be seen from the above reference that the only ones of scientific importance are those of Massee and Chittenden, because both of these investigators base their facts on research. However, as it will be shown later, both Massee and Chittenden mistook Thielavia as the cause of the "Streak" disease.

In American literature, Sheldon ${ }_{11}$ was the first one to call attention to the anthracnose of the sweet pea (Glomerella rufomaculans.)

The diseases of the sweet pea have received no other attention at the hands of American plant pathologists. 
For the past three years the writer has been investigating the diseases of the sweet pea, and as a result three papers have already been published $_{12}$.

It is the purpose of the present thesis to bring together all the results obtained in my investigations. The subject is by no means exhausted, as yet, and we hope to devote many more years to the study of the diseases of the sweet pea.

\section{THE DISEASES OF THE SWEET PEA}

The diseases treated in this thesis are as follows:

I. Fungous Diseases.

II. Bacterial Diseases.

III. Physiological Diseases.

IV. Animal or Insect Pest (Of the animal pests I will only consider the Heterodera radicicola and will discuss it under "root diseases." Of the insect pests I will only consider the green aphids and these will be discussed in relation to the "mosaic."

\section{Fungous Diseases}

A. Root Diseases.

B. Diseases of the Aerial Parts of the Plants.

C. Diseased Seeds.

\section{A. Root Diseases}

All root troubles of the sweet pea are eaused by fungi which live primarily in the soil. They can, therefore, also be designated as soil diseases. Diseased roots invariably indicate an infected soil. All soil parasites are not necessarily confined to the roots of the sweet pea only, as we shall have occasion to show later. Of the soil organisms which attack the roots, the following have been investigated:

Root rot. (Thielavia basicola Zopf.)

Root rot. Rhizoctonia (Corticium Vagum B. \& C.)

Root rot. (Chaetomium spirochaete Patt.)

Root rot. (Fusarium lathyri n. sp.)

Root galls Eel worms (Heterodera radicicola.)

ROOT ROT (Thielavia basicola Zopf)

Historical, Synonymy and Relationship. Thielavia basicola belongs to the ascomycetous family Perisporiaceæ. The fungus was 
first clescribed by Berkeley and Broome ${ }_{13}$ in 1850 , who gave it the name of Torula basicola; they found it growing at the base of affected pea plants. The torula or chlamydospore stage is the most conspicuous and it is abundantly found on the host. In $1875, \mathrm{Zopf}_{14}$ found the fungus on roots of Senecio elegans in Berlin, and in 1876, Sorokin ${ }_{15}$ found it on the roots of Cochlearia armoracia (horse radish) in Russia, and named it Helminthosporium fragile. Zopf, however, made a more thorough study of the fungus, and he discovered the perfect stage, placing it in the Perisporiaceæ, creating a new genus Thielavia after Prof. F. von Thielav of the University of Berlin.

In 1886 Saccardo ${ }_{16}$ found the same fungus. Noting the observations of Sorokin, he did not agree with him in calling the fungus Helminthosporium, and he placed it in the genus Clasterosporium. Saccardo thus failed to identify Sorokin's Helminthosporium fragile with the chlamydospore stage of Thielavia and with Berkeley and Broome's Torula basicola. It was to the credit of Sorauer ${ }_{17}$ who discovered the relationship of these different stages to belong to one and the same fungus. The name of the fungus with its synonomy is as follows :

Thielavia basicola (B. \& R.) Zopf.

Torula basicola (B. \& R.)

Helminthosporium fragile Sor.

Clasterosporium fragile (Sorok.) Sace.

Thielavia a Parasite on Other Hosts. The table on page 12 will show the list of hosts parasitized by Thielavia together with the authority for the same.

Thielavia Attacking Sweet Peas. In 1912, Chittenden ${ }_{18}$ was asked by the National Sweet Pea Society of England to investigate the dreaded "Streak" disease of the sweet pea. In his report before that society Chittenden gives an accurate description of the "Streak," so that there can be no doubt but that he had the disease well in mind, that is, he described it as a stem disease. Chittenden found Thielavia basicola to be the cause of "Streak" as he states, "careful microscopic examinations of the brown patches of the roots, and one must insist on the need for care; hasty examination may fail to reveal anything showing that they were attacked by a fungus wheih turned out to be Thielavia basicola. The same fungus was present in practically 
Name of Plant

Authority

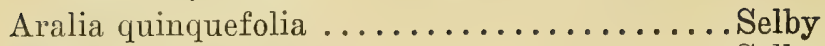

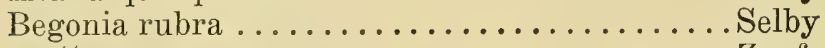

" sp. $\ldots \ldots \ldots \ldots \ldots \ldots \ldots \ldots \ldots \ldots$. Zopf

Catalpa speciosa ....................... Selby

Cochlearia armoracia ................. Sorokin

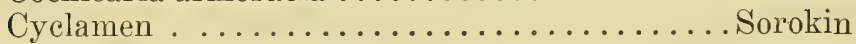

Gossypium herbaceum .............. Smith, E. F.

Lupinus albus ..........................

Linaria canadensis .......................bert

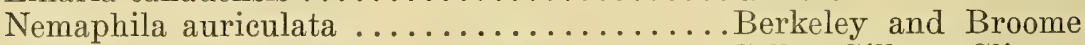

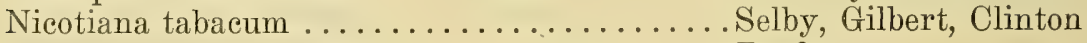

Onobrychis erista-galli ................. Zopf

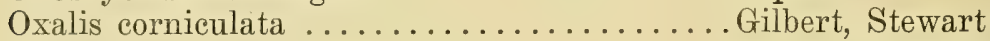

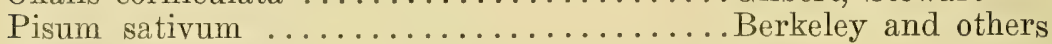

Phaseolus vulgaris .................. Zopf

Trigonella coerulea ..................

Vigna sinensis ..........................

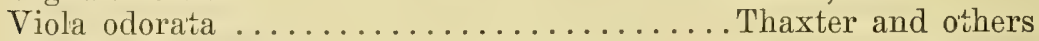

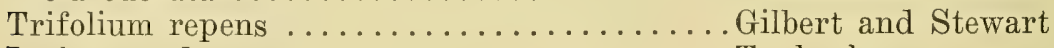

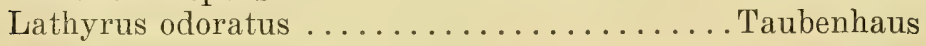

every case, sometimes abundantly fruiting, sometimes with only a few spores."

I will show later where Chittenden has erred in his investigations, and that the "streak" is not a root but a stem disease which is induced by a bacterium and not by Thielavia. In every case where Thielavia has been reported as a parasite on other hosts, it has been found on the roots and not on the stem. This same holds true for the sweet pea. Moreover, Chittenden in his artificial inoculation with the fungus, has succeeded in reproducing the typical root rot and not the "streak" on the stems. Massee ${ }_{19}$ too made the same mistake as Chittenden, for he too considers Thielavia to be the cause of the "Streak." I have seen the Thielavia root rot on half an acre of sweet peas at the trial grounds of one of our commercial seed men. The plants on that infested area were carefully examined, and no signs of streak could be found on, the stems. On the other hand, the trouble was seen to be plainly localized at the roots.

Symptoms of Thielavia Root Rot on Sweet Peas. Plants severely infected have practically little or no root sysitem since the latter is destroyed by the fungus as rapidly as the roots appear. (Figs. 1 and 2). Whatever root system is present is of a stubby nature and 


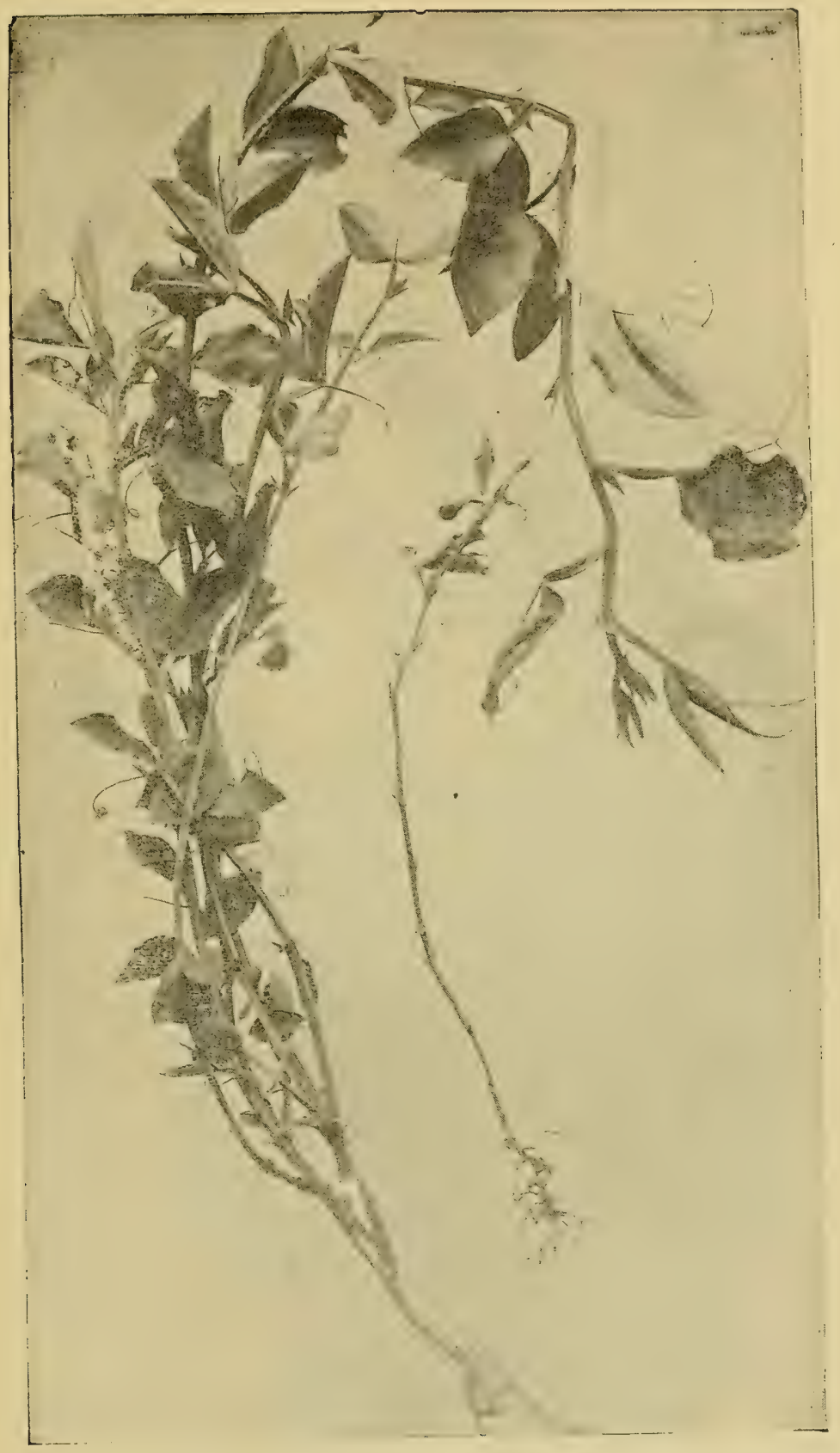

Fig. 1*, Root rot caused by Thielavia. Contrasting a healthy with a diseased plant of the same age.

* Figs. 1, 2, 9, 17, 33, 34, 35, 37, 39, 40 and 42, Electrotype, Gardener's Chronicle (England). Photographs by the author. 
charred in appearance. The fungus sometimes works upon the stem to a distance of two to three inches above ground, but never to the extent of invading the entire stem. It is probably due to this that some workers have mistaken "his disease for the well-known "streak."

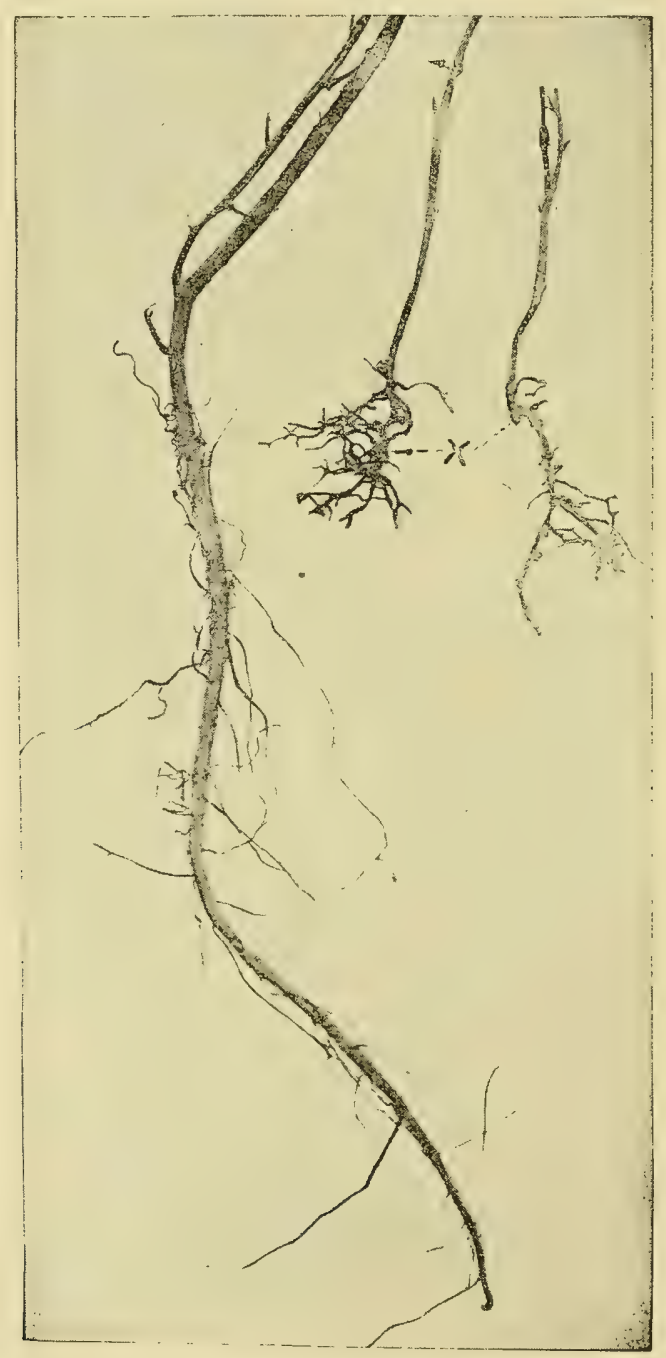

Fig. 2. Root rot caused by Thiclavia. Comparing root systems of healthy plants with diseased plants of the same age. 
Sweet peas infested with Thielavia have a dwarfed and sickly appearance. The fungus does not seem to kill it, but merely to produce an arrested development. The infected plants are useless for commercial purposes, as they fail to set flowers.

Pathogenicity. Chittenden ${ }_{20}$ seems to have been unable to infect healthy sweet pea seedlings with the fungus Thielavia basicrla under normal conditions of growth. It was only when his plants were overwatered that the fungus became an active parasite.

In my own inoculation experiments, healthy sweet pea seedlings have been readily infected by placing a pure culture of the fungus on the roots of the plants growing in sterile soil. In two to three weeks the roots were thoroughly diseased. Overwatering was not found necessary to bring about infection, although such treatment as well as injury to the roots favor the fungus in its activity. Another method adapted for proving the pathogenicity of the fungus was to sow pure cultures of the fungus together with sterilized seed (seeds treated in a solution of formaldehyde, 5 parts in 100 of water for 1-2 hr.) in sterile pots and soil. Checks were also sown with sterilized seeds in sterile pots and soil but without the fungus. Six days after sowing both lots of seeds germinated and both check and infected seedlings apparently grew equally as well. Beginning with the third week, infected seedlings ceased growing, whereas the checks made considerable progress. After six weeks the infected seedlings were seen to be decidedly dwarfed and pale green in color reproducing the typical symptoms of the disease as observed in the field. The check seedlings have by this time made decided growth. An examination of the roots of the infected seedlings revealed a diseased condition as found in the field, namely, absence of a well developed root system, and a blackening of the affected parts. The infection experiments were repeated five times always with the same result. In no case was the Thielavia seen to kill the host, but in each case a dwarfed condition of the plant was the result.

Infection of Sweet Peas with Thielavia from Other Hosts. It was found desirable to determine whether there existed any racial strains or physiological species of Thielavia basicola. Accordingly, pure cultures of the fungus obtained from cowpea, violets, parsnip and tobacco, were inoculated on sweet peas, using the same method of inoculation as previously described. In connection with this experiment 
a parallel series of inoculations was also run, using the Thielavia basicola from the sweet pea. The results obtained were the same, i. e. the Thielavia fungus when taken from other hosts than the sweet pea will readily infect the sweet pea, thus showing the absence of physiological strains or species.

Morphology of Thielavia basicola. Our studies and observations on this fungus have brought out facts found by other investigators. The mycelium of the fungus is hyalin, septate and branched. The hyphæ average from $3-4 \mathrm{u}$ in width. The mycelium becomes more or less greyish with age. There are three kinds of spore forms produced. 1. Endospores, so called because they are formed inside a special thread of the mycelium. This is the spore form that is most commonly met with in pure cultures of artificial media. The endo-

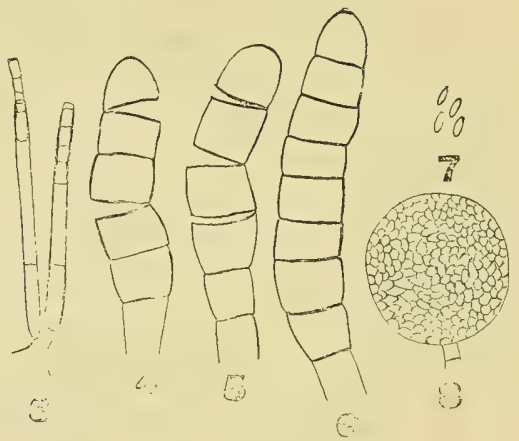

Fig. 3. Endospores.

Figs. 4, 5. Chlamydospores breaking up into individual spores.

Fig. 6. Chlamydospores, unbroken.

Fig. 7. Ascospores.

Fig. 8. Aseus.

spore case is formed on terminal branches. It has a somewhat swollen base and a long tapering cell (Fig. 3). The endospores are formed in the apex of this terminal cell and are pushed out of the ruptured end by the growth of the unfragmented protoplasm of the base. They are hyalin, thin-walled, oblong 'to linear 10-25ux4-5u.

The second kind of spores formed are the chlamydospores (Figs. 4-6). These are thick-walled dark brown bodies, born on the same mycelium as the endospores, and average from 20-50ux $10-18 u$, and correspond to the Torula stage of Berkeley's classification. 
The third kind of spores are the ascospores (Fig. 7.) These are lenticular in shape $12 \times 5 \mathrm{u}$ and are born in asci which in turn are born in spherical black perithecia. We have not as yet found the ascospore stage (Fig. 8) on the affected host, altho it is said to appear quite commonly on other hosts affected by this fungus.

Peglion $_{21}$ in 1897 was apparently the first to grow the fungus in pure culture. Aderhold ${ }_{22}$ in 1903 reports to have grown the fungus in pure culture. Clinton $_{23}$ and Gilbert ${ }_{24}$ experienced considerable difficulty in obtaining a pure culture of the fungus, due to the fact that the chlamydospores when taken from old diseased roots fail to germinate by being overrun with bacteria. At no time did the writer experience any difficulty in obtaining a pure culture of Thielavia from diseased sweet pea tissue. The following method was adapted from $\mathrm{Manns}_{25}$. Portions of the diseased roots are placed in a test 'ube in a solution of 1-1000 $\mathrm{HgCl}_{2}$ in a 50 per cent. alcohol and thoroughly shaken for thirty seconds. This will kill all surface contaminations. The disinfectant is then poured out and the material is rinsed three times in sterile water, the object being to remove all traces of mercuric chloride. Each tissue fragment is then taken separately and crushed with a sterile forceps in a tube of medium which has been melted and cooled to the proper temperature. The crushed tissue is now mixed with the medium in the tube, and the whole poured into a petri dish. After five or six days a pure growth of the fungus appears in the petri dish. The growth in this case resulted from the mycelium which has been crushed and liberated from the deeper tissue.

The fungus will grow on a variety of media. It grows well on sterilized vegetable plugs as those of potato, beet, carrot, sweet potato, corn stalks, and parsnip and particularly well on corn meal. Both endospores and chamydospores are produced on these media, but in no case did I obtain the perfect stage, although it was often looked for. Previous investigators too have never succeeded in obtaining the ascospore stage on pure culture.

Pathological Conditions of the Diseased Host. Reference has been previously made to the fact tha' the disease produced by Thielavia is confined to the root system. Infected plants have little or no root system at all, or if present it is charred and invaded by the fungus. The question arises, how do the plants persist such a long time without collapsing? It was observed that sweet peas affected with 
Thielavia, constantly make an attempt to produce new roots, but as fast as they are formed they are invaded by the fungus. It is possible, therefore, that these new rootlets help the host to persist so long, and yet not long enough to enable it to make any growth. It is also probable that there is a close symbiosis between host and parasite with the latter getting the upper hand. As far as observed from cross sections of that part of the stem which lies closest to the roots, the fungus is seen to invade all parts of the tissue with the exception of the xylem vessels. This fact, that the fungus does not enter the conducting vessels permits an upward movement of the water, and this is sufficient to prevent the host from dying.

ROOT ROT, Corticium vagum B. \& $C$.

Historical data, European literature. The first mention of Rhizoctonia can be traced to Duhamel ${ }_{26}$ who in 1728 described a disease of Saffron (Crocus sativus). He considered the sclerotia to be a special plan't and the hyphæ its roots, and named it Tuberoides. In 1782 Fougeroux de Bondaroy ${ }_{27}$ found asparagus plants which grew near a diseased saffron field to be likewise affected with Tuberoides. The first attempt to place the fungus in a systematic position was made by P. Builliard ${ }_{28}$ who referred it to the Truffles as Tuber parasiticum. Persoon $_{29}$ placed it in the Genus Selerotium, and called it Sclerotium crocorum. De Candolle ${ }_{30}$ was first to use the name Rhizoctonia. He at that time distinguished three species, R. crocorum, R. medicaginis, and R. mali. Nees ${ }_{31}$ in 1817 refers to a fungus disease of the crocus which he calls Thanatophytum crocorum. From an examination of his figures there can be no doubt but that it is Rhizoctonia. In 1830 , Duby $_{32}$ described a fungus disease of Allium ascalonicum and named it Rhizoctonia allii. In 1843 Leveilleé $_{33}$ describes Rhizoctonia as attacking Rubia 'inctorum, Solanum tuberosum, Phaseolus, and other plants. (The species of Rhizoctonia is not stated.) In 1851 the Tulsane $_{34}$ Brothers placed all the known forms of Rhizoctonia in one species which they called Rhizoctonia violacea. However, from Kuhn's critical work a few years later, $i_{t}^{t}$ seems advisable to maintain the distinction between R. solani and R. medicaginis. In Kukn's ${ }_{35}$ work which was published in 1858, a brief account is given of the smooth sclerotia of $R$. solani contrasted with the wooly sclerotia of $R$. medicaginis. Distinction is also made of $R$. crocorum and $R$. medicaginis, the latier is stated to attack beets and carrots. In 1903 
Erikson $_{36}$ concerns himself chiefly toward the discovery of biologic forms of the fungus.

In 1905, Gussow ${ }_{37}$ described the disease on potato and lucern, and he considers $R$. solani and $R$. violacea as one and the same.

In 1912 Shaw $_{38}$ investigated the morphology and parasitism of Rhizoctonia with a view of obtaining a better understanding of the supposed different species. Shaw concludes that the name $R$. violacea should be retained for all the non-fruiting forms with macrosclerotia, and the name Corticium vagum be given to the fruiting stage of the macrosclerotia of $R$. violacea, while the forms with microsclerotia should be identified as $\mathrm{R}$. solani Kuhn.

American Literature on Rhizoctonia. The American references to Rhizocitonia are as follows:

In 1891 Pammel $_{39}$ describes a rot of the beet root which he attributes to Rhizoctonia betae Kuhn.

In 1892 Atkinson $_{40}$ found a sterile fungus causing a damping-off of cotton, which he called "sore shin." The fungus can no doubt be referred to as Rhizoctonia. Later, Stone and Smith s1 $_{\text {give an account }}$ of a lettuce disease due to Rhizoctonia.

In 1901 Duggar and Stewart ${ }_{42}$ describe extensively a list of hosts attacked by Rhizoctonia. However, the species of the fungus is not given.

In 1904 Rolfs $_{43}$ reports on a potato disease due to Rhizoctonia, in which he found the fertile stage Corticium vagum B. and C. Specimens were sent by Rolfs to Dr. E. A. Burt, who pronounced it a variety of Corticium vagum $B$. and $C$. and for which he has suggested the name Corticium vagum $B$. and $C$. var. solani Burt.

In 1909 Stevens and $\mathrm{Hall}_{44}$ described a disease of the apple, pear and quince, which they attributed to a sterile fungus Hypochnus ochroleuca Noack. The fungus is described as having small sclerotia and there is no doubt but that it is a Rhizoctonia. Several workers have claimed to have connected different fruiting stages with that of Rhizoctonia. In 1869 Fuckel $_{45}$ stated that the Ascomycete Byssothecium circinans Fekl. was the perfect form of Rhizoctonia, both stages were found on decaying stems of Medicago sativa. Prunet ${ }_{46}$ also observed this association of Rhizoctonia on lucern with an ascomycete.

Hartig $_{47}$ found a Rosellinia associated with a Rhizoctonia on the roots of oak. 
Frank $_{48}$ reports Rhizoctonia violacea on grapes to be associated with Thelephora, which he named Th. rhizoctoniæ. However, none of the above authors have carried on any cultural work to prove the validity of their claims, hence none of the statements can be accepted as valid.

Rolfs $_{49}$ found a basidiomycete associated with Rhizoctonia on potato. Pure cultures obtained from spores of the basidiomycete always gave a Rhizoctonia, thus proving definitely the rela'tionship of the two forms. Rolfs basidiomycete is already known as Corticium vagum $B$. and $C$.

American, European and East Indian Hosts Subject to the Attacks of Rhizoctonia.

Name of Host

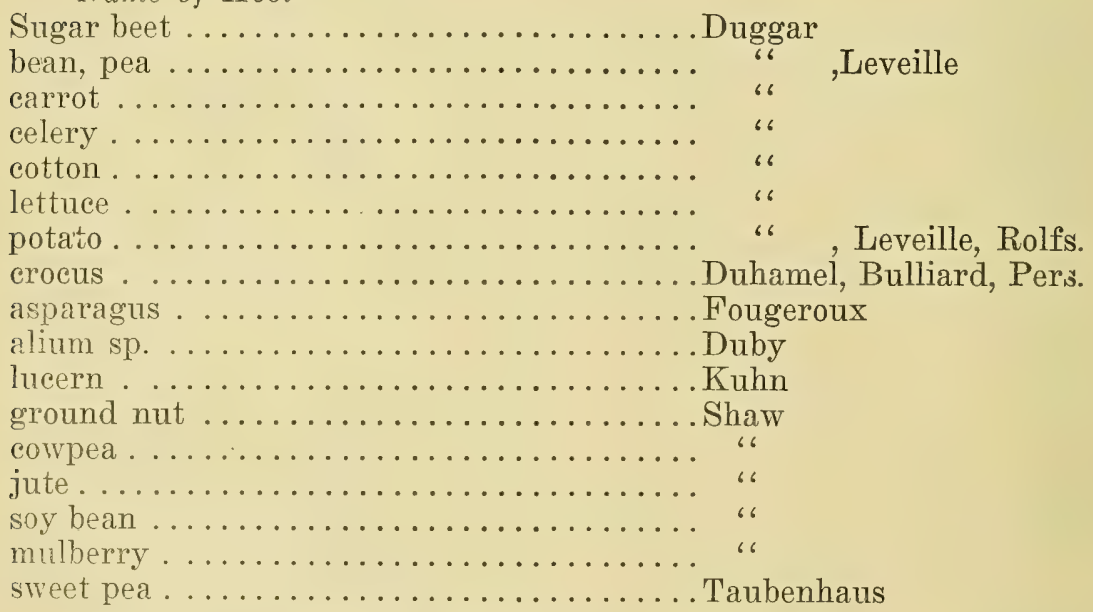

Rhizoctonia Attacking Sweet Peas. As far as could be ascertained no mention could be found in literature of a Rhizoctonia disease of sweet peas. I have observed it during winters of 1911 and 1912 on greenhouse specimens sent in by different sweet pea growers. In the fall of 1913, diseased sweet pea seedlings attacked with Rhizoctonia were collected in the greenhouse of the Universi'ty of Pennsylvania. From correspondence with Plant Pathologists, A. D. Selby reports it in Ohio, W. G. Sackett in Colorado and E. C. Stackman in Minnesota. There seems no doubt but that the Rhizoctonia root rot of sweet pea is much more widespread than is reported. 
Symptoms of the Disease. Severely infected plants have practically no root system (Fig. 9). In less infected plants only one or two rootlets may be destroyed. The fungus produces a browning effect of

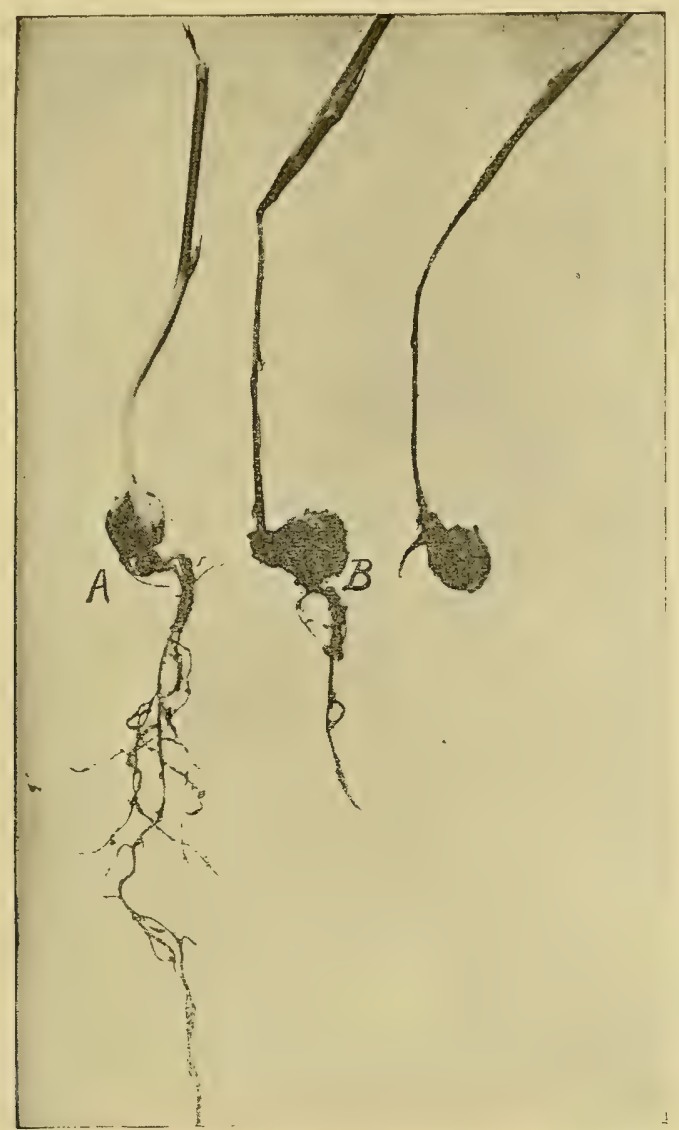

Fig. 9. Root rot caused by Rhizoctonia. (A) healthy. (B) diseased.

the root before total destruction sets in. In very early stages of infection the seedlings are seen to have a wilted appearance; as the disease progresses the infected seedlings fall over and collapse. The fungus is not often confined to the roots alone. It is often seen to work its way up the stem and this may produce a constricted area which marks it off from the healthy part. The fungus being a soil organism, it is usually introduced with manure; infection can take place at any part 
of the roots, or at the stem near the roots. When the latter is the case reddish sunken spots are observed at the base of the stein. It seems that only young seedlings can be quickly destroyed by the fungus whereas older plants seem to linger for considerable time altho such plants remain dwarfed, sickly looking and valueless for commercial purposes.

Pathogenicity. The pathogenicity of the sweet pea Rhizoctonia is readily proven by planting sterilized seeds in sterile soil and pots which were inoculated with a pure culture of the fungus. The best material to use is somewhat old cultures which have well developed sclerotia. It is from the latter that the fungus begins to vegetate and to spread in the soil. Five pots were inoculated with the fungus and two were kept as checks. The checks germinated and grew well, whereas none of the seeds germinated in the infected pots (Fig. 9a). In digging out some of these seeds they were found to be invaded with the fungus hyphæ of the Rhizoctonia. A pure culture may be readily obtained from these seeds, thus proving that the Rhizoctonia is a pathogenic organisms. Young seedlings may likewise be infected by the fungus, but as already indicated older plants are more resistant as they can live for some time with the fungus on them.

Morphology and Identity of the Sweet Pea Rhizoctonia. So far as my studies have gone, only two stages have been found of the sweet pea Rhizoctonia.

1. The Rhizoctonia stage.-This consists of long and narrow hyphal branches varying in color from hyalin to reddish brown (Fig. 10). These hyphæ are either aerial or are embedded in the substratum, varying according to the media on which it is grown. It is this hyphal growth which is most active in the parasitism of the fungus.

2. The Sclerotial stage.-In cultures which are from three to four weeks old numerous sclerotia are formed. These sclerotia are made up of closely interwoven short barrel-shaped hyphae (Fig. 11).

According to Shaw ${ }_{50}$ Rhizoctonia solani Kuhn produces only microsclerotia while Corticium vagum B. and C. produces macroselerotia. After repeated attempts the corticium stage of the sweet pea Rhizoctonia could not be obtained on artificial media. This accords with the findings of Shaw and Rolfs who could not obtain the perfect stage on culture media but found it several times on the affected host. However, as the sweet pea Rhizoctonia produces macrosclerotia and as 


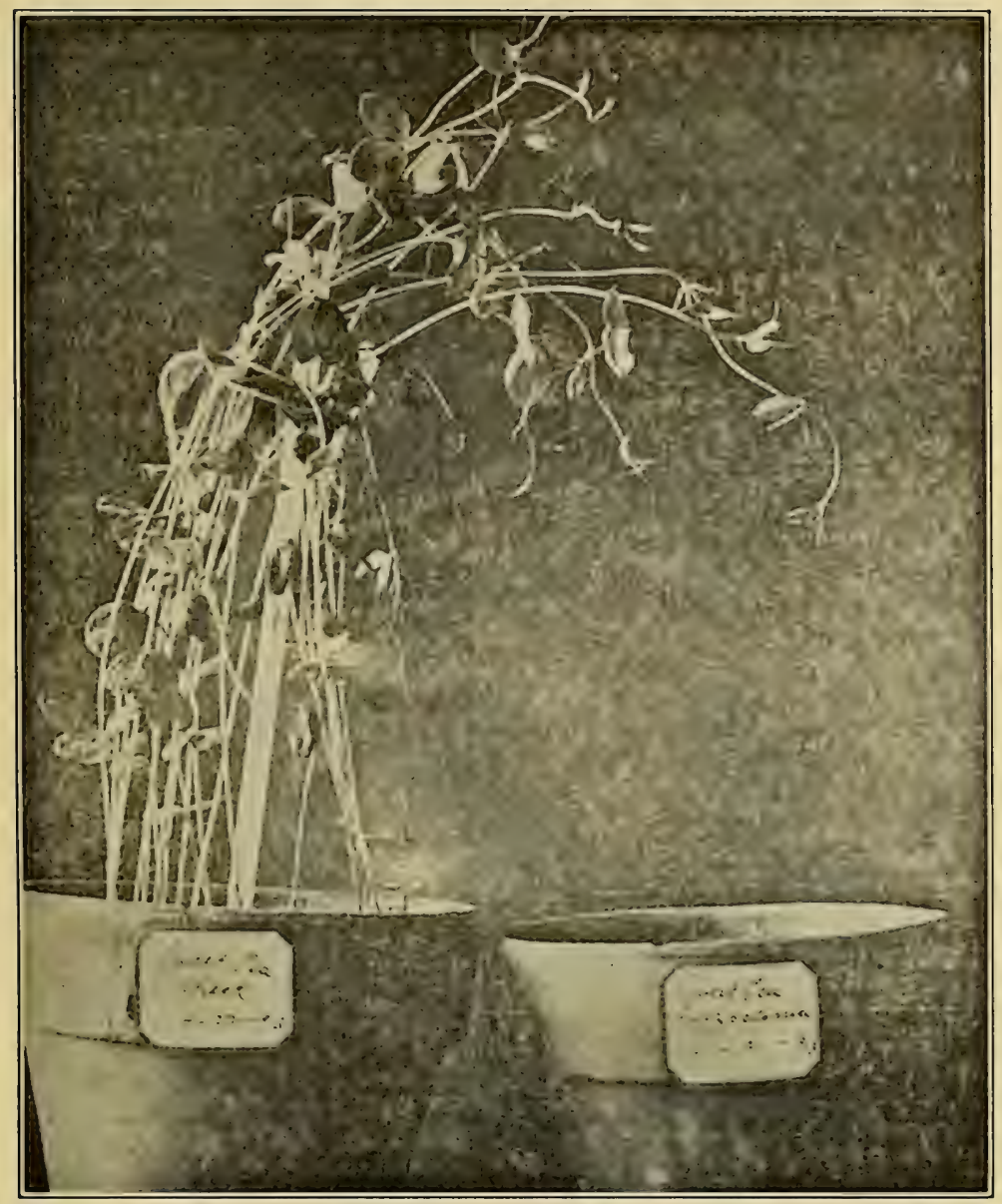

Fig. 9A. Root rot caused by Rhizoctonia. To the right the soil was inoculated with the fungus, resulting in no germination. At the left the soil was free from the fungus, resulting in good germination.

already pointed out by Shaw the macroselerotia produce the Corticium stage: the sweet pea organism is therefore referred to as Corticium vagum $B$. and $C$.

Pathological Conditions of the Host. The Rhizoctonia fungus when attacking other hosts, is known to be confined primarily to the cambium layer of the plant. With the sweet pea, conditions are sim- 
ilar. The fungus attacks the phloem of the bundles and makes its way into the parenchyma cells as well as to the epidermal cells. The effect produced is loss of turgidity, wilting, and early collapse of the

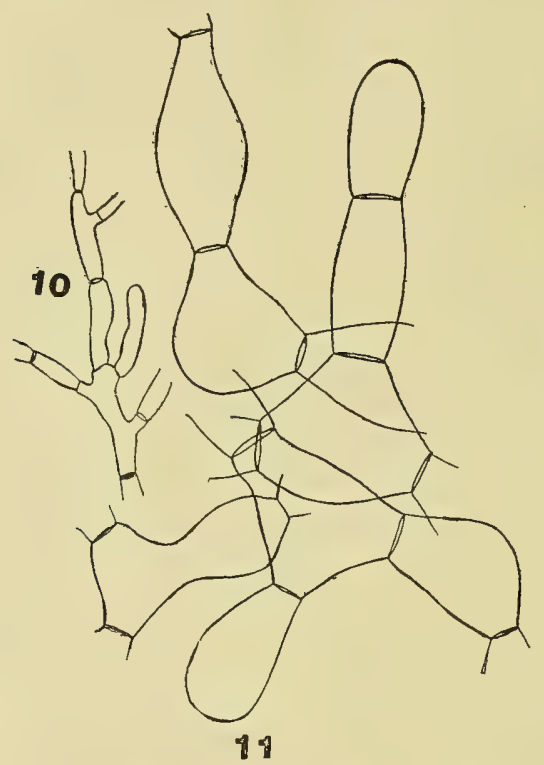

Fig. 10. Young hyphae of Rhizoctonia from sweet pea.

Fig. 11. Barrel shaped hyphae from sclerotium of the same fungus.

host. Infection may take place in the base of stem first and in this case the fungus invades both stem and root, or it may start at the roots first, then gradually work up to the stem. In either case death of the seedling is a natural consequence. In cases where the roots are first attacked by the fungus, the former deteriorates so rapidly that when pulling out a plant, it is found to be without any root system.

CHAETOMIUM ROOT ROT, Chaetomium spirochaete Patt.

Historical. In the fall of 1912 Prof. A. C. Beal of Cornell University sent me specimens of diseased sweet peas grown in the greenhouse for diagnosing the cause of the trouble. The disease was readily located in the roots. A fungus was found invading the interior tissue of the latter but no fruiting stage of any kind could be found which would help to identify the fungus. Crush cultures were made a' once from the diseased tissue, the method employed being the same 
as that described for Thielavia basicola. Some forty poured plates of nutrient agar were made in all. In 5 days a pure culture of a fungus appeared in all the plates with the exception of one which showed a Fusarium. The cultures were watched closely and in 'two weeks perithecia-like bodies developed in abundance but no spores were formed. The fungus proved to be an ascomycete belonging to the genus Chaetomium, and determined by Mrs. Flora Patterson as C. spirochaete Pati. In mid-winter of that same year, more diseased specimens were sent to me from a florist in Illinois. These specimens showed the same symptoms as those observed on Prof. Beal's material and in this case, too, the trouble was confined to the roots. As previously stated, no fruiting stage was found on the affected tissue. Cultures made from this material gave a pure growth of Chaetomium spirochaete. A search through the literature failed to show the record of any of the known Chaetomiums to be parasitic on living plants. $\mathrm{I}_{t}$ is known for instance that C. arachnoides Massee, C. simile Massee, C. bostrychoides Zopf and C. murorum Cda., all grow on dung of various animals.

Reinke and Berthold ${ }_{51}$ in their studies of the fungous diseases of the potato report to have found Chaetomium bostrychoides Zopf and C. crispatum Fckl. growing on rotted tubers. The above authors state that when germinated spores are placed on a cut surface of a healthy tuber they fail to penetrate the same, indicating the saprophytic nature of the fungus. Its presence on the decayed potatoes must have been secondary. The present thesis gives the first record of the parasitic nature of Chaetomium.

Pathogenicity. The fact that a pure culture of C. spirochaete was obtained from numerous platings of diseased material obtained from two different states at once led to the supposition that the organism was the cause of the disease. In order, therefore, to 'test out the pathogenicity of the fungus, the following experiments were tried. Out of ten sterilized pots and soil, five were sown with sterilized seeds (these were soaked in a solution of formaldehyde, 5 parts in 100 of water for one-half hour) inoculated with a pure culture of the fungus broken up in sterilized water. In the remaining five pots sterilized seeds were sown without the fungus to serve as checks. Both lots of seeds germinated and the seedlings of both the inoculated and the check pots seemed to grow well for about three weeks. After that time 
the seedlings in the inoculated lots appeared to lose their green color and to become paler and yellow. The infected plants could be readily pulled ou' from the soil and the rootlets appeared to be half rotted by the fungus, whereas the check seedlings did not exhibit such symptoms. Cultures made by surface sterilizing the affected rootlets readily gave pure cultures of Chaetomium spirochaete. The experimen't was repeated once more and this time, both checks and inoculated seedlings were watered frequently, care being taken to keep the soil very moist or even wet. This was accomplished by allowing the dish to remain filled with water in which the pots stood. In this case the checks again remained healthy, but after three weeks the inoculated seedlings had their roots mostly destroyed by the fungus; the infected seedlings could be readily pulled out from the soil. This time the greatest part of the root system was destroyed. Cultures made from parts of the remaining infected roots readily gave pure cultures of the fungus.

From these experiments it is shown that Chaetomium spirochaete altho perhaps a saprophyte will, under certain conditions, assume a parasitic nature on sweet peas. It was further shown that in poorly drained soils the viruient nature of the organisms becomes more pronounced.

Morphology and Physiology of the Fungus. The mycelium of the fungus is hyalin, closely septate and branched (Fig. 12) when grown in the substratum of the media. The aerial mycelium consists of long unbranched filaments and vary in color from very light to deep lemon. This seems to be produced within the fungous hyphae and later the yellow color is also transmitted to the media in which it grows.

Reinke and Berthold ${ }_{52}$ report to have found a conidial stage connected with C. crispatum. In our work we have as yet not found any conidial stage of C. Spirochaete. As previously stated, we have not found any fruiting stages of the fungus on the affected host. In pure culture in artificial media perithecia appear in two weeks from the time of planting and in three weeks mature asci with spores are also formed. The perithecia are covered with darkish brown hair-like appendages, thus giving it a bristly appearance. The hairs are coiled at the apex and septate at different intervals; they are covered with very minute pointed warts (Fig. 13). The asci are very evanescent 


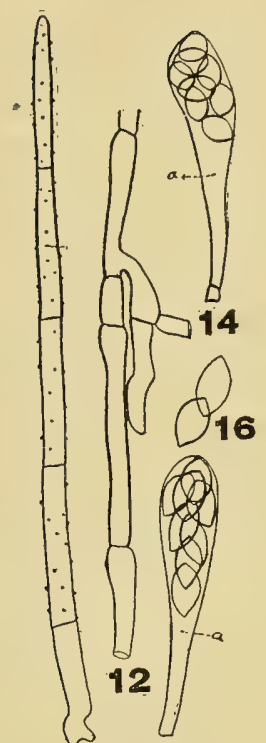

\section{5}

Figs. 12-15. Showing (12) mycelium of Chaetomium spirochaete. 13, hairs. 14 and 15 , asci. 16, ascospores.

and can only be seen in young cultures. In old cultures the ascus wall readily breaks so that it is difficult to make out the arrangement of the ascospores. There are 8 ascospores to an ascus (Fig. 14-15). The ascospores are apiculate (Fig. 16) at both ends. The wall of the ascospore is smooth, light brown when young and dark when old. The ascospores readily germinate in a sweet pea broth which is made up as follows:

Take 15 grams of ground sweet pea seeds to 1000 ce of water. Bring to a boil, filter, then add 15 grams of agar; bring to a boil, then filter, tube and sterilize in the autoclave for 15 minutes at 15 pounds pressure.

FUSARIUM ROOT ROT, Fusarium lathyri n. $s p$.

Historical. It seems that Tulasne ${ }_{53}$ was the first to recognize

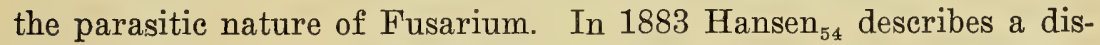
ease on oats which is attributed to Fusarium graminum Corda. In 1884 Worthington Smith $_{55}$ describes a wheat disease due to Fusispor- 
ium (Fusarium) "culmorum W. Sm., and another disease on barley due

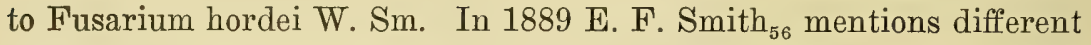
related Fusaria isolated from the soil which play the role of plant pathogens. The species of the Fusarium are not given. In the same year, in their excellent report on the loose smut of wheat, Kellerman \& Swingle $_{57}$ report on a Fusarium which lives as a parasite on the loose smut of wheat and which they named Fusarium ustilaginis K. \& Sw. In 1892 Frank $_{58}$ reports Fusarium heterosporium Nees, a parasite on several graminaceous hosts. In the same year Atkinson $_{59}$ reports on a cotton disease due to Fusarium vasinfectum. In 1893 Rostrup $_{60}$ described an oat disease due to Fusarium avenaceum. In 1899, Smith $_{61}$ describes a disease of cotton, watermelon, cowpeas, and melons as due to a Fusarium whose perfect stage was believed to be Neocosmopora vasinfecta. In 1899 Woods $_{62}$ reports on a disease of Chinese asters due to a Fusarium. In 1900 Manguin $_{63}$ reports on the parasitic nature of Fusarium roseum. In 1901 Prillieux and Delacroix ${ }_{64}$ reported on a carnation disease due to F. dianthi. In 1901 Bolley $_{65}$ reports on a flax disease due to Fusarium lini. In 1901 Sorauer $_{66}$ reports on a rye disease due to Fusarium nivale. In the same year Pammel ${ }_{67}$ reports on a wheat disease due to Fusarium roseum Lk. In $1902 \mathrm{Smith}_{68}$ reports extensively on a wilt of Chinese Aster the same disease as previously reported by Woods $_{69}$. In 1902 Hennings $_{70}$ deseribes a disease on the black locust which he attributes to Fusarium vogelii. In 1903 Van $\mathrm{Hall}_{71}$ describes a pea disease which he attributes to Fusarium vasinfectum Atk. var. Pisi. In 1904 Smith and Swingle ${ }_{72}$ reports on the dry rot of potatoes due to Fusarium oxysporum. In the same year Osterwalder $_{73}$ reports on a fruit rot due to F. putrefaciens. In 1905 Owen $_{74}$ reports on a tomato disease which he attributes to Fusarium erubescens Appel. and v. Oven. This fungus is claimed to be different from Fusarium solani, F. putrefaciens and F. Lycopersici. In 1906 Appel and Schikarra ${ }_{75}$ report on different species of Fusaria which induce disease in plants. In the same year Heald ${ }_{76}$ reports on a bud rot of carnations due to a species of Fusarium. In 1906 Hedgeock ${ }_{77}$ in his extended studies of chromogenic fungi reports Fusarium roseum as capable of discoloring wood. In 1907 Chifflot $_{78}$ reports on a pelargonium disease due to Fusarium pelargonii. In 1909 in their extended studies on corn rots, Burrill and Barrett ${ }_{79}$ report on three species of Fusaria which attack the ear of corn. In 1910 Wolf $_{80}$ reports on a pansy disease as due to Fusarium. In the same year 
Smith ${ }_{81}$ reports on a banana disease due to Fusarium, and $\mathrm{Cook}_{82}$ reports on the double blossom due to Fusarium rubi. In 1911 Bubak $_{83}$ describes a rot on ears of corn due to Fusarium maydiperdum. In 1912 Gifford $_{84}$ reports extensively on a damping off disease of coniferous seedlings due to Fusarium, the species not stated. There are of course many more Fusaria described, but the aim in this brief historical sketch is to mention the literature which bears more or less directly on the parasicic nature of Fusarium. In a very recent paper

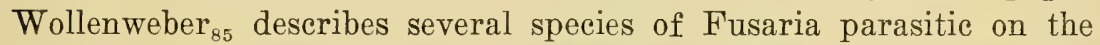
potato. He also emphasizes the importance of morphological studies as well as infection experiments as the basis of classification in Fusaria.

Fusarium Root Rot of Sweet Pea. There is no record in the literature of a Fusarium disease of the sweet pea. Several complaints from florists have shown that they could not grow sweet peas under greenhouse conditions because of a root ro't which developed early and in some cases destroyed the entire planting. Cultures made from the infected material or from the infected soil, and from seedlings sown in the laboratory on the infected soil, gave in each case a pure culture of Fusarium.

Symptoms. The first symptom of the disease is a sudden flagging of the leaves accompanied by general wilting and collapse of the seedling. Usually upon sowing the seeds a fair percentage germinate and reach the heigh't of about 8 to 10 inches when they are attacked by the fungus. If the collapsed seedlings are allowed to remain on the ground, the stems will soon be covered with the sickle shaped spores. Eventually the decayed tissue rots and disin'egrates and is soon invaded by small fruit flies which now begin to distribute the fungus from place to place by carrying its spores.

Pathogenicity. The pathogenicity of this fungus is readily proven by inoculating with a pure culture of the organism sterilized seeds planted in sterile soil. The seed germinate and reach a height of 7 to 8 inches but soon succumb to the attacks of the fungus. The fungus can be reisolated from the artificially infected seedlings and the disease induced at will (Fig. 17). The checks remain healthy provided of course all means of contamination are guarded against.

Morphology of the Fungus. The mycelium of the fungus is hyalin, septate and branched. At an early age the hyphae begin to 


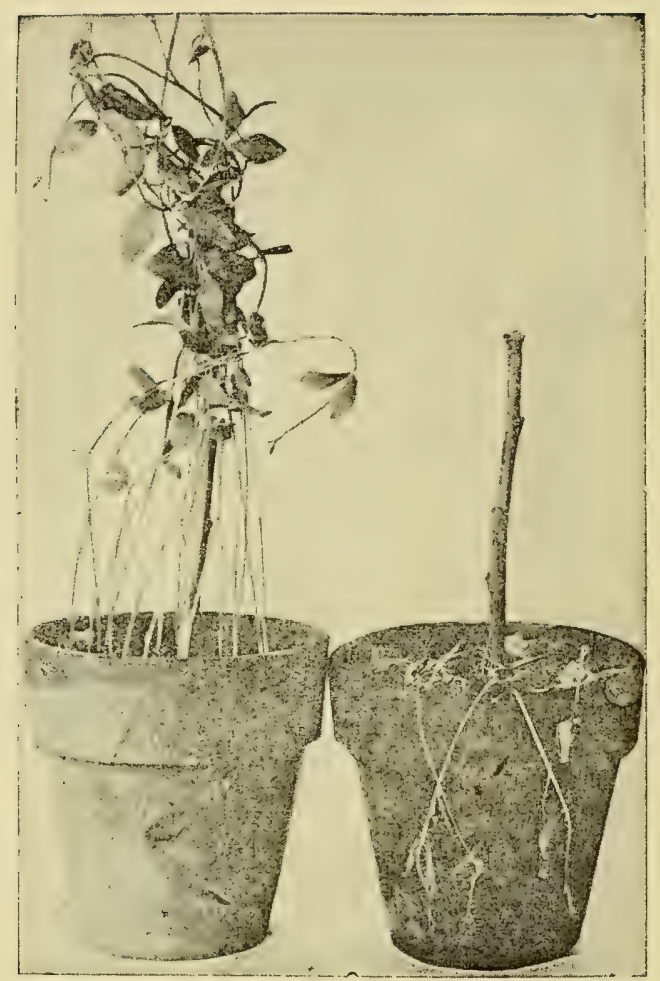

Fig. 17. Fusarium wilt or root rot. At left, healthy; at right, infected.

form chlamydospores. These are round hyalin bodies often filled with oil globules and are formed in the center of the hypha (Fig. 18), in this case the contents of the former collect into the chlamydospores. Usually also the chlamydospores are born at the tip end of the hyphae in chains of twos, threes and even fours (Figs. 19-22). Old cultures are practically one mass of chlamydospores. There are also two spore forms present and these appear as early as the third day in the pure culture. These are microconidia which are fairly abundant and macroconidia, varying from two celled to four celled. The average form is the three celled. Both micro- and macro- conidia are hyalin and smooth (Figs. 23-31). In old cultures the macroconidia shrink so that the septa become slightly pronounced (Figs. 25, 28-29). These old macroconidia soon lose their protoplasm or the latter breaks up 
presenting a granular appearance. In young cultures the outer wall of the chlamydospore is smooth, but in old cultures it becomes slightly warty or covered with minute points (Fig. 19). No perfect stage has been found to accompany this fungus either in pure culture or on the host.

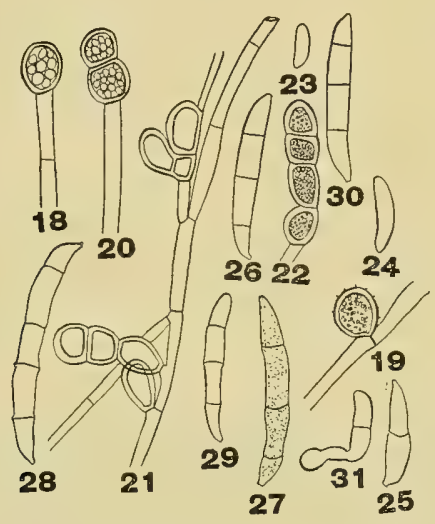

Figs. 18-32. Fusarium lathvri, showing chlamvdospores and conidia.

Identity of the Fungus. There is no doubt but that the fungus belongs to the genus Fusarium. It produces its micro- and macrospores (sickle shaped) as well as chlamydospores which according to Wollenweber $_{s 6}$ are true characteristies of the genus Fusarium. The fungus has been grown in pure culture (Fig. 32) and on different media for two years and no perfect stage has ever appeared. Unless further studies prove differently it seems that the present Fusarium is a new species and the name Fusarium lathyri n. sp. is tentatively given to it. A deseription of the fungus follows:

Sporodochia slightly erumpent to superficial on the host, but not always present on culture media. Macroconidia sickle-shaped, slightly curved and fitting into the section Martiella of Wollenweber, 2 to 4 septate, the majority being three septate, $15.8 \times 4.2^{u} \_30.8 \times 5.6^{u}$. Mieroconidia elliptical to oval $9.8 \times 2.8 \mathrm{u}-14 \times 3.50^{\mathrm{u}}$. Chlamydospores spherical, thick walled and spinulate when old, $7.3^{\mathrm{u}}-9 \mathrm{u}$ borne singly or in chains of twos, threes and sometimes in fours.

ROO'T ROT OR EEL WORM, Heterodera radicicola (Greef) Muller

Altho not belonging to the domain of this thesis the eel worm is here considered, first because of the important root knot disease it 
produces, and the second, because it opens the way to several fungous parasites.

Heterodera radicicola attacking many hosts. The eel worm is of an omnivorous nature. Mareinowski $i_{87}$ gives a list of 235 species of plants affected with the pest. Almost all of the more important families of flowering plants are present in the list, as well as one gymnosperm and a fern. The plants include both Monocotyledons and dicotyledons, herbs, woody plants, annuals and perennials. Many of our garden plants and field crops are attacked by the pest.

Of the plants said not to be affected by Heterodera, Bessey ${ }_{88}$ cites the following hosts: Crab grass (Syntherisma sanguinalis), redtop (Agrostis alba), Johnson grass (Andropogon halepensis), some varieties of oats (Avena sativa), Bromus schraderi, Eustachys petrea,

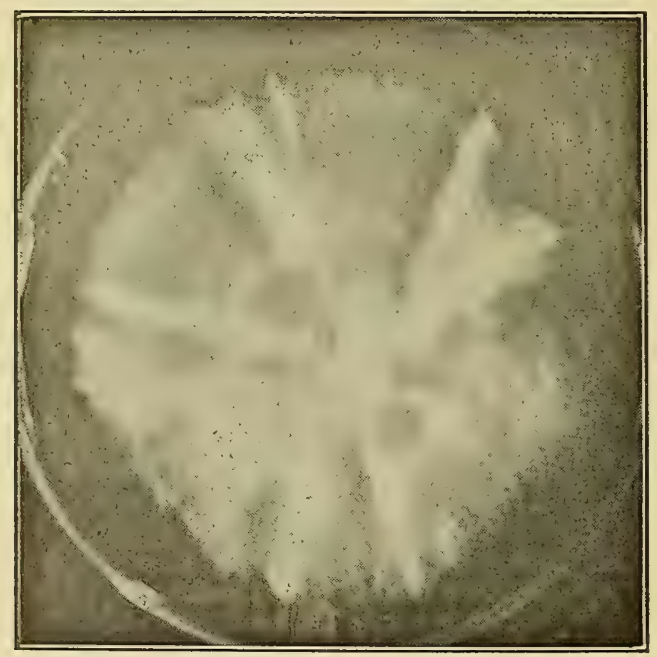

Fig. 32. Pure culture of Fusarium lathyri. the cause of sweet pea wilt

some varieties of barley (Hordeum vulgare), perennial rye grass, Lolium perenne, Echinochioa frumeniacea, Panicum miliaceum, Pennisteum sp. timothy (Phleum pratense), rye (Secale cereale), Andropogon sorghum, Triticum, maize (Zca mays), Euchlaena luxurians, Bidens leucantha, B. bipinnata, Gnaphalium purpurem, Helenium tenuifolium, some species of Solidago and Zinnia. 
Heterodera attacking sweet peas. In his excellent work on

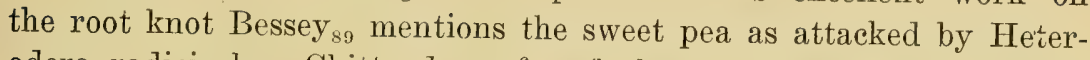
odera radicicola. Chittenden ${ }_{90}$ found the eel worm associated with Thielavia root rot.

In my own investigations I have found the eel worm capable of producing the root knot. I have often found this pest to be associated with Rhizoctonia. It seems very probable that the Heterodera worm in the case of the sweet pea opens the way to the attacks of Rhizoctonia and several other fungi. Heterodera radicicola often produces the greatest amount of damage in light sandy soil, but seems unable to thrive in heavy clay soils. In every case where seen by the writer or where reported by florists and seedsmen the eel worm was most troublesome where sweet peas have been grown on too light soils in the greenhouse. No sweet peas have been reported to be attacked by the eel worm out of doors.

Symptoms. The disease is characterized by swellings on the roots. These are either small swellings formed singly, in pairs, or in strings, thus giving the affected root a beaded condition (Fig. 33) or the swellings may be very large so as to be mistaken for root nodules. However, these galls cannot be mistaken for the normal root nodules, because the latter are lobed and are attached at one end (Fig. 34), whereas the root gall produces a swelling of the entire surface of the part affected. Infected plants usually linger for a long time, but they can be distinguished by a thin growth and yellow sickly looking leaves and stems.

\section{B. Diseases of the Aerial Parts of the Plant}

\section{STEM OR COLLAR ROT, Sclerotinia libertiana Fckl. Synonomy.}

Sclerotinia libertiana Fekl.

Peziza sclerotiorum Lib.

Sclerotinia libertiana Fckl.

" Kaufmanniana

" Postuma B. \& W.

" Coemansii Kick.

" sclerotiorum Br.

Sclerotinia sclerotiorum Ad. 
History of Sclerotinia libertiana Fckl. as a Plant Disease ProAucer. In 1860 Coemans $_{i 1}$ was the first to record a disease of carrots and iturnip which he attributed to Sclerotinia libertiana (Peziza sclerotium). In 1886 De Bary $_{92}$ also reports on a disease of turnips

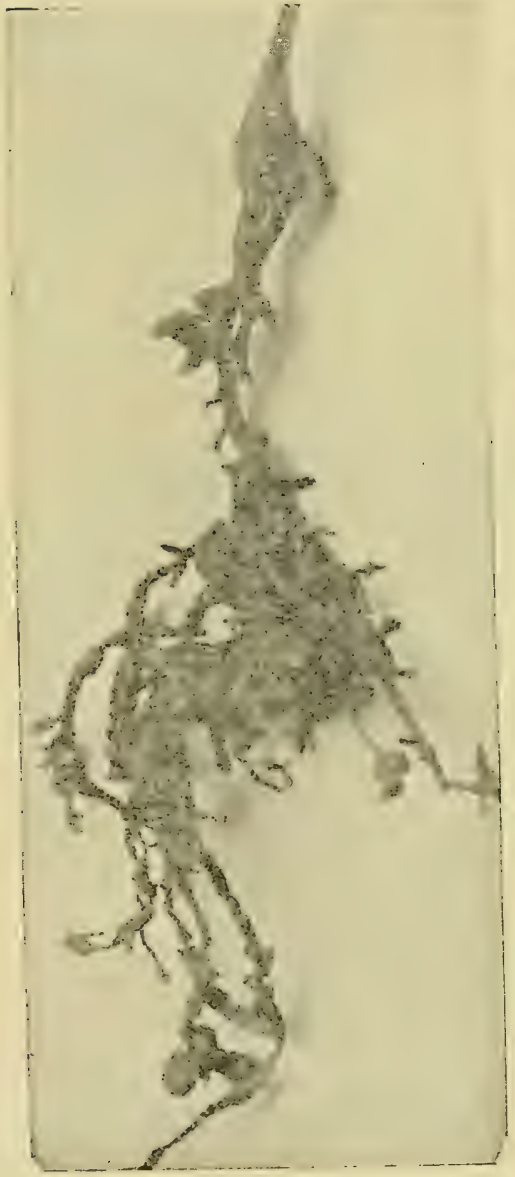

33

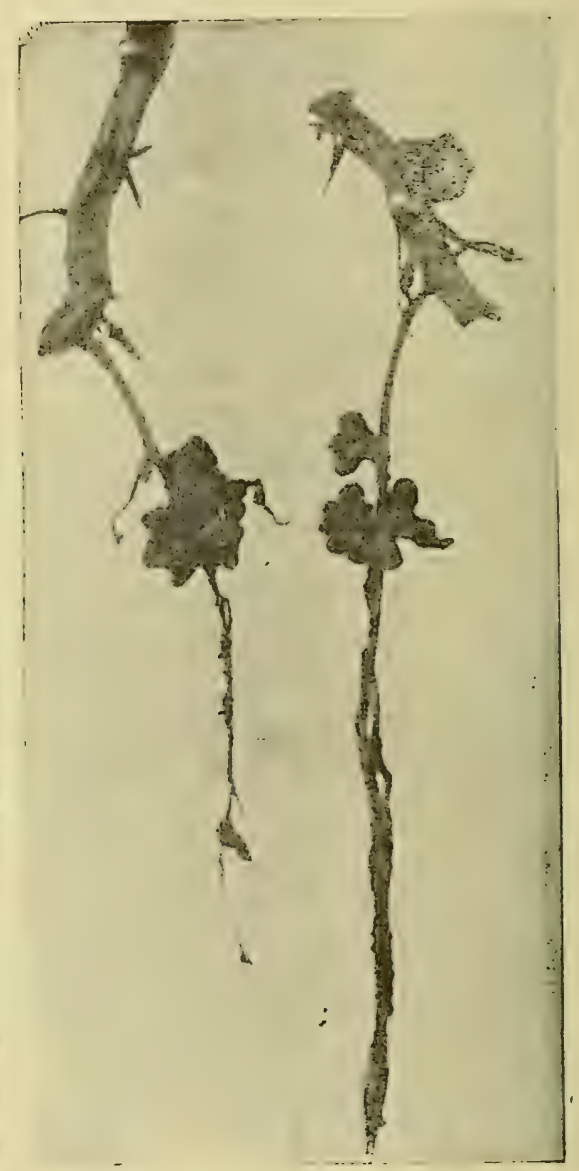

34

Fig. 33. Sweet pea roots affected with eel worm.

Fig. 34. Sweet pea nodules formed by nitrogen fixing bacteria.

and carrots due to $\mathrm{S}$. libertiana. In $1887 \mathrm{Cohn}_{93}$ reports on a potato

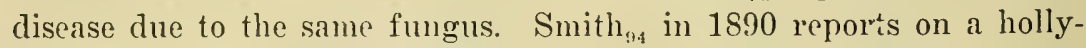
hock disease due to Sclerntiana libertiana. In 1891 Behrens $_{95}$ reports on a hemp disease due to this fungus. In 1892 Humphrey $_{96}$ reports 
on a lettuce disease which he thought was due to Botrytis cinerea, the then supposed conidial stage of Sclerotinia libertiana. Humphrey again in 1893 reports on a cucumber disease due to Sclerotinia libertiana. In 1897 Prillieux and Delacroix ${ }_{97}$ report on an importan't mulberry disease due to this same fungus. In 1900 in his extended studies on Sclerotinia, Smith ${ }_{98}$ reports on the omnivorous nature of

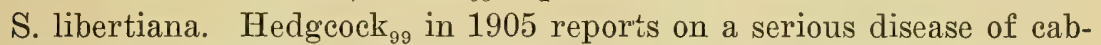
bage and cauliflower due to $\mathrm{S}$. libertiana. In the same year Parisot ${ }_{100}$ reports on a disease of Jerusalem artichokes in the western part of France and due to this same fungus. He also mentions the potato, bean, corn, carrot, turnip, rutabaga and flax as all being subject to the same disease. In 1906 Appel and Bruch $_{101}$ also report on a similar disease of turnip and parsnips. Masseron ${ }_{102}$ in 1907 reports this fungus 'to produce a serious disease on the garden and field pea. In 1911 Westerdijk $k_{103}$ reports a wide range of hosts to be attacked by the fungus such as rape, cabbage, cauliflower, kohlrabi, sesame, bean, pea, vetch, clover, lettuce, Jerusalem artichoke, dahlia, zinnia, sugar beets, carrots, 'turnips, parsnips and beets.

\section{Sclerotinia libertiana Fckl., a Fungous Disease of the Sweet} $P e a$. As far as I could ascertain there is no mention in literature of S. libertiana attacking the sweet pea. I have first noticed this disease on greenhouse specimens sent in by a grower in Pennsylvania. My first record of the disease appeared in the Florist Exchange Ev4 $_{\text {. }}$ Observations so far seem to show that the disease is limited to sweet peas under greenhouse conditions only. A special effort was made to find this disease out of doors but without success. It is well known that under certain conditions unfavorable to the host the fungus can attack a variety of hosts which grow in the open. That the fungus has not been found so far to attack sweet peas out of doors does not limit its appearance in the field at any time that climatic conditions are unfavorable to the host.

Symptoms. This is usually a seedling disease (Figs. 35-36) altho it may attack plants of all ages (Fig. 36).* And it is most severe in poorly ventilated houses or in beds which are overwatered and which lack proper drainage. The disease when present does its work quickly. Affected plants first show a wilting of the tip and flagging

*Figs. 36, 41. Electrotype, Florists' Exchange. Photographs by the author. 
of the leaves and then the seedlings fall over and collapse. The fun-

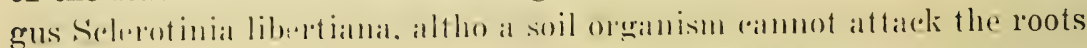

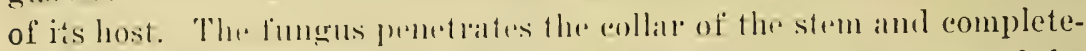
ly invales the vessels of the host. thes cherding the upwarl flow of the water lrom the roots. Freshly eollapes plants hatre a watersoaked

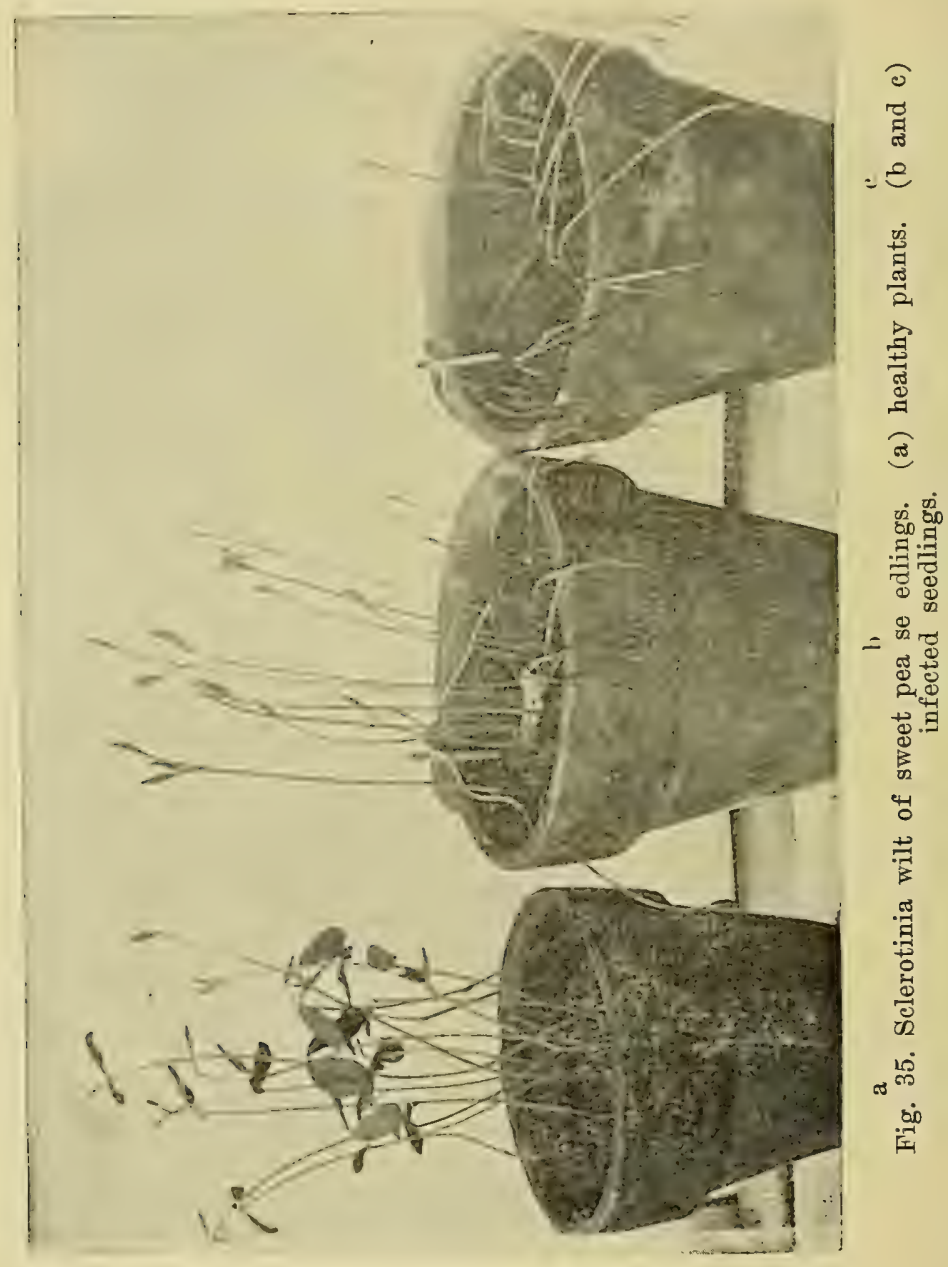

appearance, later to he overem with a white weft of fungus mycelium, findly to be followed hy selerotia which are foumd here and there on or within the affecied stems. 
Pathogenicity. In order to establish definitely the relationship of the fungrus to this disease of sweet peats under gratss, sterilized seeds were planted in sterilized pots and soil in the laboratory. All the seeds germinated and the plants were allowed to grow for three weeks, in a perfectly healthy state. Then the pots were divided in

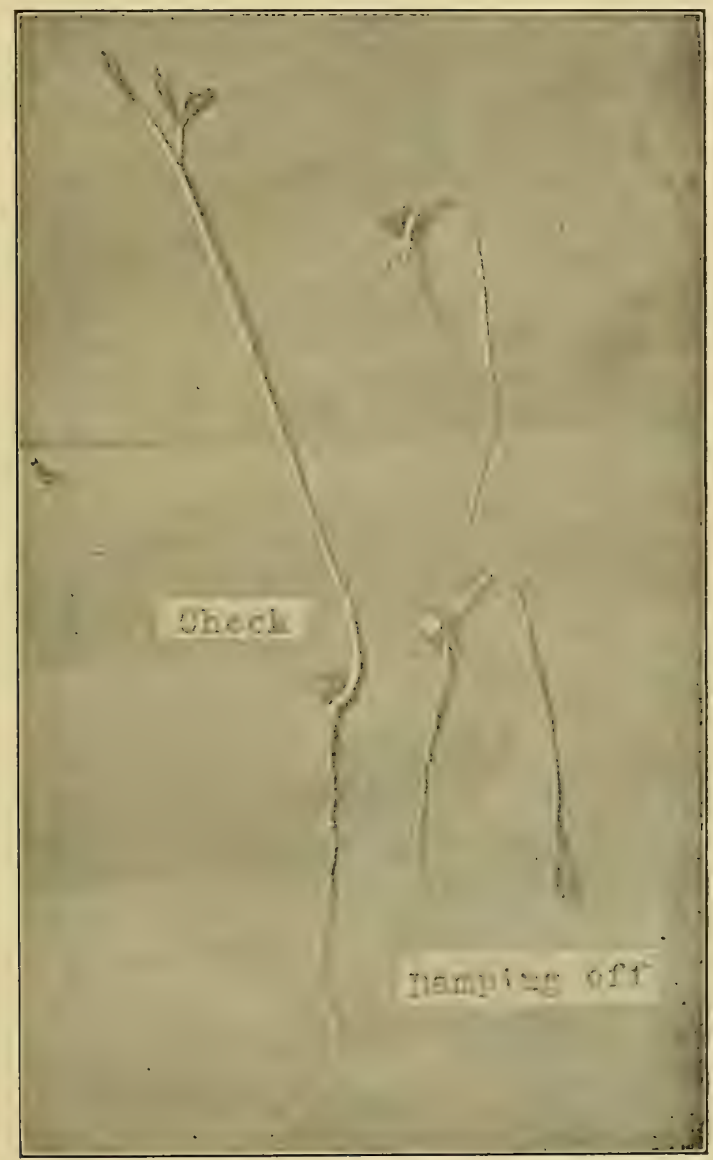

Fig. 36. Damping off caused by sclerotinia.

two lots; one lot was left as: a check and the other lot was inoculated with the pure culture of the scelerotinia by introducing pieces of the fungus in the soil. Both lots, check and infected plants, were covered with bell jars to imitate the moisture conditions of the greenhouse. 
After four to six days, wilting of the inoculated seedlings began, whereas the checks remained healthy. This was repeated several times with always the same results. This conclusively shows that the fungus Sclerotinia libertiana is able, when present in the soil, to produce a disease on sweet peas under glass. The fungus is usually brought into the greenhouse with the soil, or with the manure. Cross inoculation with the fungus from the sweet pea, lettuce, turnip and cucumber on the sweet pea produced typical cases of wilt, thus proving conclusively that the fungus from the sweet pea is the same as the Sclerotinia libertiana of the hosts mentioned above.

Identity of the Fungus. The fungus from the sweet pea was run on artificial media with parallel cultures of S. libertiana from lettuce, cowpea and cucumber. There was no difference observed in the manner of growth nor of sclerotial formation of these strains. Under pathogenicity, I have shown that cultures of S. libertiana obtained from hosts such as lettuce, turnip and cucumber readily produced the typical wilt of the sweet pea similar to that obtained when inoculations are made with the fungus from the sweet pea on the sweet pea. In order to further verify the identity of the fungus, sclerotia from cultures three months old were placed in small flat covered chambers containing sterile moist sand. These were placed outdoors in the cold for four weeks, then brought in the laboratory and kept at room temperature. The moisture was maintained by adding every three to four days some sterile water. In nine weeks the selerotia germinated by sending out from each a number of grayish stalks, and in two weeks the apothecia developed at the tip of the stalks. In shape and measurement of asci and ascospores the fungus answered in every description that of Sclerotinia libertiana.

Morphology of the Fungus. In my work I find no conidial stage of a Botrytis type or of any other type to be connected with Sclerotinia liberiana of the sweet pea. This is in accord with the studies made by Smith, R. $\mathrm{E}_{\cdot 105}$. There seems no doubt but that Botrytis cinerea which is often found to accompany S. libertiana is in no way connected with the former.

POWDERY MILDEW, Erysiphe polygoni?

The sweet pea mildew was first described by Massee $_{106}$ as being prevalent in England. Erysiphe polygoni was attributed as the cause, both of sweet pea mildew and that of the edible 
garden pea. In this country Stewart ${ }_{107}$ was the first to record a powdery mildew on the sweet pea. However, Stewart did not find the perithecial stage, and hence the fungus was not determined. The powdery mildew is a very prevalent disease on

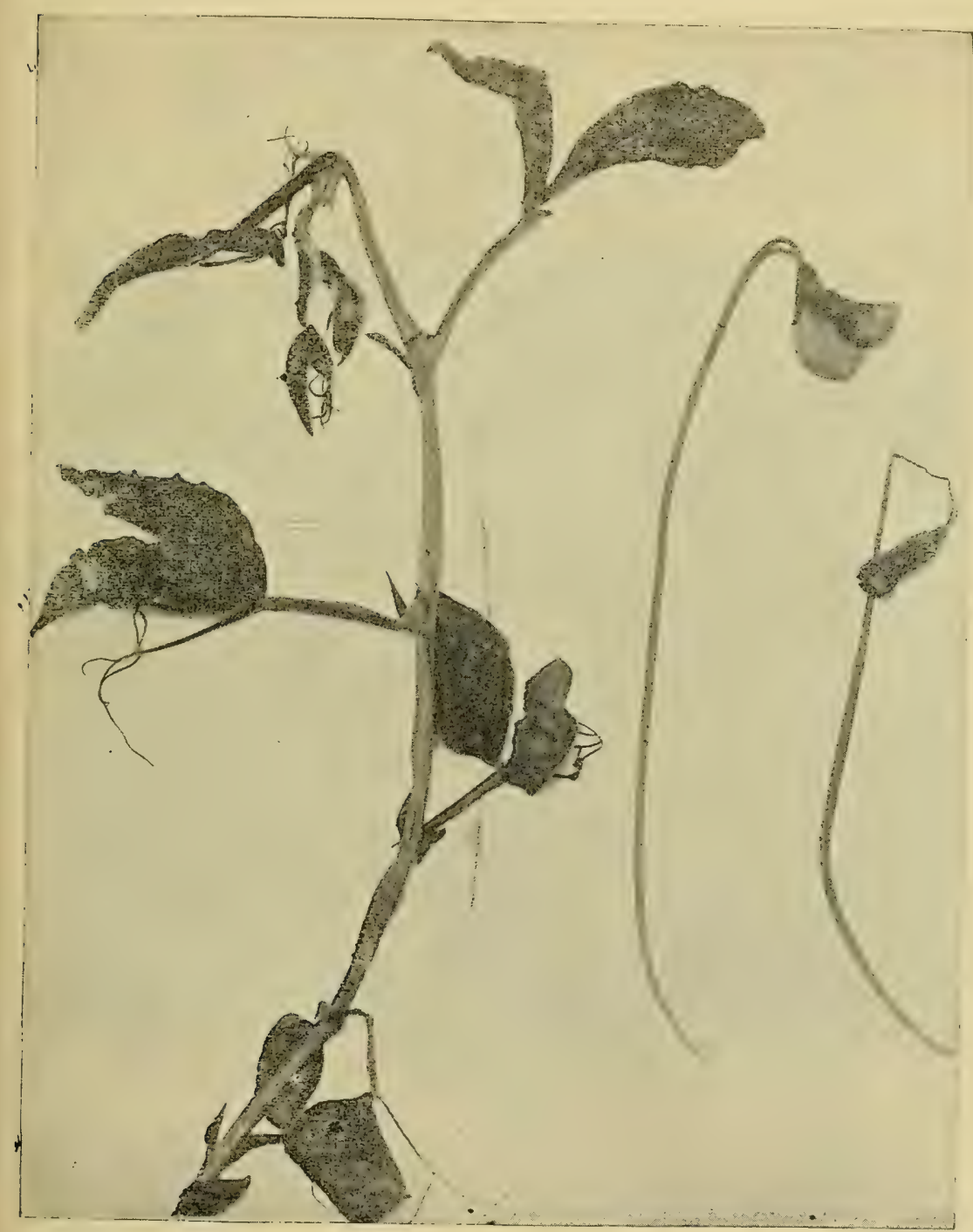

Fig. 37. Anthracnose disease of sweet pea on stem and puduncles. 
greenhouse sweet peas, and on irrigated fields or where they are planted on a large scale for seeds. Ordinarily, however, in small garden lots, and especially where the plants do not revive any water, the disease is practically unimportant since the attack is usially very mild during the active growing season, but beromes somewhat more abundant when the plants have passed all usefulness. The writer had the opportunity of collecting specimens at random from six large houses, and from three acres of out-door sweet peas in Mass. and from a similar three acre plantation in Pa. Like Prof. Stewart, the writer has only met with the conidial or Oidium stage. On our own

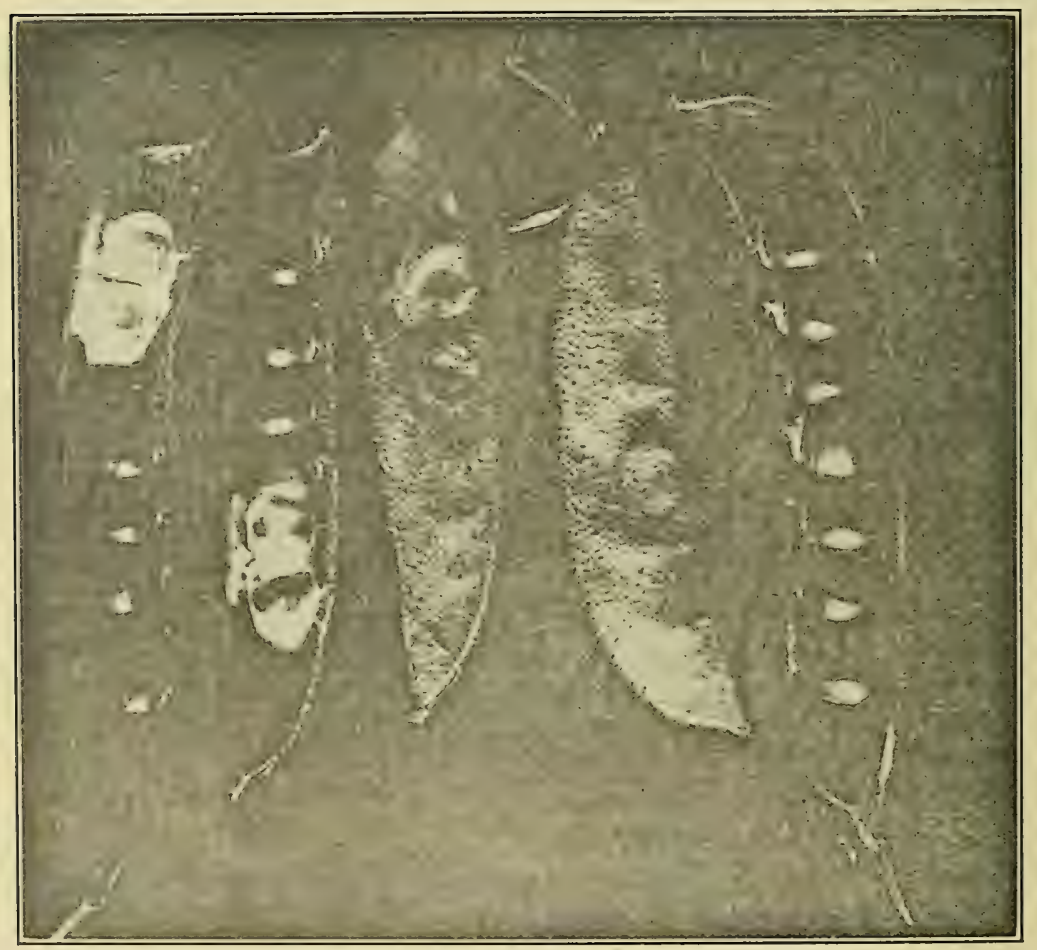

Fig. 38. Anthracnose disease of pods and seeds.

sweet pea field, we have carefully watehed for a perithecial stage but without suceess. Late in the fall, batly infected leaves have been collected and put away to winter over, but that material up to date, April, 1913, has failed to develop perithecia. 
ANTHRACNOSE, Glomerella rufomaculens (Berk.) S. \& V. Sch.

A very serious anthracnose disease of the sweet pea on the Delaware Experiment Station farm was called to the attention of the writer during the latter part of July, 1910. This disease proved to be the same or very similar to the one reported by Sheldon ${ }_{108}$ from Wes's

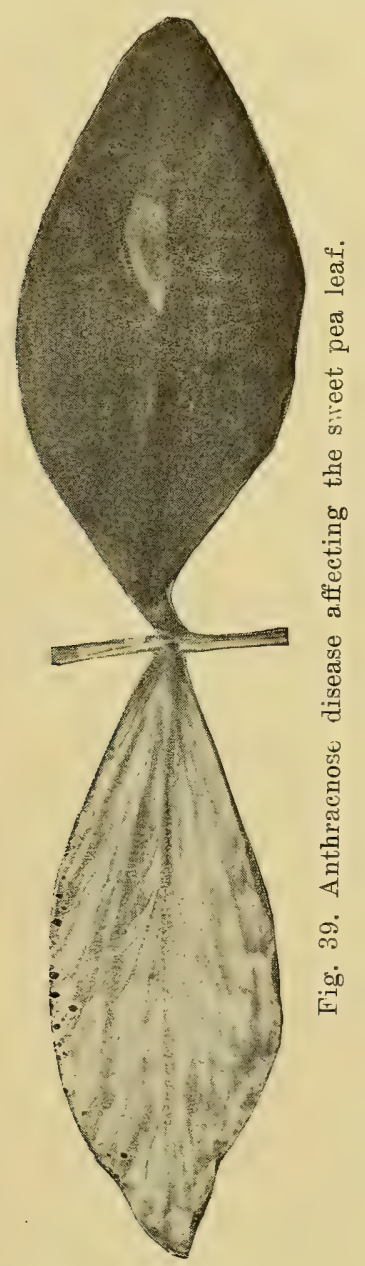

Virginia in 1905, and is very probably the so-called "wilt" which has been so often referred to in old seed catalogues and treatises on sweet peas. 
Symptoms. The disease occurs on the stems, leaves (Fig. 39), flowers and pods but is most severe on the latter. There is a general wilting of the affected parts followed by dying, which begins at the tips of the younger shoots and works downward (Fig. 37). The older parts of the plants are not killed immediately but may persist for some time after being attacked by the fungus. The dead parts shrivel, become brittle, and are soon covered with minute acervuli. The affected pods are at first a dirty white in appearance but assume a dull color, which is due to the presence of the acervuli. A definite canker, which is so characteristic of the bean anthracnose is not produced. Although the disease on the stems seems to be restricted to the youngest growths, the pods may be infected at any stage of their development. The seeds of the diseased pods are always infected, become shrivelled and frequently do not reach maturity (Fig. 38.)

Pathogenicity. Sheldon called attention to the identity of the Gloesporium of the sweet pea with Glomerella rufomaculans (Berk.) Spauld. \& von Sch. which is the cause of the bitter rot of the apple. With this in mind, the writer made the following experiments in the autumn of 1910. Sweet pea seeds, which to all appearances were perfectly healthy, were carefully selected, sterilized by immersion for 15 minutes in a $5 \%$ solution of formaldehyde, and planted in pots in soil which had been sterilized by heating for one hour in the autoclave. The seeds germinated in 5 days and the seedlings were allowed to grow for three weeks. Fifty plants were allowed to grow in each pot. The temperature of the room ranged as high as $72^{\circ} \mathrm{F}$. during the day and several degrees lower during the night, but not low enough to injure the plants. All the seedlings grew well and were perfectly healthy. The day before inoculation the pots with the seedlings were covered with bell jars thus forming moist chambers. These covers were removed one day after inoculation. Two methods of inoculation were employed: (1) the introduction of spores into the living stems through punctures made with a sterilized needle; (2) by liberally spraying the surface of the plants by means of an a'tomizer with spores suspended in sterilized water. Fruits of apples and pears on the trees in the orchard were also treated in the following manner: Healthy fruits on the trees were first washed with a $5 \%$ solution of formaldehyde and then rinsed with distilled water. They were then inoculated through sterile needle punctures and covered with paper bags. For the inoculation, pure cultures were used of Gloeosporiums 
from various sources as indicated below. The resulta of these experiments are given in Table $\mathrm{I}$.

The data in Table I show: (1) that the original organism of the sweet pea is pathogenic to tho sweet pea, and also to the apple in which

\section{TABLE I}

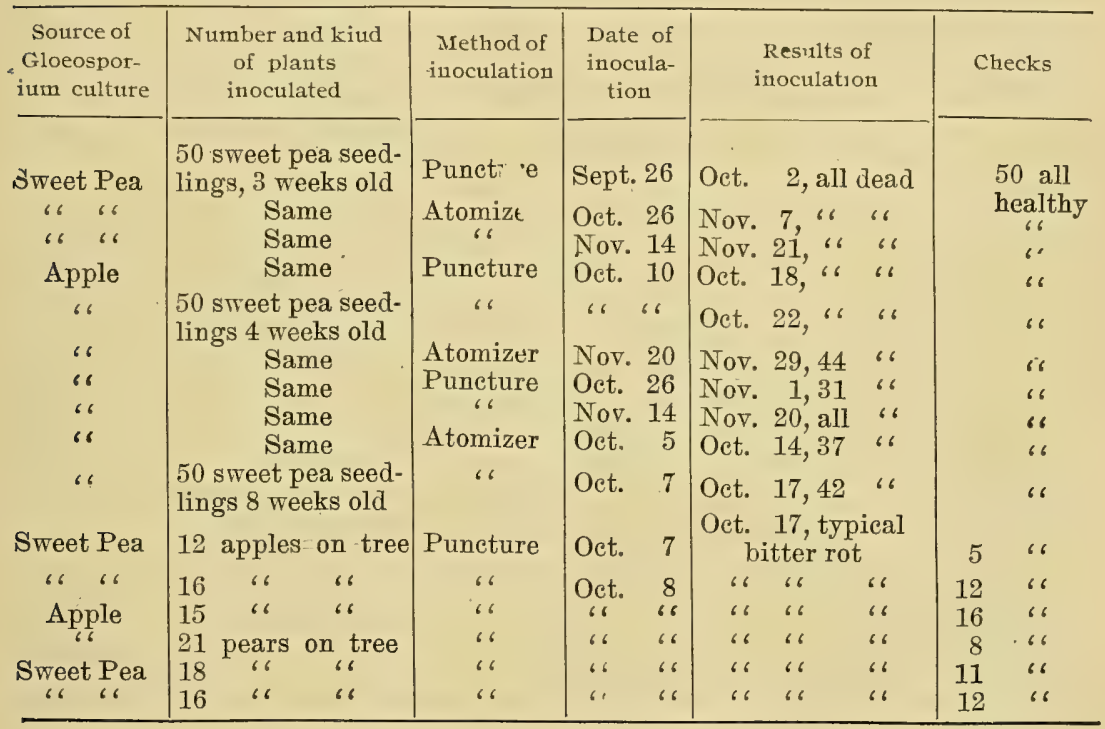

it causes the typical bitter rot; (2) that Gloeosporium fructigenum Berk. from the apple causes a disease on the sweet pea which is similar to the disease caused by the original sweet pea Gloeosporium. This definitely proves that Glomerella rufomaculans (Berk.) Spauld. $\&$ von Sch. is the cause of the anthracnose disease of the sweet pea.

Relation of other Gloeosporiums to the Sweet Pea Disease. While working on the question of the identity of the bitter rot of the apple and the anthracnose of the sweet pea, it was considered desirable to determine whether other species of Gloeosporiums could produce an anthracnose of the sweet pea similar to that caused by the bitter rot organisms of the apple. Therefore, sweet pea seedlings were inoculated with spores from pure cultures of five different Gloeor sporiums then in stock in the laboratory. The results of these experimen'ts are given in Table II. 
TABLE II

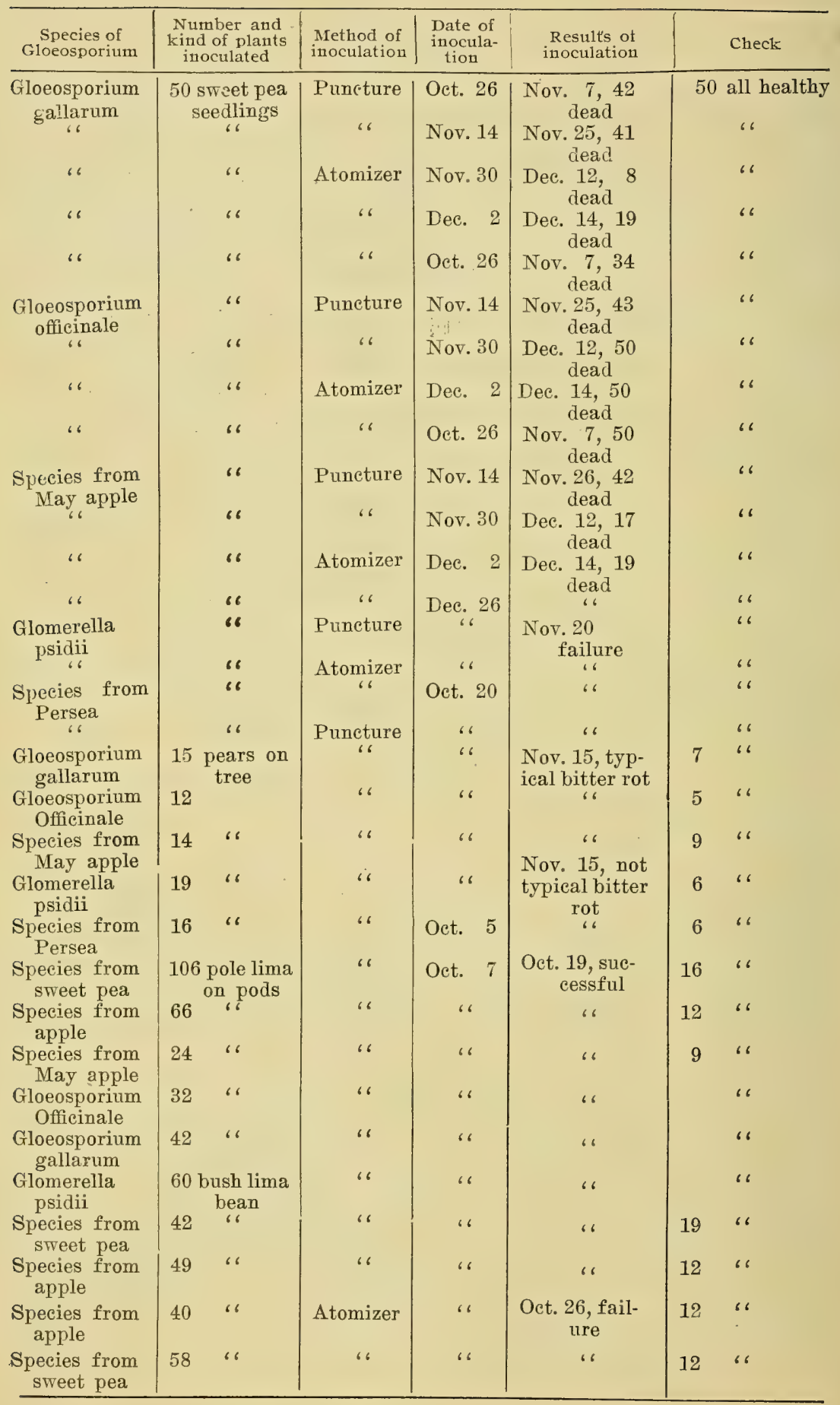


From Table II it will be seen that the Giveosporium from the May apple fruit (Podophyllum peltatum), G. gallarum Ch. Rich. from oak gall, and $G$. officinale E. \& E. from sassafras leaves, are able to infect sweet pea seedlings through puncture inoculations as readily as the sweet pea or the apple Gloeosporium. Furthermore, that $G$. officinale readily infects sweet pea seedlings by atomizer inoculations, the infection being nearly $100 \%$. While G. gallarum and the species of Gloeosporium from the May apple fruit also infect sweet pea seedlings, the percentage of successfully inoculated seedlings is smaller with the atomizer inoculations than when the inoculations are made by needle punctures.

Glomerella psidii (G. Del.) Sheldon and the Gloeosporium from Persea failed to infect sweet pea seedlings.

The apple trees in the old orchard of the Experiment Statron did not bear enough fruits to permit inoculation experiments with the above five organisms; hence Kieffer pear trees which bore heavily were chosen for this purpose. They were accordingly inoculated with the five Gloeosporiums already mentioned. The results of these inoculations (Table II), show that the species of Gloeosporium from the May apple $G$. gallarum and $G$. officinale produce the typical bitter ro't on the pear, while the Glocosporium from the guava and Persea infect the pear, but cause dull spots in which the acervuli are black and the spores are borne on long black conidiophores. Similar results were obtained when pear fruits were inoculated with the same Gloeosporium and kept in moist chambers in the laboratory. These experiments also show (Table II) that all the Gloeosporiums here considered, except the species from guava and Persea very readily produced an anthracnose disease on the pods of the lima beans in the field, which was similar to the anthracnose of the sweet pea, but quite unlike the bean anthracnose, Colletotrichum lindemuthianum (Sace. \& Mag.) B. \& C. All the Gloeosporiums referred to above attacked the pods of the lima beans in the field when the inoculations were made by means of punctures, but not otherwise. The spots produced on the lima bean pods by Glomerella psidii are gray with grayish acervuli and made up of black setae very similar to those of a true Colleto'trichum, but unlike C. lindemuthianum. None of the above species of Gloeosporiums would infect bean or vetch seedlings. The same precautions were taken in inoculating the bean pods and pears in the field as with the apples. 
Further Studies of some Glocosporiums and their relation to the Sweet Pea Anthracnose. The first year (1910) the inoculations were carried on at a time when both the apples and the pears were almost mature, and ripe fruits being a more favorable medium, since they are physiologically less active than young ones, it was felt advisable to start the present inoculations of the apples and pears in the orchard at a much earlier date, this time using more organisms. The inoculations were begun in 1911 when the fruits were the size of a grape, and were repeated at various stages of their development. The Kieffer pear and the Rubicon and Paradise Sweet apples were selected for this purpose. The inoculations were made by means of punctures through the cuticle. For each organism a different sterilized needle was used. Natural infection of the inoculated fruits was prevented by means of heavy paper bags which were tied to the limbs to which the inoculated fruits were attached. Any inoculated fruits which happened to drop off fell into the bags and were retained there. In every case where infection occurred it first appeared at the point of inoculation. For each organism eight fruits were used as checks. These were punctured with a sterile needle and covered with paper bags, and in all cases remained healthy. Investigations were also carried on with sweet pea, specimens of which were grown in the laboratory from carefully selected and sterilized seeds grown in sterilized poits and soil. Checks were also used, fifty seedlings for each organism, and these in all cases remained healthy, although they were punctured with a sterilized needle. Only spores from pure cultures were used for the inoculations. The results obtained are given in Table III.

From Table III it will be seen that Glom. rufomaculans from apple and sweet pea, Gloe. gallarum Ch. Rich., Glom. gossypii (South) Edg., Gloe. diospyri E. \& E., Colletotrichum phomoides (Sacc.) Chest., and C. nigrum Ell. \& Halst. produce the typical anthracnose disease on the sweet pea and the symp'toms produced by all the above organisms were identical with those produced by the original Gloeosporium isolated from diseased sweet pea plants in the field. Many more inoculations than are indicated in Table IV were made with the above named organisms on the sweet pea. They were omitted from the table, since the results obtained were similar to those given above. The da'ta in Table III further show that Gloe. piperatum E. \& E. failed to infect the sweet pea by atomizer inoculation, while infection by puncture inoculation was fairly successful. When this organisms 
was reisolated from seedlings infected by puncture, $i_{c}^{i}$ regained its virulence, and then became able to infect sweet pea seedlings by atomizer inoculation. Glom. rufomaculans from the fig failed to infect the sweet pea, and, as will be seen later, it also failed to infect apples and

TABLE III

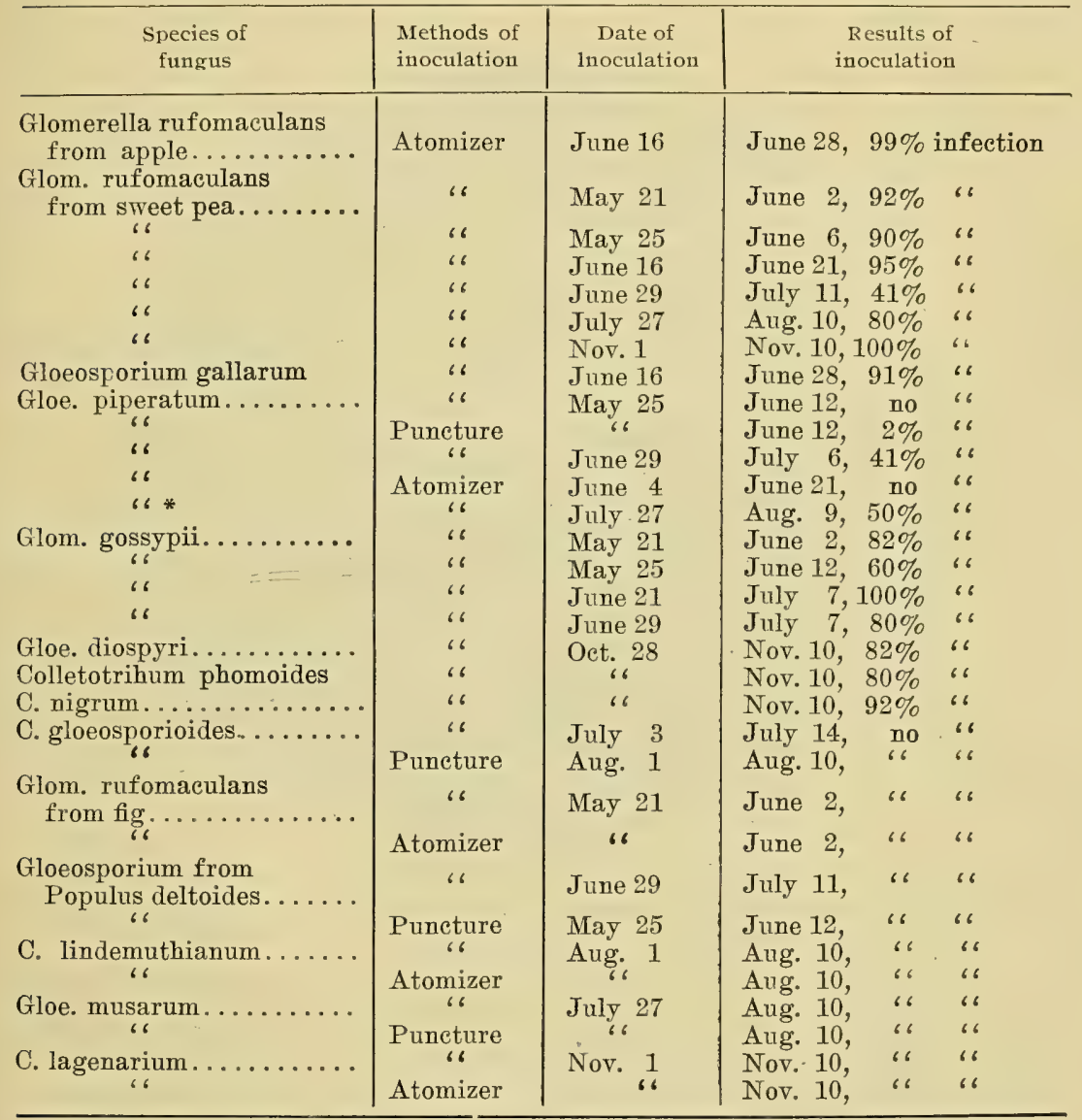

pears on the tree. Edgerton ${ }_{109}$ states that the above itwo organisms readily lose their virulence when grown for some time on artificial media. The Gloeosporium sp. from Populus deltoides, Colletotrichum lindemuthianum (Sace. \& Magn.) B. \& C., and Gloe. musarum Cke.

*Gloeosporium piperatum reisolated from sweet pea seedlings infected by puneture inoculation. 
\& Mass. failed to infect the sweet pea after repeated trials both by puncture and atomizer inoculations. In comparing Tables I and II we see that the organisms which infect the sweet pea also infect the apple, with the exception, however, of Gloe. gossypii, which readily infects the sweet pea by atomizer inoculation, but always fails to infect apples on the tree.

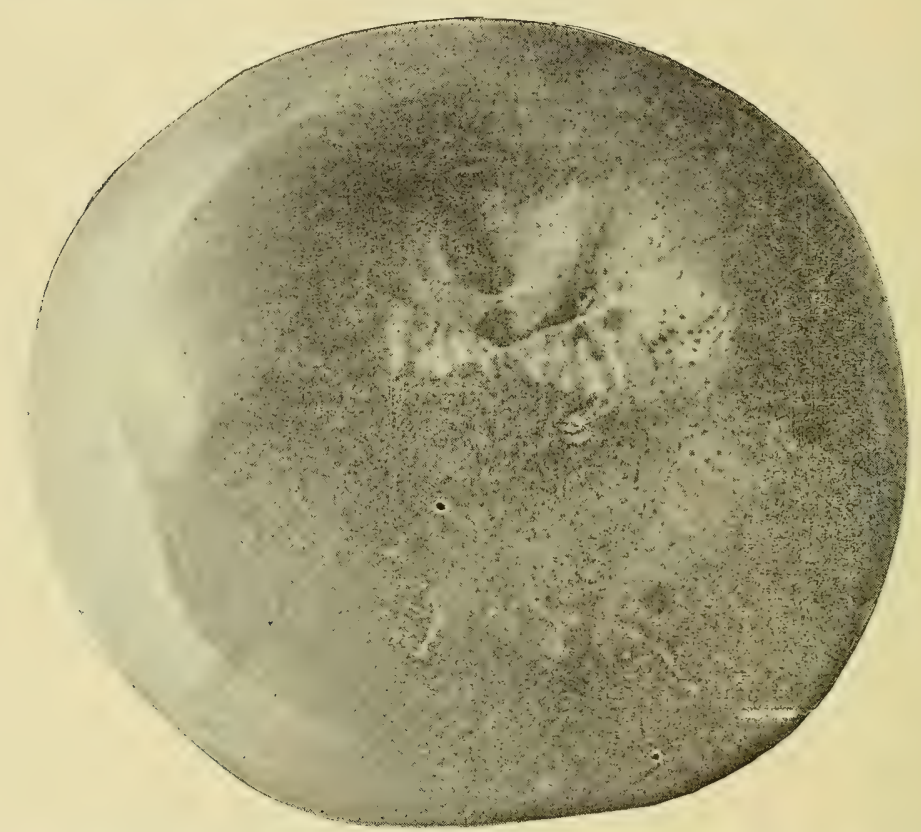

Fig. 40. Bitter rot of apple induced by the same fungous which causes anthracnose of the sweet pea, viz.-Glomerella rufomaculans.

The da'ta in Table IV show that none of the organisms used could infect the Rubicon apple on the tree when the fruits were about the size of a large grape. Later, however, by June 26, the first positive infection was obtained with Glom. rufomaculans from the apple. At this same date all the other organisms used failed to infect. On July 15 the same condition prevailed. By August 19, typical bitter rot infections were obtained with Glom. rufomaculans from the apple and sweet pea, Gloe. officinale, Gloe. gallarum, Gloeosporium sp. from May apple fruit, and Gloe. piperatum. Negative results were obtained with Glom. rufomaculans from fig, Glom. gossypii, Glocosporium sp. from Populus deltoides, Colletotrichum lindemuthianum and Gloe. 
musarum. Further inoculations were made on the Rubicon apple until September when the fruits were ripe and the results were the same as mentioned above.

Field inoculations were tried on the Paradise Sreet apple with the organisms mentioned in Table IV and with like intervals of time between them. The results obtained were the same as with the Rubicon except that positive infection with Glom. rufomaculans from apple was not obtained before Sept. 7. Inasmuch as the Paradise Sweet is a late variety this indicates the greater resistance of late over early varieties.

TABLE IV

\begin{tabular}{|c|c|c|c|}
\hline $\begin{array}{l}\text { Species of } \\
\text { fungus }\end{array}$ & $\begin{array}{l}\text { No. fruits } \\
\text { inoculated }\end{array}$ & $\begin{array}{c}\text { Dates of } \\
\text { in oculation }\end{array}$ & $\begin{array}{l}\text { Results from } \\
\text { inoculation }\end{array}$ \\
\hline $\begin{array}{l}\text { Glom. rufomaculans } \\
\text { from apple.......... } \\
\text { Glom. rufomaculans } \\
\text { from sweet pea...... } \\
\text { Gloeosporium officinale } \\
\text { Gloe. gallarum ......... } \\
\text { Gloeosporium sp. from } \\
\text { May apple......... } \\
\text { Colletotrichum phomoides } \\
\text { Gloe. piperatum......... } \\
\text { C. gloeosporioides....... } \\
\text { Glom. gossypii........ } \\
\text { Gloeosporium sp. from } \\
\text { Populus deltoides...... } \\
\text { C. Jindemuthianum...... } \\
\text { C. lagenarium.......... }\end{array}$ & $\begin{array}{c}6 \text { fruits } \\
\text { for each } \\
\text { organism } \\
\text { ، } \\
8 \\
8 \\
8 \\
10 \\
10 \\
10 \text { fruits } \\
\text { for eaci } \\
\text { organism } \\
8 \\
\\
10 \\
10 \\
10\end{array}$ & $\begin{array}{c}\text { June } 2 \\
\text { June } 6 \\
\text { June } 14 \\
\text { ، } \\
\text { June } 27 \\
\text { 6 }\end{array}$ & $\begin{array}{l}\text { June } 12 \text {, all healthy } \\
\text { June } 21 \text {, all healthy } \\
\text { June } 26 \text {, all typical bitter rot } \\
\text { “ all healthy } \\
\text { June 15, all typical bitter rot } \\
\text { “ } 8 \text { fruits show small spots } \\
\text { " } 2 \text { fruits are healthy } \\
\text { " ame as above }\end{array}$ \\
\hline
\end{tabular}


Field inoculations were also carried on with Kieffer pear fruits. The latier being a variety which ripens very late, positive infection on the fruit with six of the organisms could not be obtained earlier than Oct. 6. The above fungi which produce the anthracnose disease of the sweet pea and the bitter rot on the apple also produce typical bitter rot on the Kieffer pear.

The foregoing experiments have conclusively proved that the anthracnose disease of the sweet pea is identical with Glom. rufomaculans which produces the bitter rot of the apple. Moreover, the six organisms above mentioned, which were previously considered as distinct species, are now shown through the above experiments to be identical with Glom. rufomaculans, since they readily produce the typical anthracnose disease on the sweet pea and the hitter rot of the apple and the pear fruits on the tree. The experiments further indicate the saprophytic nature of Glom. rufomaculans ${ }_{110}$ since no infection could be obtained on very young apples or Kieffer pear fruits on the tree. In the Delaware bulletin just referred to an explanation is given of the causes of the difference in resistance between different varities of the same fruits and between young and older fruits of the same variety. If we look for an explanation as to why Glom. gossypii infects sweet peas and fails to infect apples and pears on the tree but readily infects the same fruits when they are picked and placed in moist chambers in the laboratory, we are brought to the following theory: It seems that the Glom. gossypii at one time was identical with Glom. rufomaculans, but that through long association with the cotton plant it has become so modified in its habits as to make it a physiological species capable of infecting the sweet pea and possibly other hosts, bu't having lost the power to infect the apple. From this it would seem that it is the cell contents of the host which may in some cases modify the physiological habits of an organism. To refute the above statement it could not be argued that the sweet pea can be infected by all species of Gloeosporium. This is not the case, since experiments have proven that only the organisms which infect the apple can also infect the sweet pea, with the above exception.

The writer hopes to continue experiments along these same lines with the object of finding out whether certain other supposedly different species of the Glomerella type are not one and the same.

Mode of Infection and Period of Incubation. The anthracnose of the sweet pea is mainly a disease of the tender parts of the 
plant. Infection starts at the tips and the fungus works downwards invading both stems and leaflets until it reaches a node on the older parts of the stem, where it is stopped in its course. It is not infrequent, however, to find whole branches dying, and sometimes the entire plant is involved. In such eases it has been found that the plant is suffering from insect attacks, either by plant aphids ( $A$ phis sp.), or more especially the red spider, (Tetranychus bimaculatus Haw.). These help the fungus both by weakening the host plant and by distributing the spores over its surface. The spores when germinating have no difficulty in penetrating the oldest parts of the host if it has been punctured by these insects. This explains why the plants suffer most during the hot dry weather, since at that time the aphids are most abundant. Infection often begins with the blossoms at the junction between the flower and the peduncle, in which case the blossom shrivels. The pods, also, even those which are nearly ripe, are often seen to be badly affected. Here, too, the aphids will be found to have opened the way for the fungus. These symptoms are observed in the field when infection takes place naturally, or in the laboratory where the plants are artificially inoculated with Glom. rufomaculans from the sweet pea. The same mode of infection and the same symptoms are observed with the other organisms which are capable of infecting the sweet pea.

The spores of Glom. rufomaculans from the sweet pea usually germinate in from six to itwenty-four hours, according to the amount of moisture in the atmosphere. The germ tubes enter the host by breaking through the epidermal cells of either leaf or stem. In case the spore lodges on a stomate, the germ tube grows away and avoids entrance. It may be that the gases which are given off at the stomates are toxic and prohibit the entrance of the germ tube, which often breaks through the epidermal cells as soon as the spore germinates. At other times the spore germinates by sending out a short germ tube which forms an appressorium which attaches to the epidermal wall. This appressorium is then seen to germinate, its germ tube breaking through the epidermal cell.

The period of incubation varies from three to five days according to the amount of moisture in the atmosphere. The acervuli appear within five days after wilting begins unless the weather is dry, when they may not appear until eight to ten days after infection. In the field the sweet pea anthracnose is at its height during July and Aug- 
ust. This is also the time when the bitter rot of the apple makes its appearance in the orchard. It is thus easy to understand how readily the natural cross inoculation may be effected.

Morphology of the fungus. The spores and mycelium of the Gloeosporium of the sweet pea do not differ from the corresponding structures of Glomerella rufomaculans. Sheldon first observed endospores of the Gloeosporium of the sweet pea in pure cultures, and the writer has observed the same structures in hanging drop and plate cultures of Glomerella rufomaculans from the apple and the sweet pea, G. officinale and G. psidii.

The formation of endospores is as follows: In some of the mycelial threads the protoplasmic content rounds itself into one or more cells, resembling chlamydospores. At the tip end of these cells a filamen't grows out within the empty part of the mycelial thread and at the tip of this filament the endospore is formed in the same manner as the conidia on the conidiophores of a Gloeosporium. The endospore is broken off and pushed forward for the formation of a new one. Further studies are necessary to determine the conditions necessary for endospore formation. The spores of $G$. fructigenum, G. Gallarum, and the Gloeosporiums from sweet pea and May apple, all germinate in the same manner, by sending out a stout germ tube. On five different synthetic media these Gloeosporiums produce growths and fructifications of the same character. The spores of the species from guava and Persea germinate by sending out a very thin germ tube. They also differ in manner of growth and fructification on the synthetic media from the other organisms used. Un'til the perfect stages are found, it appears from these studies that we are justified in considering $G$. gallarum, G. officinale and the Gloeosporium from the May apple fruit as one and the same with Glomerella rufomaculans (Berk.) Spaul. \& von Sch. of the apple and the sweet pea.

Life History. In order to determine. whether the disease is carried over with the seeds of the sweet pea, a large quan'ity of diseased pods were collected and kept over winter, some in the laboratory and some out of doors. Spores from both lots of materials were 'tested Nov. 22, Dec. 22, 1910, Jan. 22, Feb. 22, March 15, 20, 24, April 20, May 21, and June 20, 1911. In all cases the spores germinated well and produced normal colonies on bean agar. Spores of cultures obtained from the sowing of June 20, 1911, readily infected healthy 
sweet pea seedlings, wnlch were grown in pots in the laboratory. This indicates that the organism is carried over the winter as viable spores on the pods and on the seeds, and there is very little doubs that the disease is introduced into new localities through diseased seeds.

\section{MOSAIC DISEASE OF THE SWEET PEA}

Brief History. The first study of the disease was made by Mayer $_{111}$ in 1866 on the mosaic of tobaceo. Mayer found that the disease was not induced by insufficient mineral nutrients. He also found the disease to be distributed over large areas irrespective of soil conditions and further proved that the juice of the leaves of affected plants, when injected into healthy leaves would reproduce the disease in from ten to eleven days. Mayer found that a temperature of $60^{\circ}$ C. does not destroy the infectious nature of the juice, but that a temperature of $80^{\circ}$ kills it. Mayer could not find any animal or fungus parasite to be associated with the disease, altho he believed the irue cause to be bacteria which could not be isolated.

In 1892 Iwanowsky $_{112}$ confirmed Mayer's work. He too was unable to isolate the specific germ on artificial media but states that he saw the bacteria and proved their presence in the tissues of the affected host. In 1894 Prillieux and Delacroix ${ }_{113}$ found this same disease on tobacco in France.

In 1897 Marchal $_{114}$ described under the name of "La mosaique du tabac" a disease similar in appearance to that described by Mayer $_{115}$. Marchal claims to have obtained from diseased leaves a motile bacillus forming chains in culture media, and capable of reproducing the disease by inoculating with a pure culture.

In 1898 Beijerinck added considerable to our knowledge of this disease. He apparently proved the absence of bacteria in the development of the disease. When the juice of diseased plants is passed through filters, the liquid, while remaining perfectly clear and free from bacteria still retains the power of infection. He found that only growing meristematic tissue could become diseased. Among many other things he also found that soil from diseased plants may infect healthy plants. He further showed that the infective material could be transported through considerable distance without losing its virulence. He assumed the virus to be a non-corpuscular fluid like material which has the power of growth when in contact in a sort of sym- 
biosis with growing cells. He called it therefore "a living fluid contagium."

In 1902 Woods $_{116}$ concludes that the disease is due to the presence of oxidizing enzymes in the plant; these he designated as oxidase and peroxidase.

In 1904 Selby $_{117}$ refers to the mosaic disease of tobacco as a nonparasitic disease, he, accepting the conclusions of Sturgis and Woods.

In a recent paper, Allard $_{118}$ has succeeded to transfer by means of inoculation the mosaic of tobaceo to other solanaceous plants of the following genera: Nicotiana, Lycopersicum, Petunia, Physalis, Datura, Hyoscyamus, Solanum and Capsicum. T. Allard also found aphids to be carriers of the disease.

Mosaic Disease of the Sweet Pea. As far as known there is no mention made before of the mosaic disease of the sweet pea. The writer first made a study of the disease in the summer of 1912 and his first published report appeared in the Florist Exchange ${ }_{119}$.

Like the anthracnose, the mosaic of the sweet pea is a very important disease. Both out door and greenhouse plants are alike subject to it.

Symptoms. Mosaic is readily distinguishable by a yellow dotting or mottling of the leaf, presenting in some instances a beautiful mosaic structure, hence its name (Fig. 41). Affected leaves seem to linger for a time but they eventually lose all their chorophyll and soon drop off. Another symptom of this disease is a curling of leaves (Fig. 42), resembling the curling induced by the green aphids, but in this case the aphids had no association with it. The disease makes its appearance after the seedlings are from three to four weeks old. Often, the disease is so bad and the curling so pronounced that the planis thus affected cannot make any headway and remain dwarfed. An attempt is made by these curled parts to produce a few flowers, but the later are borne on very short peduncles as compared with the long peduncles of healthy plants of the same variety. Frequently, however, the affected plants outgrow the disease entirely, and thus a distinct line of demarcation is observed between the previously diseased part and the healthy part of the new growth. At other times infected plants lic:p on growing and even flowering, with the disease keeping pace. 


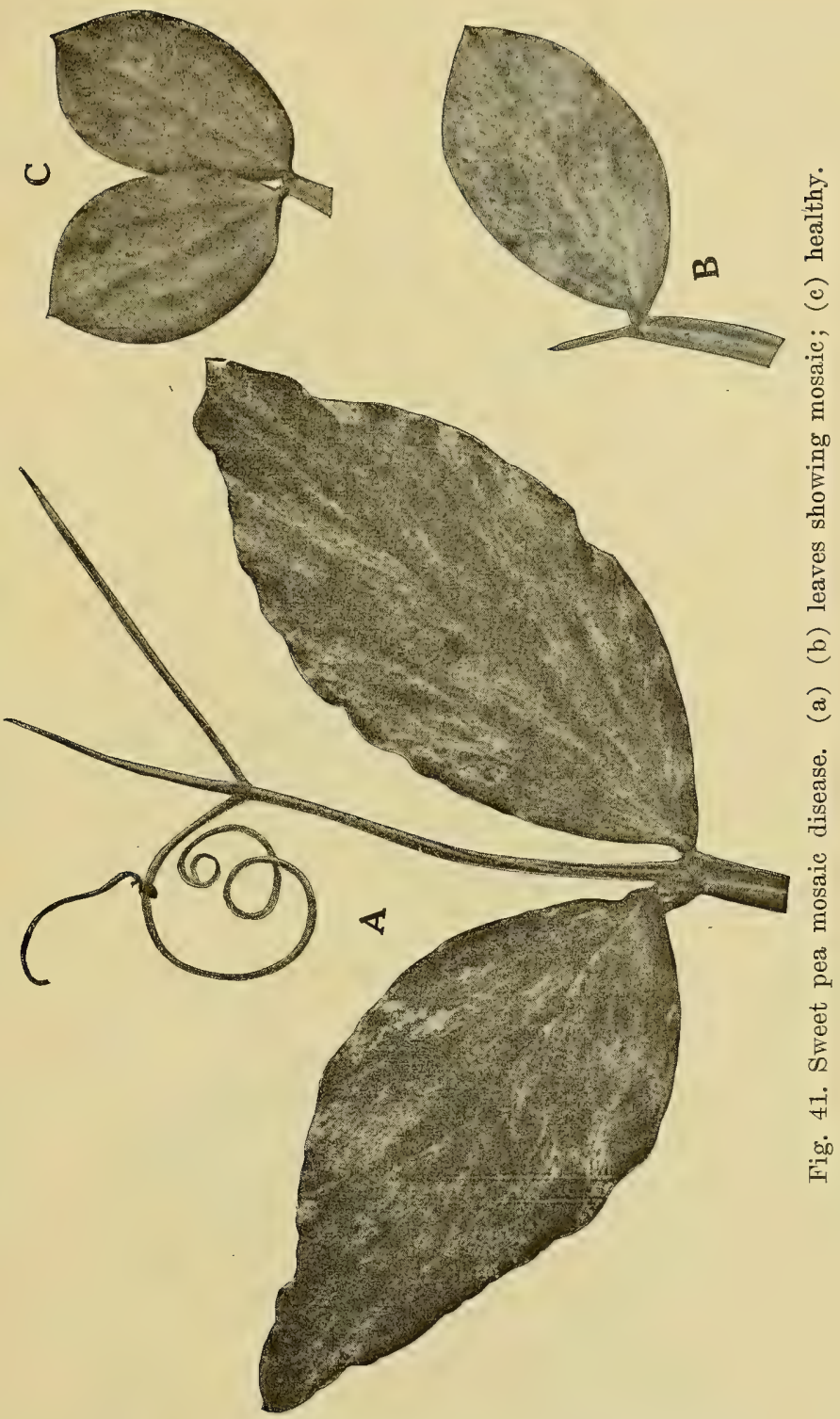

Pathogenicity. Like peach yellows and mosaic disease of tobacco and tomato, this disease of the sweet pea, too, can be reproduced by a puncture with a sterile needle from the diseased leaf into 
a healthy leaf. No organism could be obtained in culture, nor could it be detected with the microscope. Nevertheless, this disease is contagious, as is the peach yellows. Whon the disease first made its appearance in our experimental sweet pea field, the diseased areas

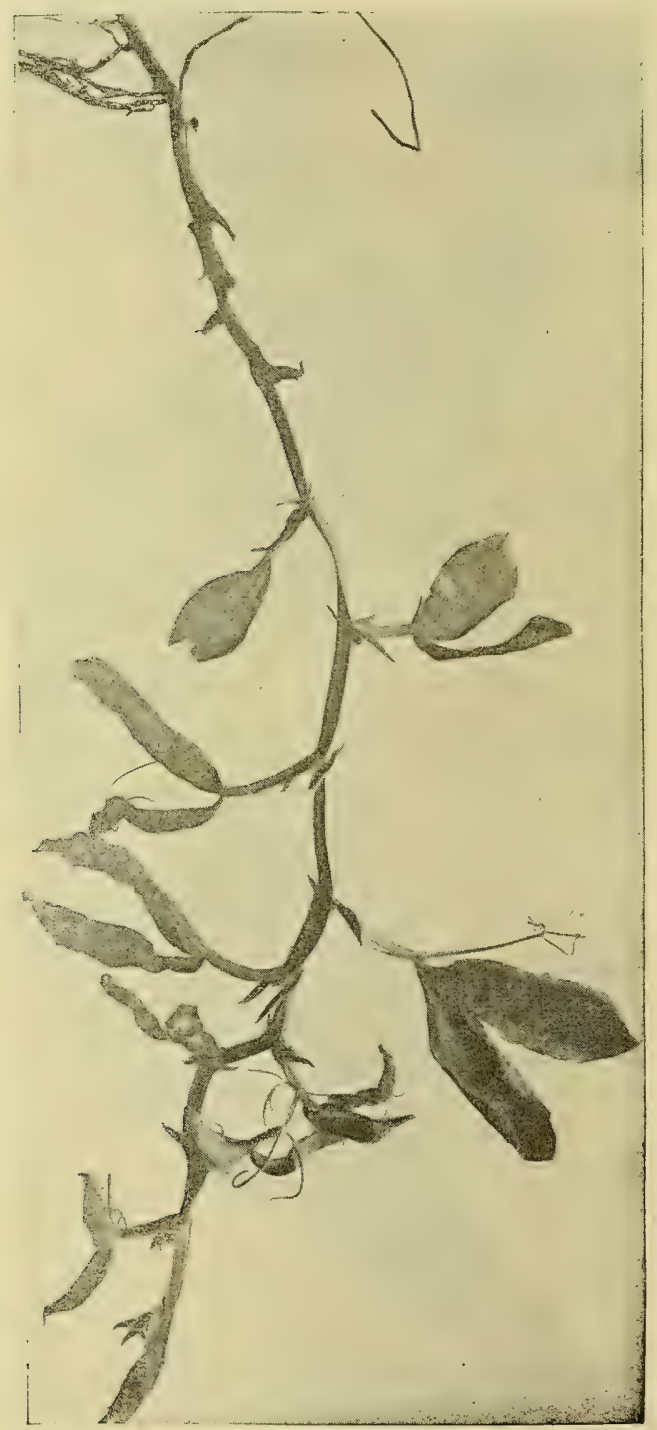

Fig. 41 Mosaic disease causing dwarfing of the plant and rolling of the leaves. 
were immediately located in order to learn something of its spread. They formed two small areas, one in about the center of the field, the other in the southeast corner. Within ten days another survey was made and the whole field was found to be infected. With the exception of the dwarf Cupid varieties, which are seemingly immune, all the rest were found to be affected with the mosaic. When first investigating this disease I thought that, perhaps, this mottling of the leaves was merely a variegated condition. We also thought that perhaps the curling of the tender tips as well as the mosaic effect was due primarily to the presence of aphids, which at the beginning of the season were so plentiful. Experiments were then undertaken to determine definitely these points. Accordingly, sterile pots with sierile soil were isolated in a glass chamber and the plants were allowed to grow for three weeks to see if any disease would develop on them. However, these plants remained very free from any disease. The pots with plants were then divided into four lots; into Lot I were introduced a few siem mothers of aphids from affected mosaic plants in the field. In Lot II were introduced a few stem mother aphids from apparently healty plants in the field. The plants in Lot III were punctured with sterile needles and by pricking a mosaic affected leaf, and then puncturing with the same needle the healthy leaves. Lot IV was punctured merely with the sterile needle, the plants of this lot were designed to serve as checks. In each lot there were two pots with plants in order to duplicate each experiment. After ten days the lot which were inoculated with the aphids from the diseased and healthy plants both began to show the symptoms of mosaic. This, therefore, would appear to show that the mere puncture of aphids would be responsible for the mosaic disease. However, this is not the case, as we will soon see. Moreover, it is easy to suppose, and that on very good ground, that the aphids taken from seemingly healthy plants in an infected field might themselves have been infected before. But this would be no valid proof. Lot III, which was infected with needle punctures from diseased leaves, began after ten days to show the mosaic disease, while the check punctures remained all heal'thy to the end of the experiment. This definitely proves that the aphids are not the cause of the irouble but are merely the carriers of the mosaic disease. It seems, therefore, that any steps taken to control the aphids may also serve to control the mosaic. From this, too, it is evident 
that not only the aphids, but also any biting or sucking insect may help spread the disease.

It has been definitely proven that the mosaic disease is contagious, since it can be produced at will by artificial inoculations. The symptoms produced in artificially inoculated plants are similar to those in the field, namely, a yellowish spoiting or mottling of the leaves and a tendency of the leaves of the tips of the plant to curl.

Cause of the Mosaic Disease. Mention has been made of previous workers who with ourselves have definitely proven the infectious nature of the disease. Attempts to prove the cause of the trouble have resulted in failure. Mayer ${ }_{120}$ failed to find the association of animal or fungus parasites with the disease. He thought that bacteria were the cause of the disease, but all inoculations with bacteria cultivated from the surface of diseased leaves, and with mixtures of different bacteria gave negative results.

Beijerinck $_{121}$ disproved the theory that the cause of the trouble was bacteria, by showing that the juice of diseased plants filtered through Chamberland filters while remaining perfectly clear and free from bacteria still retained the power of infection.

Sturgis $_{122}$ in his conclusions states as follows:

"It (mosaic) is not caused by predaceous insects, nematodes, or parasitic fungi.

"Bacteria have not been associated with the disease but no critical method for their isolation or culture has been applied, and therefore the question of their influence cannot at present be answered.

Woods $_{123}$ believes the disease to be of a physiological nature and of enzymic activity. Woods claims to have reproduced the disease several times by merely removing the tip of a rapidly growing plant.

Suzuki $_{124}$ in his studies of the so-called mulberry dwarf troubles in Japan (all evidence seems to show that this disease is of a similar nature as our mosaic), concludes that the principal cause of the disease is due to the practice of subjecting the mulberry trees to repeated low cuttings, thus removing the reserved food which is required for growth. Woods believes that it was the enzyme (peroxidase) of the leaves that induced the disease because he claims that he induced the disease artificially by injecting into a healthy plant the juice from another healthy plant. Woods found more peroxidase in diseased than in healthy plants. "It is through the introduction of the enzyme 
into the infected host that pathological changes are brought about which resul't in an increase of the normal enzymes of the cell and the decrease of available reserve food. When this condition is reached, it is very difficult for the plant to outgrow the trouble." Accepting this hypothesis, Woods is a' a loss to explain how the disease is spread.

In my investigations repeated trials failed to reveal the presence of either fungus or bacteria in culture. Nevertheless I do not believe with Woods that the disease is physiological and enzymic. I strongly believe the trouble to be cither bacterial or protozoie* and the pathogenic nature of the disease strongly points to this conclusion. That all attempts to obtain a living micro-organism in pure culture have failed does not argue against the possibility of its being either bacteria or protozoa, but simply that our present cultural or filtering methods are not suitable for its detection or retention. Previous to the discovery of Bacterium tumefaciens, by E. F. Smith, no one suspected the crown gall of plants to be of bacterial origin, cultural attempis in each case failed to reveal the organism.

As I have already indicated, Beijerinck showed that the juice of diseased plants when filtered through Chamberland filters, while remaining clear and free from bacteria still retains the power of infection. This proof too does not argue against the possibility of the bacterial or protozoic nature of the mosaic, because the former may be even smaller than bacteria and readily pass through the Chamberland filters. It is therefore possible that Beijerinck's filtered fluid was contaminated with the pathogen and this is why the filtered fluid retained its pathogenic nature. Neither can we accept Wood's statement that healthy plants when cut back develop the disease unless we admit again of the possibility of contamination. If the mosaic pathogen is not present or has not made its appearance on a certain host, the latter can be eut back time and again without the disease ever making its appearance. Before I introduced the disease through puncture inoculation with diseased tissue in the laboratory, I cut back my experimental sweet pea plants in order to prevent them from growing too high and altho I have practiced this very often I have never had a case of mosaic develop from this operation. It is also difficult to believe with Woods that the disease is of a physiological and enzymic nature. Enzymes in plants are natural factors of imF. Manns.

*The idea of the protozoic nature of mosaic was suggested to me by Dr. T. 
munity to protect that plant from disease. Diseased plants will naturally possess a higher enzymic content just as much as the leucocytes in the human blood increase in case of wounds, etc. That this peroxidase of Woods from diseased plants should possess the power of infection is very possible as I have already pointed out the former may be contaminated. That the peroxidase of healthy plants when inoculated into a healthy plant should be able to produce the disease as Woods claims to have done, is probable, only if we admit of possibilities of contaminations which may have been the case. As already stated, the pathogenic nature of the disease points to a living organism as being the cause.

In Wood's enzymic explanation we have no means of accounting for the spread of the disease. Under pathogenicity we have shown that green aphids carry and spread the disease from leaf to leaf and from plant to plant. This by itself is sufficient proof that a living organism is the cause of the mosaic, for if as Wood maintains, the peroxidase of a healthy plant when inoculated into a healthy host will reproduce the disease and if there be no chemical difference between peroxidase of healthy and diseased plants, then why is it when green aphids from perfectly healthy plants are transferred to healthy sweet peas the disease never develops but the mosaic readily makes its appearance by introducing green aphids from diseased plants to healthy ones. If the aphids can carry the peroxidase from diseased plants why do they not carry the same from the healthy plants while sucking their juice? This to my mind is the strongest argument against Wood's physiological and enzymic nature of the mosaic, and on the other hand it strongly points to the probable activity of a living bacterial or protozoic organism. Aphids are not the only agents capable of carrying and distributing the disease, for there are others which may do it. Among the biting insects we have the "corn root worm beetle" (Diabro'ica longicornis), the striped potato beetle (Epicanta vittata) and several others which feed on the sweet pea and at the same time help to distribute the mosaic.

Transmission of the Mosaic through Seed or Soil. Beijerinck claims that soil around diseased plants may infect the roots of healthy plants. In order to determine whether the disease is carried in the soil, the following experiments were tried. A number of sterile pots were 'taken and arranged in groups. Group A. consisted of pots filled with sterile soil, on the level surface of which leaves infected with 
mosaic were spread. Sterilized seeds were sown on the surface of the leaves and the infected leaves and seeds were covered with a 2 -inch layer of sterile soil.

Group B. consisted of 2 poits filled with sterile soil but the latter was mixed thoroughly with a quantity of mosaic infected leaves.

These pots were sown with sterilized seeds and covered with a 2-inch layer of sterile soil.

Group C. consisted of two pois filled with sterile soil and sown with sterile seeds and then thoroughly watered with water from a vase in which mosaic infected plants stood for two days.

Group D. consisted of two pots filled with soil taken from the field and from a spot where mosaic infected plants grew.

Group E. were untreated checks, that is, two pots with sterile soil were sown with sterile seeds and placed at a distance from the infected series. All the pots were then watered with distilled water up to the end of the experiment. The seeds in all the groups germinated and the plants were allowed to grow for ten weeks when they had attained considerable size and in no case did the mosaic appear, thus apparently proving that the mosaic soil is not a factor in carrying the disease. There is no evidence either that the mosaic is carried with the seeds for in no case did the disease appear in the laboratory where unsterilized seeds were used.

\section{Diseases of the Sweet Pea not known to be present in this Country}

In an article in "The Sweet Pea Annual," Massee ${ }_{125}$ describes the following diseases, which as far as known, have not as yet made their appearance in this country on the sweet pea.

Pea Blight (Peronospora trifoliorum)

Pea Spot (Ascochyta pisi)

\section{PEA BLIGHT, Peronospora trifoliorum De By.}

According to Massee, this is the most destructive disease to peas, lupines, and to most of the pea family. The disease may appear and spread quickly when the plants are only a few inches high, or it may attack older plants. In dry weather the mycelium of the fungus present in the tissue spreads throughout the leaf, 
which soon assumes a sickly yellow-green color, and finally bleaches, shrivels and dies without showing any, or only a small amount of mould on the surface. In damp, dull weather infected leaves show yellow patches, which soon becomes covered on one or both surfaces with a very delicate greyish-lilac mould. The summer spores are produced on the leaves, or on any other part of the host. The winter, or resting spores, are imbedded in the tissue of the host that has been previously killed by the fungus. The resting spores have a very thick smooth brown wall. Peronospora viciae is also stated to be able to produce a disease on sweet peas.

\section{PEA SPOT, Ascochyta pisi Lib.}

According to Massee, this disease also attacks the French beans and several other leguminous crops. The first indications of disease on the pods is the appearance of pale green spots of variable size and irregular shape. These blotches continue to increase in size for some time and eventually become whitish, bordered with a dark line, and have the surface studded with minute black points which are the pycnidia of the fungus.

\section{Diseased Seeds}

Under the discussion of the anthracnose disease I have shown that the fungus (Glomerella rufomaculans) is transmitted with the seed. In that case infection starts at the pods and the fungus works inwards gradually penetrating the seed coat and the seed proper (Fig. 38). Such seeds when harvested have a shirveled appearance and when planted with healthy seeds introduce the fungus in the soil and then the disease begins to attack the adjacent seedlings, thus spreading throughout the whole field.

Another disease that may be transmitted with the seeds is the "Streak". In examining infected plants we can readily see the organism (Bacillus lathyri) invade the pods and then work into the seeds. Pure cultures of the organism may readily be obtained by surface sterilizing an infected pod, picking out the seed with sterile forceps and then dropping the same into a plate of media. We have as yet no data to prove that the organism can survive the drying when it is only present on the surface of the seed coat. However, as is often the ease, the organism works through the seed coat and into the seed. Under such conditions it is very probable that it may be carried over 
winter while present in the seed tissue. Such seeds when planted introduce the parasite into the soil and from there the disease gets a foothold to carry on its destructive work.

Sweet pea seeds as we buy them from the seedsmen are put in small paper packages. During my work on the sweet pea diseases I had occasion to open two thousand of such packages. In very few

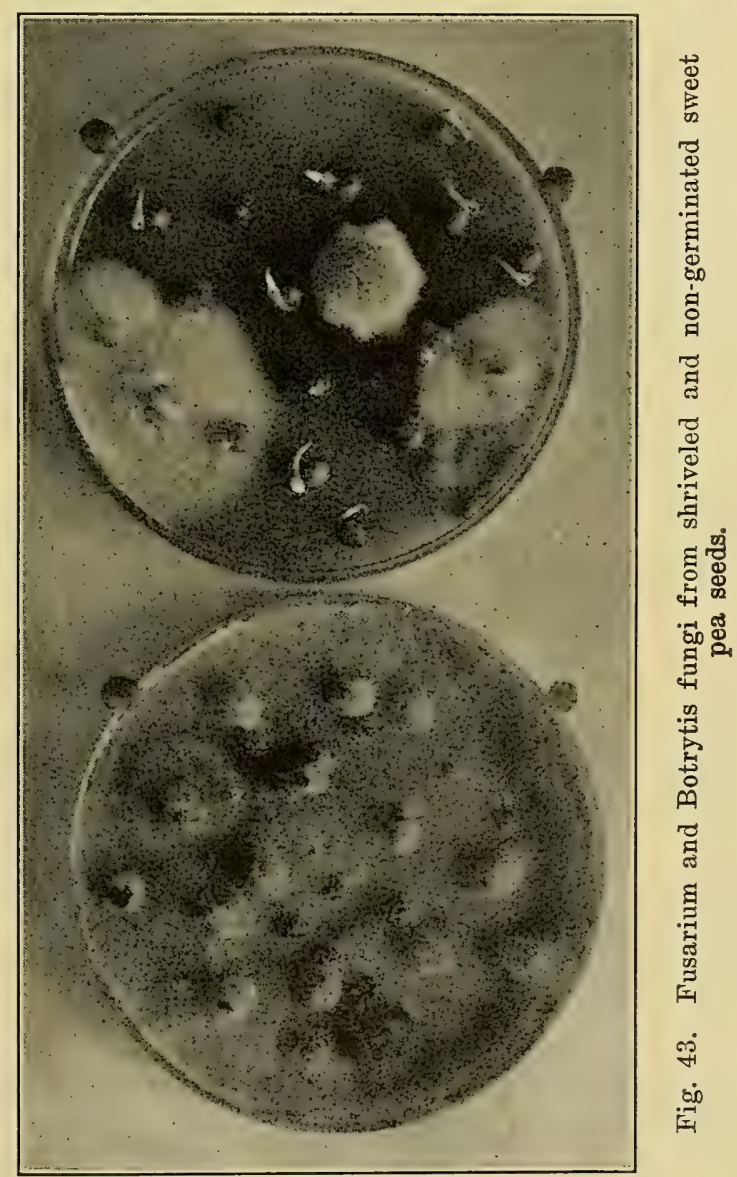

cases were all the seeds plump and full. A cer'tain percent were shriveled and gave the appearance of being diseased. It was thought, therefore, advisable to make a study of such shriveled seeds to deter- 
mine whether or not they are disease carriers and the nature of the pathogens. The technique employed was as follows:

Fresh packages of sweet peas were opened and the percent. of shriveled seeds in each package determined, labeled and separated. The next step was to soak each lot of seed with a $5 \%$ formaldehyde solution for $1 / 2 \mathrm{hr}$. and then to wash it three times in sterile water in order to remove all trace of formaldehyde. Then with a sterile forcep, each lot of seeds thus treated was dropped into a petri dish containing nutrient agar that had been melted and cooled to the proper temperature. As the agar solidified the plates were placed in the incubator and kept there for one week. Observations were made every other day to determine the percent. of germination and to make transfers into slant tubes of agar of all fungus or bacterial growth which appeared on the shriveled seeds (Fig. 43). The results obtained are given in Table $\mathrm{V}$ from which will be seen that a large percentage of

\section{TABLE V}

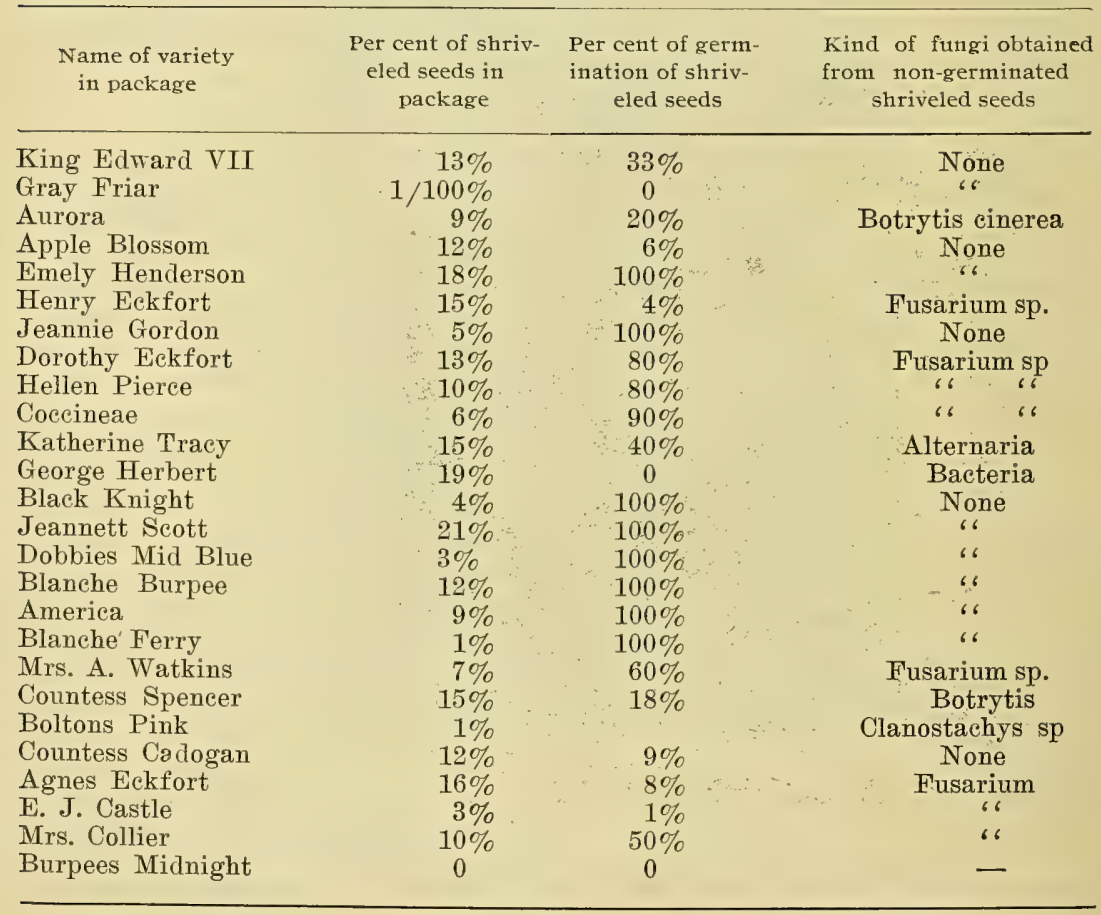


the so called shriveled seeds readily germinated. It was further observed that these before germination became plump and resembled in every respect the germinated healthy seeds which were treated in the same way as the shriveled and were run as checks. It seems then that shriveling in the seeds is merely correlated with a loss of water. Whether shriveled seeds in the long run produce weaker plants has not been determined. Observations so far have shown that the seedlings from the germinated shriveled seeds were in every way equal in vigor to the seedlings of the germinated plump seeds.

Of the non-germinated shriveled seeds, those which remained free from fungous growth ean be classed as hard seeds and those probably would have germinated if the seed coat had been pierced. The germinated seeds which showed growth of fungus or bacteria were at once seen to become soft and rotted. Of the organisms isolated from the non-germinated seeds there were two species of Fusaria, one species of Alternaria, one species of Clonostachys, Rhizopus nigricans and Botrytis cinerea. These after repeated itrials failed to infect healthy sweet pea seedlings, thus seemingly proving tha' they are saprophytes and of secondary nature. Their presence on some of the weak and non-germinated seeds, no doubt helped in the decay of the former, but they fail to play the role of active parasites on growing plants.

\section{Bacterial Diseases}

So far only one kind of bacterial disease of the sweet pea has been observed and that is the "streak" disease. "This has been determined to be caused by a newly described organism, viz. Bacillus lathyri Manns and Taubenhaus.

\section{STREAK IN ENGLAND}

Historical. In correspondence with Mr. T. A. Weston of Orpington, England, the former states that the disease was first observed by H. J. Digges of Dublin in about 1904 or 1905.

In 1906 T. A. Weston 126 gave the name of "streak". to the disease referred to above (the cause of the disease was not given). In 1908 Massee $_{127}$ in a letter to a correspondent who had sent in diseased specimens replied, "the disease is of a physiological nature" and "brought about by over feeding." In 1912 Chittenden $_{128}$ believed that the fungus Thielavia basicola was the cause of the "streak". For the first two years of his inoculation experiments Chittenden 
failed to infect healthy seedlings with the Thielavia fungus. It was only by overwatering his plants that he succeeded in getting some root infection, as he states: "To sum up, as far as our experiments go, the 'streak' disease is brought about by the a'tack of the fungus Thielavia basicola on plants that have received some check at the root." Chittenden has failed to reproduce the typical "streak" but merely the Thielavia root rot as I have already indicated under my description of the above fungus. In the same year Massee $_{129}$ again studied the disease and attributed it to Thielavia basicola.

In 1912 Dyke $_{130}$ found Macrosporium solani constantly associated with the disease, and believed it to be the cause of the trouble.

\section{STREAK IN THE UNITED STATES}

As far as I know, up 'to 1913 there were no American references to this disease.

Massee' $\mathrm{s}_{131}$ short note led me to believe that the disease was physiological. Under Mosaic disease, I have shown that some workers believed it to be a physiological disease. While working on the mosaic, and having "the "streak" in mind, $\mathrm{I}_{132}$ made the following statement:

"In England the sweet peas suffer from a disease known as 'streak'. This disease is very much dreaded by English gardeners, as it causes great losses. From the description given of that disease it seems to be similar to the new mosaic disease of this country. However, we refrain from passing final judgement un'til we have the opportunity of seeing the English specimens and of making comparisons. In England the streak disease is attributed to a fungus Thielavia basicola, which attacks the roots. In our investigations we have not found the Thielavia fungus or any other organism associated on the roots of mosaic affected plants. In fact, such affected plants were found to have as normal a root with as much in the way of legume nodules, as the healthy ones. If our mosaic disease proves to be the same as the streak disease of England, it will be safe to assume that the Thielavia in England is secondary and merely follows the already weakened mosaic affected plant."

The above was published on July 20, 1912, and the statement was made before the American Sweet Pea Society at Boston early in July of the same year.

In the middle of July of 1912, I first noticed a peculiar disease on the stems of sweet peas grown in our experimental field. The disease 
was characterized by dark streaks running along the stems. This suggested a't once the possibility of its being the "Streak" disease of England. Diseased specimens were brought in the laboratory, and microscopical crush mounts were made, but no organism was found that would give any clue as to the nature of the trouble.

In submitting specimens to Prof. Manns and in consultation with him, it was suspected that the trouble might be of bacterial origin. We at once started to make cultures from the diseased material and a pure culture of a yellow bacterium was obtained. Platings made from diseased material from widely separated gardens gave a pure culture of the same bacterial organism. Cultures made from diseased material sent in by Wm. Sims of Boston, Mass. and by T. A. Weston of Orpington, England, all gave an organism similar to that isolated from the home material. Stains made of this organism revealed a bacillus sp. In the meantime Prof. Manns recalled that he had seen a similar streak disease on clovers in Ohio. A search for plants infected in this way showed it upon elovers and upon some other leguminous plants in the vicinity of Newark, Del.

Inoculations made with the bacterial organism on the sweet pea reproduced the typical "streak" disease. That the "streak" is present and widespread in the United States there is no doubt. I have seen it in widely different localities in Delaware, in Pennsylvania, in Massachusetts, and in New York. A letter addressed to me by C. C. Morse \& Co., of California, gives the folowing information:

"The 'streak' disease has not appeared in California as yet, and this is accounted for by the fact that growers so far have not gotten into methods of over-manuring their grounds."

As previously stated, the American literature contains no reference to the disease. Manns and Taubenhaus* published their first account of the disease in the Gardeners' Chronicle of England, announcing the "streak" as being a bacterial disease and the parasite a newly described bacillus, giving it the name of Bacillus lathyri.

"Symptoms.t Like the Bacteriosis of beans, streak makes its appearance in the season of heavy dew. On the sweet pea the disease usually appears just as the plants begin to blossom; it is manifested by

*Manns, T. F., and Taubenhaus, J. J. "Streak, a Bacterial Disease of the Sweet Pea and Clovers." The Gard. Chron., London, Apr. 5, 1913.

tAbstracted from above article. 
light reddish-brown to dark brown spots and streaks (the older almost purple) along the stems, having their origin usually near the ground, indicating distribution by spattering rain and infection through the stomata. The disease becomes quickly disitributed over the more mature stems until the cambium and deeper tissues are destroyed in continuous areas, when the plant prematurely dies. From the stems the disease spreads to the petiole, flower, peduncles and pods. The symptoms in these cases being similar to those on the stems. On the leaves, however, the disease appears as small roundish spots which gradually coalesce, and eventually involve the entire leaf, which when killed presents a brownish dark appearance."

Pathogenicity. The pathogenicity of the causative organism may be proven by diluting a pure culture of the organism in sterilized water and by spraying on the plants with an atomizer. This should be done in the evening when the temperature is cooler and there is less chance for evaporation of the applied infectious liquid.

The disease makes its appearance from seven to ten days after artificial infection and the symptoms are similar to those produced in nature. The organism may be reisolated from the artificially infected plants and the disease induced again at will on healithy plants, in each case the check remaining healthy.

Natural or artificial infection can only take place on mature plants which have started to bloom. All attempts to inoculate plants in all stages of growth previous to the blooming has failed. It seems that the host possesses certain protective properties previous to the blossoming which inhibits the growth of the parasite. Failure to infect young plants was not due to abnormal conditions or to bad technique. The disease in the field does not make its appearance until the plants have started to blossom.

Isolation and Morphological Studies. Over 1,500 plate cultures of beginning or young lesions were made from the several hosts. The organisms may almost invariably be taken in abundance in pure cultures from the beginning lesions in the stems of sweet peas when the surface is properly sterilized.

The isolation work readily indicated the parasite to be a bacterium; a yellow organism which grows luxuriantly upon all the nutrient media, and especially rapid upon nutrient media containing sugars. 
On standard nutrient glucose agar the colonies appear within 24 to 36 hours. The center becomes granular and the colonies have a marked tendency to become stellate or auriculate.

Morphological studies show the organisms to be a comparatively small rod-shaped bacillus, which in fresh cultures is rarely found in chains, and seldom united in twos or fours. The flagella are not easily demonsirated; they are shed so readily that usually not more than two to five may be stained, and these are generally quite short. However, when proper material is selected, carefully fixed and stained, the flagella may be demonstrated 'to be very long and delicate, and to number 8 to 12 , well distributed peritrichially*.

\section{Physiological Diseases}

By physiological diseases of the sweet pea we mean all disturbances in the plants which are not induced by fungi, bacteria, insects, or any other parasites but is expressed in a disturbance in the metabolism of the plant. This disturbance seldom results in the sudden death of the plant.

Under Physiological diseases I will consider the following two troubles: 1. Büd drop. 2. Arrested development.

\section{BUD DROP}

As the name implies the young flower buds at a very early age turn yellow and drop off. This drop should not be confused with the drop produced by the anthracnose disease. In the latter case, the flower develops into a normal spike but it is attacked soon by the fungus Glomerella rufomaculans which girdles it at a point of attachment between the flower and the peduncle. In this case the flower often drops off leaving behind the beheaded peduncle. In the latter case, however, the minute young flower bud never develops; instead it turns yellow and drops off.

There seems no doubt that the drop is a physiological disease and is induced by an unbalanced condition of food elements in the soil. This may occur in a soil that has been excessively fed or in a soil that is lacking in plant food.

The following extract of a letter from a grower whose plants have suffered severely from the drop and who gives the history of his soil

*A more detailed account of this organism will soon appear in a Delaware Bulletin by Dr. T. F. Manns: 
treatment will help to confirm the physiological nature of the disease.

"The soil is rich and is located in a valley near a creek, the subsoil is similarly rich but is not of a mucky nature. Before sowing the peas the field was trenched and a thick layer of pig manure mixed with a little hen manure was put at the bottom of the trench. The manure was mixed up with soil in the trench and the seeds sown thereon. After germination and when the plants reached from 8 to 10 inches, a commercial fertilizer (kind of fertilizer not stated) was worked in at both sides of the row. A short time before blooming, a layer of coarse stable manure was put around the plants to serve as a mulch. During blossoming time the flower buds began to drop off heavily and what promised to be a successful crop of blooms looked as though it would result in total failure." It is here very evident that the plants were supplied with too much nitrogenous matter but with little of potash and other mineral elements.

Cultures made from these fallen buds failed to produce an organism of any kind.

In order to remedy this trouble Prof. T. F. Manns suggested the application of $150 \mathrm{lbs}$. muriate of poiash and $600 \mathrm{lbs}$. acid phosphate per acre. This treatment was followed out by the grower and the drop ceased within a week resulting in a perfect crop of flowers.

On poor soils I have often seen this same "flower drop" and ic is also especially evident where sweet peas are grown in pots and in poor, light, gravelly soil in the laboratory. An application of a balanced fertilizer to these pots readily helped the plant to overcome the bud drop.

\section{ARRESTED DEVELOPMENT}

This trouble, too, is a physiological disease and is induced by the use of excessive fertilizers. The following facts from the letter of a grower who has suffered from this trouble will also help to confirm the belief in the physiological nature of the disease.

The seeds were sown Nov. 1st in pots and planted Dec. 15 in the beds in the greenhouse. Previous to the planting the beds were well manured with horse manure which was applied six months before planting. Besides this, wood ashes were also applied to the beds at the rate of $1500 \mathrm{lbs}$. to $4500 \mathrm{sq}$. feet of bed space. This would be equivalent to nearly seven and one-half tons per acre. About one 
month after planting some of the plants turned yellow and died. Upon examining the dead diseased specimens the plants were found to be dwarfed with a sickly yellowish appearance. The roots presented a burned appearance suggesting the attacks of Thielavia. Microscopical examinations and cultures made from the diseased tissue did not reveal the presence of any parasite which could be associated with the soil. In submiting some of the soil to Prof. T. F. Manns for examination, he found it strongly alkaline. Hard wood ashes contain about $30 \%$ caustic lime and from 5 to $12 \%$ potash. According to Prof. Manns it was the excess of these elements in the soil that made it so highly alkaline, and this condition injuriously affected the plants. This kind of injury could be considered purely physical since it is brought about by the exposed surface of the roots to an alkaline substance. Nevertheless any injury which interferes with the metabolism of the roots is reflected in a derangement of the metabolism of the plant. The resulting injury is therefore of a physical nature.

As a remedy for this trouble Prof. Manns advises the use of acid phosphaite, followed by a good drenching of water. This will neutralize the alkaline effect of the soil and also help to balance the plant ration.

\section{METHODS OF CONTROL}

Under methods of control the following lines of investigation have been earried on:

Resistant varieties

Seed treatment

Treatment of soil with chemicals

Studies of the fungicidal value of some chemical poisons

Formaldehyde treatment of soil

Steam 'treatment of soil

\section{RESISTANT VARIETIES}

To tesi out the resistance of different varieties of the same host to a certain parasite, the general practice is to plant in the field the varieties to be tested and to allow full sway to the natural causes of 
infection. At the end of the growing season an estimate is taken of the per cent of infection of each variety and on that basis a scale of resistance is formulated. While this method by itself is fairly valuable, the method nevertheless is unreliable because a certain variety which under the above test proves highly immune or highly susceptible to disease will, under different condicions of climate, etc. prove the opposite of what it has promised to be in its first trial. The reason is very obvious. No two varieties are alike as well as no two individuals are alike. Conditions in the field are not always ideal for every variety of a certain host to become susceptible to disease. If this were the case we would have all our crops ravaged by pests. In order to make a reliable test of the resistance of different varieties it is necessary 'to have the same conditions of soil and care and then to submit the varieties to the severest test by making all conditions ideal for the parasite 'to attack the plants. To carry out this idea, I planted 100 sweet pea seeds of each variety to be tested in sterile soil and pots in the laboratory. Previous to the planting, the seeds were sterilized by being soaked in a $5 \%$ formaldehyde for $1 / 2 \mathrm{hr}$. The seeds of the different varieties did not all germinate evenly due to the hardness of the seed coats in some seeds but eventually they all germinated. When the plants were eight weeks old each pot with its different variety was well watered and then covered with a bell jar. The latter was sterilized by being previously washed with a 1-1000 mercuric bi-chloride solution and then rinsed with distilled water. The plants remained under the bell jars for 48 hours, where all were seen to be uniformly covered with drops of water. A large amount of moisture accumulated under the bell jars and this was plainly visible by the drops of water standing on their walls. Under such conditions of moisture as described above, infection readily takes place. The infecting material chosen for this purpose was the fungus Glomerella rufomaculans, which causes the anthracnose disease. Accordingly a heavy suspension of spores from a pure culture was diluted in sterilized water and then applied to the plants by means of an atomizer. The inoculated plants were covered again for 48 hours. After that the bell jars were removed and the plants left uncovered. The result of the experiment is given in Table VI.

From Table VI it is seen that of all of the varieties tested not one of them proved to be entirely resistant. On the other hand it is seen 
that the percent of infection differs with the variety. This means then that in each variety there are certain individual plants which are resistant to this particular fungus tested. Attempts were made to reinfect those plants which remained healthy after the firs' inoculation and it was found that nearly $50 \%$ in each case was infected and the rest remained resistant and continued to grow well. This conclusively shows that while no one variety is entirely immune to a disease yet there are nevertheless certain individuals of that variety which have developed the power of resistance. It is well known that if a plan't is resistant to a particular disease, it may be very susceptible to another disease. The problem, therefore, is to test the desired va-

\section{TABLE VI}

\begin{tabular}{|c|c|c|c|}
\hline $\begin{array}{l}\text { Name of variety (seed- } \\
\text { lings six weeks old) }\end{array}$ & \multicolumn{2}{|c|}{$\begin{array}{l}\text { Fungus used (spores in sus- } \\
\text { pension of water) }\end{array}$} & $\begin{array}{c}\text { Per cent of } \\
\text { infection }\end{array}$ \\
\hline King Edward VII & Glomerel & haculans & $90 \%$ \\
\hline Gray Friar & "، & 66 & $80 \%$ \\
\hline Aurora & "، & 6 & $93 \%$ \\
\hline Apple Blossom & 6 & "6 & $90 \%$ \\
\hline Emely Henderson & “6 & "6 & $40 \%$ \\
\hline Henry Eckfort & “6 & “ & $100 \%$ \\
\hline Jeannie Gordon= & "6 & 6 & $98 \%$ \\
\hline Dorothy Eckfort & 6 & "6 & $100 \%$ \\
\hline Hellen Pierce & ، & 6 & $92 \%$ \\
\hline Coccineae & "6 & 66 & $70 \%$ \\
\hline Katherine Tracy & 6. & "6 & $70 \%$ \\
\hline George Herbert & “ & "6 & $60 \%$ \\
\hline Black Knight & "6 & “6 & $80 \%$ \\
\hline Jeanett Scott & “6 & "6 & $72 \%$ \\
\hline Dobbie Mid Blue & "، & 66 & $40 \%$ \\
\hline Blanche Burpee & 66 & "6 & $90 \%$ \\
\hline America & " & "6 & $100 \%$ \\
\hline Blanche Ferry & ، & 66 & $100 \%$ \\
\hline Mrs. A. Watkins & “6 & " & $100 \%$ \\
\hline Countess Spencer & “6 & “6 & $90 \%$ \\
\hline Black Michael & "، & 66 & $60 \%$ \\
\hline Bolton's pink & "6 & " & $80 \%$ \\
\hline Countess Cadogan & “ & "6 & $100 \%$ \\
\hline Mrs. Bieberstedt & 66 & 66 & $20 \%$ \\
\hline Agnes Eckfort & "6 & 66 & $100 \%$ \\
\hline Burpees Dainty & ، & 66 & $100 \%$ \\
\hline E. J. Castle & “ & "، & $1 \%$ \\
\hline Glady's Union & "، & 66 & $4 \%$ \\
\hline Captain of the Blues & "، & 66 & $60 \%$ \\
\hline Duke of Westminster & "s & 16 & $80 \%$ \\
\hline Mrs. Collier & “ & “6 & $70 \%$ \\
\hline Burpees Midnight & “ & “6 & $40 \%$ \\
\hline
\end{tabular}

rieties with all the known diseases to which they are subject. In these tests all the immune individuals must be selected and by crossing and 
selecting we will build up a strain which will possess complete immunity to all or at least to most of the diseases to which that variety is subject.

\section{SEED TREATMENT}

I have previously shown that the sweet pea seeds are capable of carrying and of introducing one of the most dreaded diseases of the sweet pea, namely, the anthracnose (Glomerella rufomaculans). Sweet pea seeds were also found to carry several species of fungi which seem to be unable to assume the role of parasites. Nevertheless, the time may come when these fungi may become parasites of the sweet pea.

It was, therefore, thought necessary to devise some means of treating the seeds which woud kill all external as well as internal parasites, and at the same time not inhibit the germinative power of the same. The following are the methods which have been tried:

Effect of temperature

Effect of sulphuric acid treatment

Effect of formaldehyde treatment

Effect of Temperature on Seed. In order to test the effect of temperature the following experiments were tried. Ten different varieties were thoroughly mixed and lots of 100 seeds each were picked out and put in pieces of cheese eloth and tied up with a string. The experimental temperatures of the water used were boiling water, $90^{\circ}, 80^{\circ}$, and $60^{\circ} \mathrm{C}$. The seeds were immersed in the water with the varying temperatures and kept there for different in'tervals of time, as is indicated in Table VII. In each test a duplicate series was always made, i. e. using two packages of 100 seeds each. The per cent of germination in each ease expresses the average taken from each duplicate series. After each treatment seeds were placed in sterilized petri dishes containing moistened filter paper which had been previously sterilized by being placed in boiling water for two minutes.

After placing the seeds in the petri dish more sterile water was added in order to secure the amount of moisture necessary for germination. The plates were then placed in the incubators for 10 days, observations being made every two days. The resulit of the experiment is given in. Table VII. 


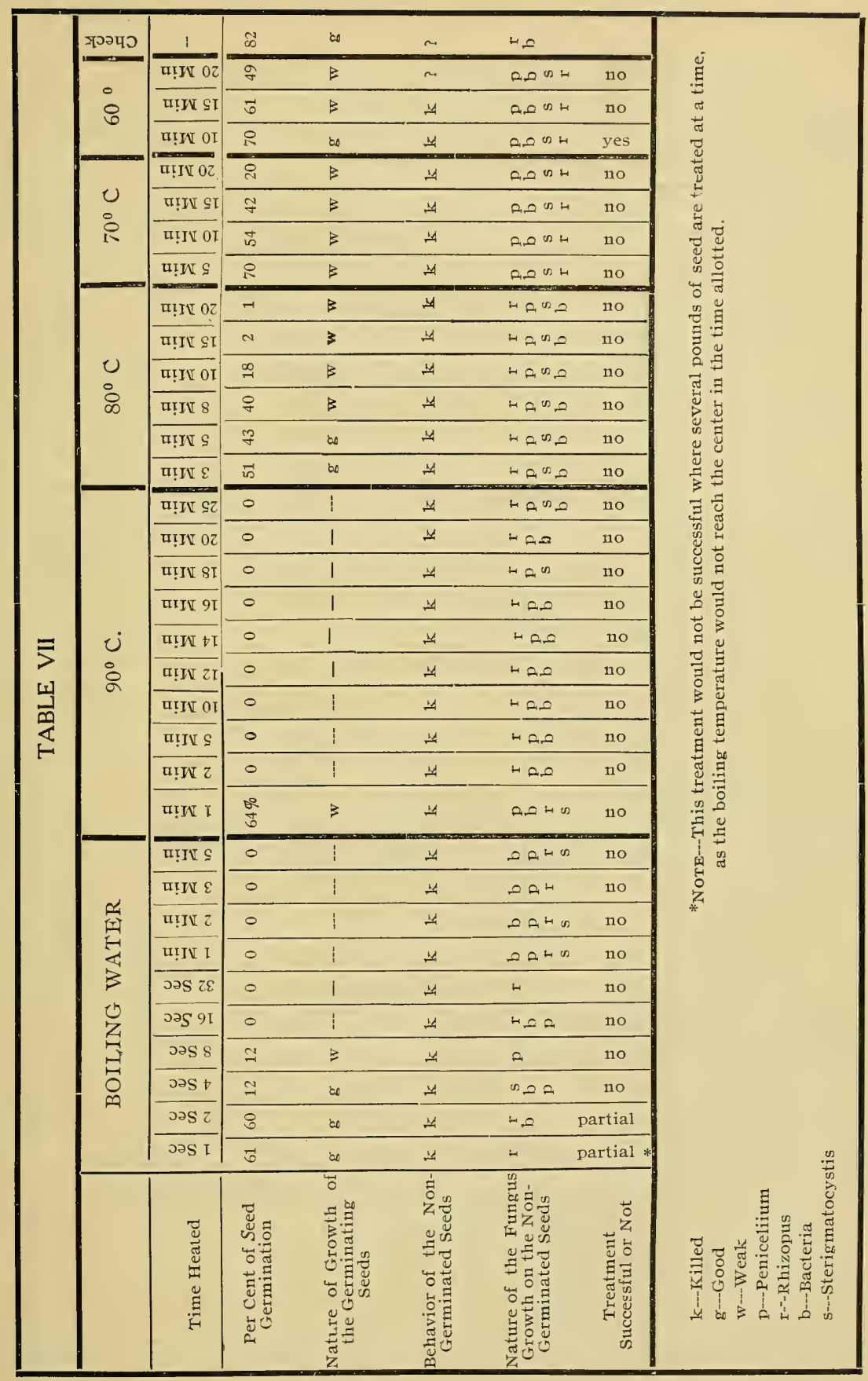


From Table VII it is seen that of all the temperatures tried, placing the seeds in boiling water for one or two seconds, seems to offer only little promise of success.

Placing the seeds in water of $90^{\circ} \mathrm{C}$. for one minute insures a somewhat higher per cent of germination. However, the growth of seedlings seems to be weaker than either checks or those boiled for one or two seconds.

The series treated with water at temperatures of $80^{\circ} \mathrm{C} ., 70^{\circ} \mathrm{C}$, and $60^{\circ} \mathrm{C}$. did not meet our expectations of success. However, these results are not final, as they simply open up a line of investigation for the future.

Effect of the Sulphuric Acid Treatment on Seed. Historical. Rostrup $_{133}$ was one of the first investigators to use sulphuric acid on hard seed in order to hasten germination. Todaro ${ }_{134}$, while working independently, found that concentrated sulphuric acid of a density of 1.84 acted upon hard seeds of many leguminous plants, rendering them capable of prompt germination. Thornber ${ }_{135}$, too, found that when certain seeds are treated with sulphuric acid, their germination was hastened. Schneider-Orelli ${ }_{136}$ also found the sulphuric acid treatment of value in hastening the germination. Bolley ${ }_{137}$ also found sulphuric acid to benefit the germination of seeds. In 1912 Love and Leight ${ }^{\prime} y_{138}$ also found the same general beneficial results on germination of seeds treated with sulphuric acid.

My object in treating sweet pea seeds with sulphuric acid was to find out its effect on germination, and as a preventive mears ir destroying all possible adhering spores of pathogenic organisms. The method was to place the seeds to be treated in glass receptacles and then to cover the seeds with pure sulphuric acid. The time of tratment was five minutes, fifteen minutes, one-half hour, one hour and une and a half hours. After the treatment the acid was poured off and the glass receptacle was put under running tap water for five minutes and then rinsed three times in sterilized water. After that the seeds were placed on moist filter paper in petri dishes, and the latter were put in the incubator for ten days. A series of untreated seeds were also run as checks.

The results obtained from the seeds treated five minutes, fifteen minutes and one-half hour were practically the same, i. e., in each case the percentage of germination was much higher in the treated 
seeds than in the checks. In the former the percentage of germination ranged from $95 \%$ to $100 \%$, while in the later it ranged from $60 \%$ to $85 \%$. The seeds treated in the acid for one hour showed $50 \%$ injury, and the $11 / 2$ hour treatment gave only $2 \%$ germination.

In order to test the effect of sulphuric acid on the fungus flora of the seeds, 10 ce of the acid was put in test tubes, and the latter were inoculated heavily with spores of Glomerella rufomaculans and allowed to stand for five minutes, fifteen minutes, half-hour and one hour. Transfers of the treated spores were made by means of a loop into melted tubes of agar. These were well shaken and poured into petri dishes, cooled, and placed in an incubator. Check cultures were also run by using untreated spores transferred directly into agar. In three days the check plates all showed a vigorous growth of a pure culture of the fungus where none of the series of the treated spores showed signs of germination even after eight days. This proves, then, that sulphuric acid can be used with advantage in treating seed both to increase the per cent of germination and also to kill all spores which adheres to the seed coat.

Formaldehyde Treatment of Seed. The method employed here was the same as for the sulphuric acid. The strength used was $5 \%$, and the time of treatment was five minutes, fifteen minutes, half hour, one hour and one and a half hours. It was found that the one and a half hour treatment seemed to have reduced the percentage of germination, whereas, all the other treatments did not affect in any way the germination.

Where there was no injury apparent, the formaldehyde treatment did not seem to help the germination of the seeds as did the sulphuric acid. However, it no doubt helps to kill the adhering fungus spores of the seed coat. This latter advantage makes the formaldehyde treatment a valuable preventive means.

\section{TREATMENT OF SOILS WITH CHEMICALS}

The object of this treatment was 'to determine: 1 , the effect of the treatment on the growth of the plant and its resistance to disease; 2 , the effect on the soil flora; and 3 , the effect on the nitrogen content and ammonification. The method employed was to sow 50 seeds in a pot (18 pots in all); the soil employed was unsterilized light garden leam. 
The chemicals and the strengths used are indicated in Table VIII. After the seed had germinated and the plant had attained three inches in height, I began to water them twice a week with the respective chemicals. The checks were treated with distilled water. The experiment was run for two seasons, in each case up to the flowering time of the host.

The results of the first season are not indicated in Table VIII because with one exception as stated below there was no apparent difference between the treated and the check plants. During the first season, the treatment did not affect in any way the fungus or bacterial flora of the soil. Both treated and check plan'ts, before the close of the first season, were inoculated with spores of Glomerella rufomaculans. But both lots gave about the same percentage of infection. This clearly indicated the wonderful power of the soil to absorb mineral poisons and to fix them in such a way as to make them harmless 'to plant growth. Ordinarily, neither plant, fungi, nor bacteria could grow in a solntion of 1-1000 copper sulphate, for instance. However, when this same solution is applied to the growing plants through the soil, the latter fixes it so that the plants continue their growth and reach maturity as they would if the copper sulfate were not there. The same holds true for the soil flora.

The only injury apparen't to the plants during the first season's trial was on the series watered with $1 / 100 \mathrm{MnSO}_{4}$. Altho growing fairly well, these plants were seen to lose their chlorophyll at an early date. These plants died just before blossoming, and $a_{\llcorner}^{2}$ that stage they were white with no trace of chlorophyll.

The results obtained from the second season's growth are tabulated in Table VIII.

In order to determine the effect of the different chemical treatments on the soil flora, the method employed for isolating the organisms was the same as that recommended by Prof. T. F. Manns ${ }_{139}$. Plates containing $1 / 1000$ and $1 / 10,000$ of a gram of soil was made. Two kinds of media were used for this purpose, the composition of which is given in Table VIII. The media marked XXI is purely synthetic and is of value in bringing out the azotofiers. It is also valuable in bringing out the bacterial flora of a soil and in keeping down the saprophytic fungi. Medium II on the other hand, is more likely to bring out the fungus growths and to keep in check the bacterial 


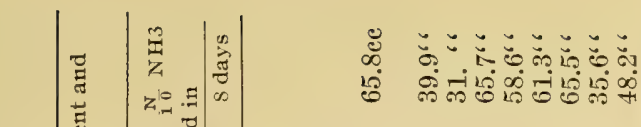

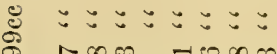

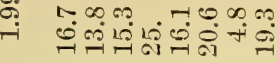

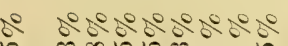

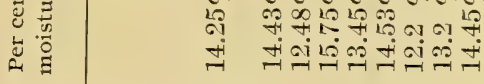

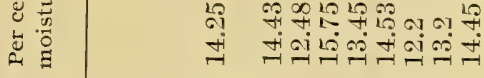

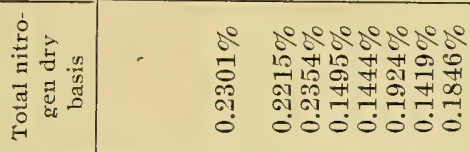

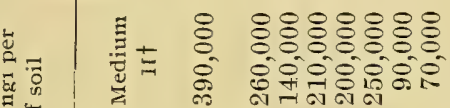

$$
\begin{aligned}
& \text { इㄴ }
\end{aligned}
$$

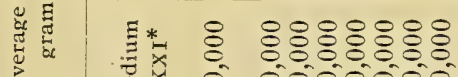

$$
\begin{aligned}
& \text { 苟 }
\end{aligned}
$$

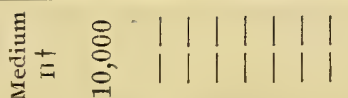

$$
\begin{aligned}
& \text { 荘 } \\
& \text { 苟 }
\end{aligned}
$$

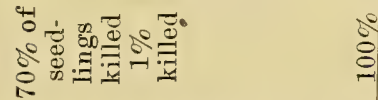

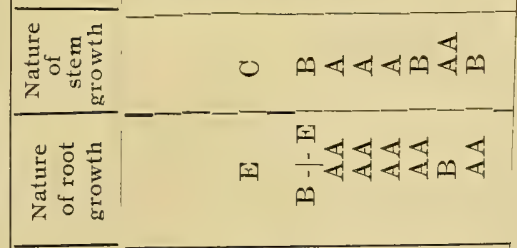

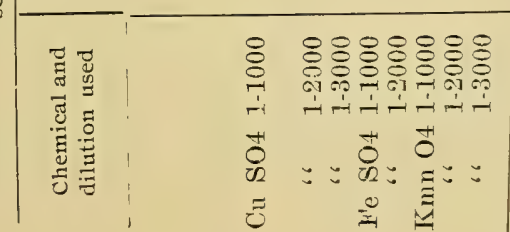





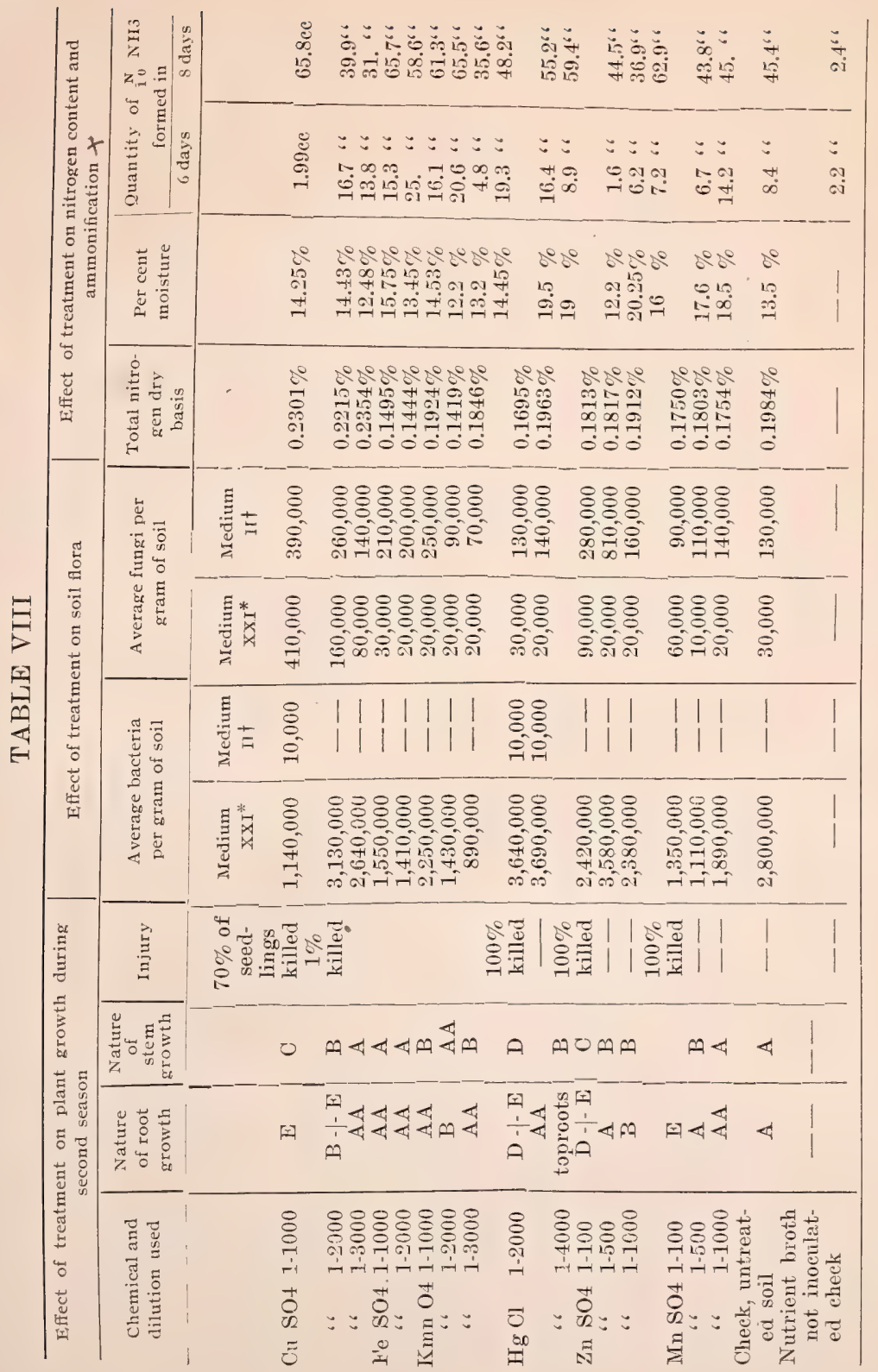

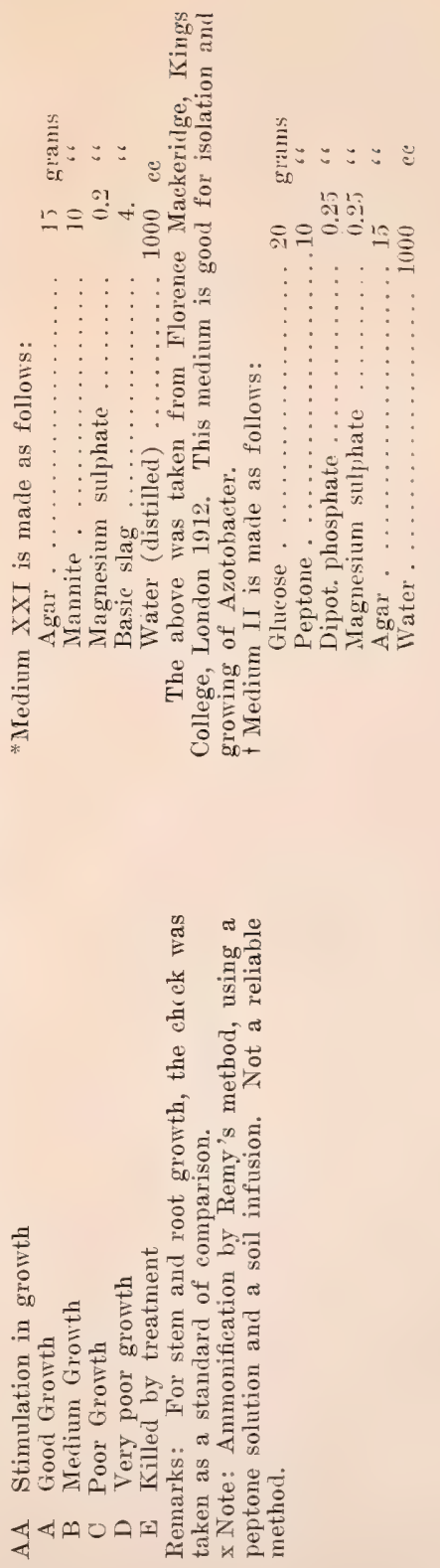



flora. The nitrogen was determined* according to the Kjeldahl (modified) method $_{140}$.

Ammonification was determined by inoculating $100 \mathrm{cc}$ of nutrient broth containing one gram of peptone with 1 ec of an infusion made by shaking 10 grams of soil in 100 cc of water.

From Table VIII we see that the results obtained vary considerably, especially during the first six days, which more nearly represents the ammonifying power. Under copper sulphate for instance, $1 / 1000$ killed $70 \%$ of the seedlings and the growth of the latter was quite stunted. The average number of bacteria per gram of soil was also less when compared to the checks, whereas there was an actual increase in the nitrifiers, which resulted in an increase of total nitrogen and ammonia. On the other hand, copper sulphate $1 / 3000$ produced stimulation in plant growth; there did not seem to be an appreciable decrease in the general bacterial flora, but there was a resultant decrease of ammonifiers. Again, under $\mathrm{Hg} \mathrm{Cl}_{2} 1 / 2000$, the result was a killing of all the seedlings, but an increase in the bacterial flora as well as nitrification and ammonification. $\mathrm{Hg} \mathrm{Cl}_{2} 1 / 4000$ gave stimulation in plant growth, soil flora, and in ammonification.

Table VIII is extremely interesting, as it opens up so many new phases in soil biology, soil bacteriology, and in plant pathology.

\section{STUDIES OF THE FUNGICIDAL VALUE OF SOME CHEMICAL POISONS}

Those who are actively engaged in the study of methods of control in plant disease, will readily realize how uncertain it is to depend upon field methods alone. In order to test out the value of a fungicide the only method used consisted in spraying the particular plant to be treated, with that fungicide, and of noting results. With such a method one works in the dark. Moreover, a great deal of time is lost, because each trial, or each modification of a trial means one season of growth. In 1910 Reddick and Wallace ${ }_{141}$ worked out a quick method of determining the efficieney of a certain spray material. In brief, the method is as follows:

The fungicide to be tested is sprayed on a clean slide with an atomizer. It is then allowed to dry in order to permit any chemical

*Mr. Paul Emerson under the direction of Prof. Manns carried out this phase of the work. 
changes to occur that are likely to be induced by exposure to a'tmospheric conditions. It is supposed that the same chemical changes which take place on the leaf previous to infection also take place on the slide in the laboratory before the spores are placed to germinate. This more nearly duplicates natural conditions, and the results at time of germination practicaly indicate the relative fungicidal value of the chemical tested. When thoroughly dry, each slide is placed in a petri dish containing enough water to keep the air well saturated. Spores of the particular fungus which we wish to control are mixed in water, and drops of this water are placed, with a dropper, on the treated slide. The petri dish is now covered and 24 hours are allowed for the spores to germinate. The inhibition of germination of all the spores in the drops placed on the slide indicates the value of the fungicide. While the method above described is excellent, it nevertheless has its drawbacks. We know that in practice we do not spray our plants every day, but this is usually done every three or four weeks. The method employed by Reddick and Wallace cannot account for the fungicidal value of a certain spray material during the two or three weeks from the time of its first application. In my studies I have supplemented this deficiency by the following method. While adopting the method used by Reddick and Wallace of applying the fungicide and of drying the slide, I have worked out the following modifications. Instead of spraying only a few slides and of inoculating them at once, I have sprayed some fifty slides at one time with each chemical. These slides were all dried and divided into different lots. Lot I was used for germination at once, lot 2 used, say, after an interval of one week, etc. This method allows the time element to have its full effect on the fungicide concerned, and each germination 'test definitely indicated whether that fungicide deteriorates rapidly or not. The fungicide which preserves its germicidal value the longest is probably of the greater economical value. The fungicides tested and the strengths used are indicated in Table IX.

It will be seen from the above table, that copper sulfate at the strength of $1 / 100$ up to $1 / 500$, and potassium permanganate $1 / 2 \%$ up to $3 \%$ completely inhibited the germination of the spores of Glomerella rufomaculans for nearly 'two months. On the other hand, lime sulphur $1 / 10$ up to $1 / 50$ gave most unsatisfactory results from the very first test, and its fungicidal value rapidly weakened with age. This was still more eviden' with the "Sulphurated Potassium" also 


\begin{tabular}{|c|c|c|}
\hline$A$ & 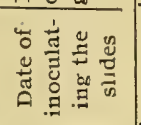 & 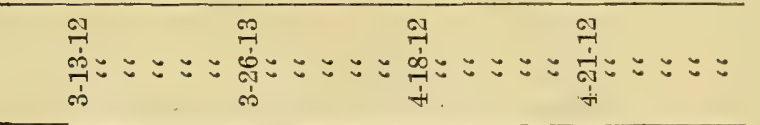 \\
\hline & 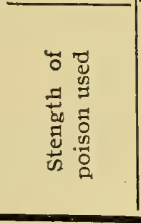 & 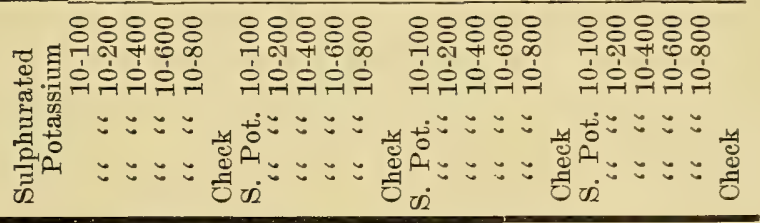 \\
\hline & 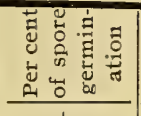 & 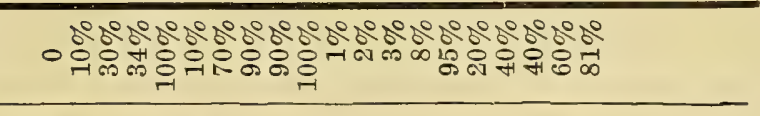 \\
\hline 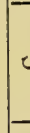 & 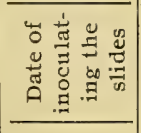 & 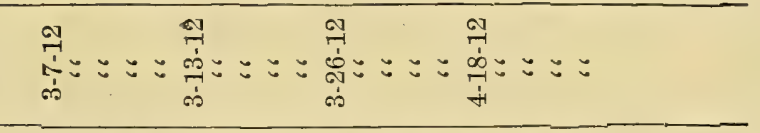 \\
\hline & 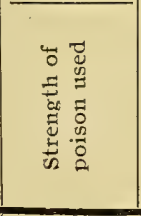 & 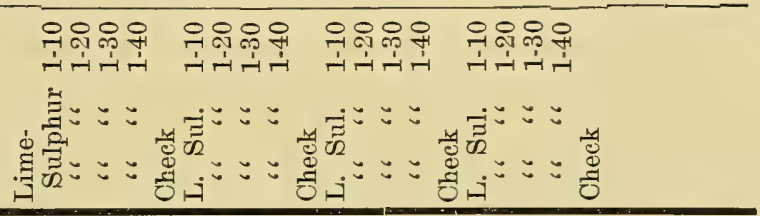 \\
\hline & 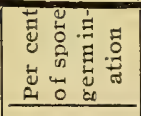 & 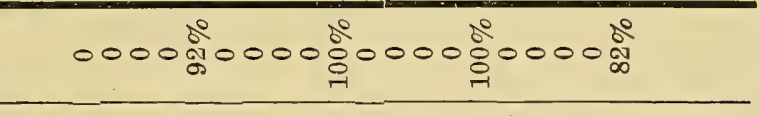 \\
\hline & 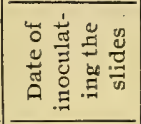 & 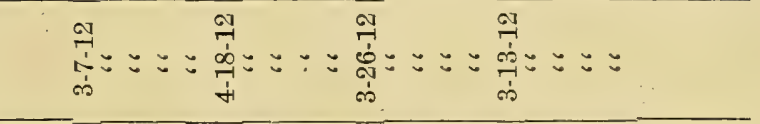 \\
\hline & 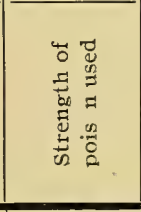 & 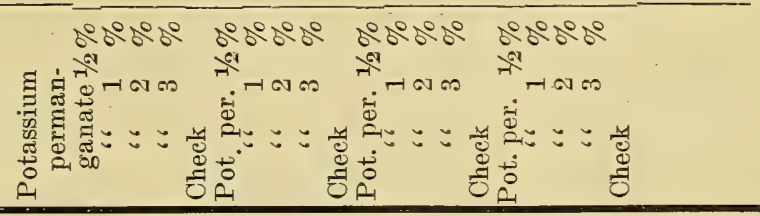 \\
\hline & 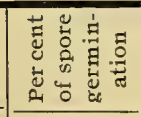 & 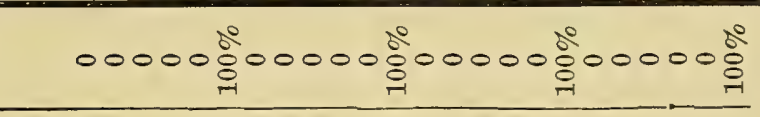 \\
\hline & 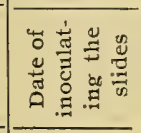 & 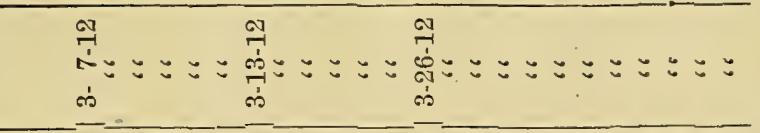 \\
\hline & 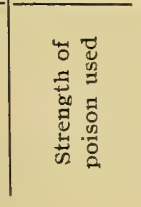 & 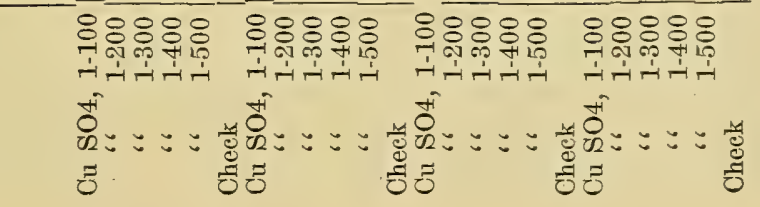 \\
\hline
\end{tabular}


known as "Liver of Sulphur." Lime sulphur is a valuable fungicide in controlling apple scab (Venturia inequalis) and sulphurated potassium is a valuable fungicide in controlling mildew (Oidium sp.), but evidently these two fungicides are of no value in the control of the sweet pea anthracnose. On the other hand, copper sulphate and po'tassium permanganate both prove very toxic to the spores of the anthracnose. The next step therefore, was to test all the strengths used of these two fungicides by spraying them on sweet pea plants in field, and by watching to see if these poisons produced burning of the leaves and stems. Copper sulphate at the sirengths of $1 / 100,1 / 200$, $1 / 300,1 / 400$ and $1 / 500$ all burned the leaves of the sweet pea. Hence while the above strengths possess valuable germicidal properties their use upon the sweet pea is prohibitive. This means that weaker strengths are to be tried until the proper limit is reached, i. e. the limit which does not decrease the germicidal value of the copper sulfate and which does not produce injury to the plant. This we intend to carry on further in the future. Potassium permanganate $1 / 2 \%$ up to $3 \%$ does not produce any injury to the plant whatsoever. As a matter of economy, therefore, $1 / 2 \%$ of potassium permanganate proves a valuable fungicide in the control of the sweet pea anthracnose. It should be applied to the plant not oftener than it is washed off by rain. The method can be used in testing out an endless number of chemicals and there is no doubt that a good many will prove valuable additions to our list of fungicides.

\section{Soll Treatment in the Greenhouse}

Growers who are troubled with Rhizoctonia or Fusarium in their greenhouse beds, will find the following directions valuable ${ }_{142}$.

\section{STEAM STERILIZATION}

"The preventive method which promises best results to those who have the convenience for applying it is that of sterilization of the seed beds by steam.

"In addition to the killing of the fungus, this method, in common with surface firing, 'to be described later, has several advantages over formalin treatments. The weed seeds in the soil are very largely killed, and this alone, according to the testimony of the farmers who have used sterilization, pays for the cost of treatment, as the beds do not have to be weeded and thus a large amount of hand labor is obviated. The physical texture of the soil is altered by the heat and 
made more suitable to root development and, moreover considerable plant food is made directly available to the seedlings. Furthermore, the heating of the soil just before sowing in the spring has an appreciable effect in starting the seedlings off quickly.

"With the elimination of the fungus it is possible to employ those methods forcing the plants by extra fertilization, increased watering, and higher temperature which would otherwise be unsafe as favoring the development of the root-rot fungus.

"Ordinary greenhouse method-The method of sterilization to be used will depend to some extent on the size, the location, and the permanency of beds and the cost of application.

"The method in general use for the sterilization of soil in greenhouse benches might advantageously be employed in beds that are to be used year after year without change of location, as the equipment would be more or less permanent. This consists in placing one foot below the surface of the soil a system of $11 / 2$-inch pipes which are perforated with $1 / 4$-inch holes on their under side at intervals of 6 inches throughout their entire length. The pipes should run lengthwise of the bed, 18 inches apart, and be connected with a steam boiler capable of producing 80 to 100 pounds pressure. Before trea'tment the soil should be thoroughly spaded up and pulverized to permit ready access of the steam to all parts, and all fertilizers should be applied at this time.

"The bed to be treated should be covered with several thicknesses of old burlap or blankets to confine the heat to the soil. The steam should be applied at a pressure of 80 to 100 pounds, as at a high pressure it is much drier and the soil is not wet as much as when lowpressure steam is used. A treatment of from one to two hours is usually sufficient to thoroughly sterilize the soil to a depth of 18 inches. A few potatoes laid in the surface will indicate the thoroughness of the treatment by the degree to which they are cooked. The blankets might advantageously be left on for some time to make the treatment more thorough.

"While this method offers some advantages for seed beds of limited area, in that the pipes may be left in the ground and used year after year with little extra labor and may also be used for subirrigation, the initial cost of installation, especially on large seed-bed areas, may be prohibitive. 
"Inverted-pan method. The method which has given the best results in practice, and which because of its simplicity and small cost recommends itself for use on large or small areas, is the invention of Mr. A. D. Shamel, of the Bureau of Plant Industry, and was devised by him to sterilize nematode-infested soils in Florida. The apparatus consists of a galvanized iron pan, 6 by 10 feet and 6 inches deep, which is inverted over the soil to be sterilized and the steam admitted under pressure. The pan is supplied with steam hose connections, has sharp edges, which are forced into the soil on all sides to prevent the escape of steam, and is fitied with handles for moving it from place to place, the weight of the entire pan being not over 400 pounds.

"The soil is prepared as in the greenhouse method, a few potatoes being buried at a depth of a foo't to gauge the degree of heat attained. A soil thermometer may also be used if desired. The steam should be kept at as high a pressure as possible, 80 to 100 pounds being best, and the treatment should con'inue for one to two hours, depending on the pressure maintained. In experiments conducted in the spring of 1907 , one hour's steaming at $80^{\circ} \mathrm{C}$. under 100 pounds pressure gave best results in killing both the fungus and the weed seeds. When one section of the bed is treated the pan is lifted and carried to an unsterilized portion and the operation repeated until the entire bed is steamed.

\section{FORMALDEHYDE STERILIZATION}

"The use of a formalin solution for the sterilization of greenhouse soil against Rhizoctonia has been in vogue for some time with excellent resulits, and furnishes a very simple means of combating the root-rot. The method is as follows: The beds are thoroughly prepared the same way as for the other methods of sterilization described and are then drenched with a formalin solution composed of 1 part of commercial formalin to 150 to 200 parts of water, three-fourths to 1 gallon of this solution being used to the square foot of bed space. The solution should be put on with a watering pot with a hose and distributed as evenly as possible over the bed, so as to thoroughly wet the soil to the depth of a foot. It will in most cases be necessary to put this solution on in two or three applications, as the soil will not take in this quantity of water immediately. The beds should then be covered with heavy burlap or a tarpaulin to keep in the fumes for a day or so, and then aired for a week before sowing the seed. 
"Spring applications of formalin are open to the following objections: The addition of such a large quantity of water to the soil keeps it wet and cold for some time longer than would naturally be the case, thus delaying germination as well as subsequent growth; the necessity of airing the beds to remove the formalin fumes and to allow the soil to dry out also causes delay in seeding. To obviate this difficulity the beds should be treated in the fall, before freezing weather sets in. In this case a stronger solution, 1 to 100 , may well be used, as there will of course be no danger then of injuring the seedlings."

\section{SUMMARY}

1. It has been shown that the sweet pea is subject to a number of diseases.

2. The following classes of diseases have been investigated: I. Fungous; II. Bacterial; III. Physiological; IV. Animal or Insect Pests.

3. Contrary to the statements of Massee and Chittenden, Thielavia basicola does not produce the "streak," but produces only a root rot of the sweet pea.

4. The pathogenic nature of Corticium vagum B. \& C. has been established.

5. Chaetomium spirochaete has been shown for the first time to be a plant pathogen, and especially to produce a root rot of the sweet pea.

6. A new Fusarium root disease has been described, and the name Fusarium lathyri Taubenhaus has been given to the fungus, and its pathogenicity established.

7. Of the Animal parasites the eel worm (Heterodera radicicola) has been shown to produce a root gall disease of the sweet pea. The disease is carefully described. The eel worm has also been shown to open the way to the attacks of several fungous diseases.

8. Sclerotinia libertiana has been shown for the first time to produce a collar rot as well as a stem disease of the sweet pea.

9. Studies on the mildew of the sweet pea have shown the disease to be very prevalent under greenhouse conditions as well as out of doors. The cause of the mildew is a species of Oidium. Observations up to date have failed to reveal the perfect stage of the fungus. 
10. Extended studies and cross inoculations have definitely proven that the anthracnose disease of the sweet pea and the bitter rot of the apple are caused by the same fungus Glomerella rufomaculans.

11. It has been also proven that the following pathogens, namely, Gloeosporium gallarum from oak gall, Gloes. diospyri from persimmon fruit, Gloe. officinale from the Sassafras, Colletotrichum nigrum from the pepper plant, Colletotrichum phomoides from the tomato, appear to be identical and the same as Glomerella rufomaculans, since they can all produce the anthracnose disease of the sweet pea and the bitter rot of the apple. Cross inoculations would no doubt reduce the great number of our so-called different species of Gloeosporiums.

12. The mosaic has been shown for the first time to produce a disease on the sweet pea. The pathogenicity and the infectious nature of the disease have been clearly demonstrated. Exceptions are taken with Woods that the disease is of a physiological nature but that it is induced by either bacteria or pro'tozoa which neither our microscope nor our present method of staining are able to detect. Insects and especially the green aphids seem to be the main carriers and distribu'tors of the disease.

13. Manns and Taubenhaus have definitely proven that the "streak" disease is caused by Bacillus lathyri M. \& T. and not by Thielavia basicola as previously believed by Massee and Chittenden.

14. Bud Drop in one form is here shown to be induced by a high nitrogen supply not properly balanced by phosphoric acid and potash; by addition of the latter the trouble is quickly corrected. Arrested development may be due to overtreatment of soil with wo d ashes the treatment being too caustic. Such an error may be corrected by the addition of acid phosphate.

15. Under methods of control it is shown that no one variety is immune to the anthracnose but there are certain individuals in each variety which are more or less immune to the disease.

16. Boiling the seeds for one or two seconds destroys the spores of parasitic fungi, but commercially the treatment is not applicable on large quantities of seed at a time.

17. Soaking the seeds in sulphuric acid for five minutes, fifteen minutes and one-half hour increases the per cent of germination and at the same time kills all the spores which adhere to the seed coat. 
18. Soaking the seeds in a $5 \%$ formaldehyde solution from five minutes to one hour does not iincrease nor decrease the percent of germination but helps to kill the spores which adhere to the seed coat.

19. Watering soils with chemical poisons does not increase the resistance of the plants which are grown on that soil. The latter adsorbs and fixes some of these poisons so as to make them harmless to plant growth.

20. A new method has been devised in determining the length of time in which any fungicide can remain efficient in controlling plant diseases when sprayed on the plant to be treated. 


\section{REFERENCES}

1. Condensed from A. C. Beal. Sweet pea studies III. Cornell Agr. Expt. Sta. Bul. 320: 661-713. 1912.

2. Bailey, L. H., Cyclopedia of American Horticulture, p. 1752. 1902.

3. Cuthbertson, Michael, Sweet pea cupid, Gard. Chron., Vol. XX, third series: 404, 1896.

4. Massee, George. Fungoid diseases of the sweet pea. Sweet Pea Annual: 18-22, 2 figs. 1906 (London).

5. Weston, T. A., The "Streak', The Gardener, 1906.

Weston, T. A. The streak disease of sweet peas. The Gardener: 585, 1907.

6. Anonymous. Sweet pea diseases. The Fruit Grower, Fruitier, Florist and Market Gardener: 295, 1907.

7. Massee, George. Sweet pea streak. Sweet Pea Annual: 22, 1909.

8. Massee, George. A disease of sweet peas, asters and other plants. Roy. Bot. Garden Kew Bul, of Misc. Information, No. 1: 44-52, 1 plate, 9 figs. 1912

9. Chittenden, F. J. Diseases of sweet peas, Sweet Pea Annual: 14-24, 1912 (London).

10. Dyke, W. Sweet pea streak. Amateur Gardening: 593, 1912.

11. Sheldon, J. L. Concerning the identity of the fungi causing an anthracnose of the sweet pea and the bitter rot of the apple. Science N. S. 22: 51-52. 1905 .

12. Taubenhaus, J. J. A Study of some Gloeosporiums and their relation to a sweet pea disease. Phytopahtology 1: 196-202, 1911.

Taubenhaus, J. J. A further study of some gloeosporiums and their relation ot a sweet pea disease. Phytopathology 2: 153-160, 1912.

Taubenhaus, J. J., and Manns, T. F. Diseases of the sweet pea. Gard. Chron. Vol. LIV: 21-26. 1913 (London).

13. Berkeley, M. J., and Broome, C. E. Notices on British fungi. Ann. and Mag. Nat. Hist. s. 2, Vol. 5: 461, 1850. London.

14. Zopf, W. Thielavia, genus novum, Perisporiacearum. Verhandl. Bot. Ver. Prov. Brandenburg j. 18. Sitzungsber 30 juni, 1876, pp. 101-105. Berlin, 1876.

15. Sorokin, N. Ueber Helminthosporium fragile sp. n. Hedwigia. Bd. 15: 113-114, 1876.

16. Saccardo, P. O. Clasterosporium fragile (Sorock.) Sacc. Sylloge Fungorum. 4: 386, 1886.

17. Sorauer, P. Handbuch der Pflanzenkrankheiten (Aufl. 2) 1886. Berlin.

18. Loc. cit. p. 9.

19. Loc. eit. p. 8

20. Loc. eit. p. 9 
21. Peglion, V.-Atti R. Accad. Lincei, an 294, s. 5, Rend. Cl. Sci. Fis., vol. 6, semestre 2, pp. 52-56. Roma, 1897.

22. Aderhold R. Impversuche mit Thielavia basicola zopf. Arb. Biol. Abt. Land. Forthw. Kaiserl. Gesundh. 4: 463-465. 1905.

23. Clinton, G. P. Root rot of tobacco. Conn. Agr. Expt. Sta. Rept. 1907.

24. Gilbert, W. W. The root rot of tobacco caused by Thielavia basicola.

Bur. Plant Indust. BuI. 158, 1909, Washington, D. C.

25. Manns, T. F. Studies in diseases of cereals and grasses. Ohio Agr. Expt. Sta. Bul. 203. 1909.

26. Duhamel, H. L. Explication physique d'une maladie qui fait perir plusieurs plantes dans le Gatinois et particulierement le Safran. Mem. Acad. Sciences, Paris, 1728.

27. Fougeroux de Bandaroy, Hist. de l'Acad. Roy. d. Sc. Annee 1782, p. 89, 1785, Paris. Paris.

28. Builliard, P. Histoire des champignons de la France T. I. p. 81, 1791,

29. Persoon, C. H. Synopsis methodica fungorum Gottingae p. 119, 1801.

30. De Candolle, A. P. Memoire sur les Rhizoctones. Mem. de Museum d' Histoire naturelle T. II, p. 209, 1815, Paris.

31. Nees, von Esenbeck. Th. F. L. System der Pilze Schamme p. 148, 1817.

32. Duby, H. E. Botanicum gallicum. Ed. II, Paris, p. 867, 1830.

33. Leveille, J. H. Mem. sur le genre Sclerotium. Ann. d. sc. nat. bot. T. XX, 1843, Paris.

34. Tulasne, L. R. and C. Fungi hypogaei p. 1851, Paris.

35. Kuhn, J. Krankheiten des Kulturgevachse, 1858.

36. Erikson, J. Einge Studies uber den Wurzeltoter (Rhizoctonia violacea) des Mohre mit besonderer Rucksicht auf seine Verbreitungs. fahigkeit Centrallblatt f. Bakt. Abh. II, Vol. X: $721 \& 766,1903$.

37. Gussow, Th. Jour. Roy. Agr. Soc. England. p. 175, 1905.

38. Shaw, F. J. F. The morphology and parasitism of Rhizoctonia. Mem. Dept. Agr. in India. Bot. Vol. IV, pp. 115-153, 2 plates. 1912, India.

39. Pammel, L. H. Bul. 15, Iowa Agr. Exp. Sta. 1891.

40. Atkinson, G. F. Some diseases of cotton, Bul. 41. Ala. Agr. Expt. Sta. 30-39, 1892.

41. Stone, G. E., and Smith, R. E. The rotting of greenhouse lettuce. Mass. Agr. Expt. Sta. Bul.-186, 1901.

42. Duggar, B. M., and Stewart, F. L. The Sterile fungus Rhizoctonia, Cornell Agr. Expt. Sta. Bul. 186, 1901.

43. Rolfs, F. M. Potato failures. A second rept., Colo. Agr. Expt. Sta. Bul. 91, 1904.

44. Stevens, F. L., and Hall, J. C. Hypochnose of pomaceous fruits. Ann. Mycologici, Vol. VII, 1909. Diseases of economic plants, 1910.

45. Fuckel, L. Symbolae mycologicae. Wiesbaden, p. 142, 1869.

46. Prunet, A. Sur le Rhizoctonia de la lucerne. Compt. Rend. T. C. XVII 1893, Paris.

47. Hartig, R. Untersuch aus d. forstbotan. Institut. zu Munchen, 1888. 
48. Frank, B. Ein neur Rebenbeschadiger in Rhenihessen. Zeitsch. f. d. Landw. Vereine d. Gossh. Hessev. 1897. No. 19, p. 167.

49. Loc. eit. p. 19

50. Loc. cit. p. 19.

51. Reinke J. und Berthold G. Die Zersetzung Der Kartoffel Durch Pilze. Berlin, 1879. pp. 100, tables XI.

52. Loc. cit. p. 26

53. Tulasne. Selecta fungorum carpologia tom. III. 1865.

54. Hansen, Ch. Dr. Jour. Roy. Mier. Soc. 321. 1883.

55. Smith, Worthington G. Diseases of field and garden crops, 1884.

56. Smith, E. F. The fungus infestation of agricultural soils in the United States. Proc. Amer. Assoc. Adv. Sce. 48: 303, 1889.

57. Kellerman, W. S., and Swingle, W. T. Loose smuts of cereals. Second Ann. Report, Kansas State. Agr. Expt. Sta. 213-238. 1889.

58. Frank, Jahb. d. deutsch landw. Ges. 1892.

59. Atkinson, G. Some diseases of cotton. Ala. Agr. Experiment Sta. Bul. 41, 1892.

60. Rostrup. Landboskrifter, Bd. V, 1893.

61. Smith, E. F. Wilt disease of cotton, watermelon and cowpeas. Bu. Plant Indus. U. S. Dept. Agr. Bul. 17, 1899.

62. Woods, A. F. The aster disease. Gardening 7: 277, 1899.

63. Manguin, Louis. Sur le parasitism Fusarium roseum et de especes affinie.

64. Prillieux et Delcroix. Sur la maladie des oeillets produits par le Fúsaruim dianthi P. \& Del.

65. Bolley, H. L. Flax wilt and flax sick soil. N. D. Sta. Bul. 50, 27-60, 1901.

66. Sorauer, P. Pflanzenkrankh. 11: 217-228, 1901.

67. Pammel, The grasses of Iowa. 1901.

68. Smith, R. E. "Growing china asters. Mass. Sta. Bul. 79, 1902.

69. Loc. cit. p. 28.

70. Hennings. P... Ztschr. Pflanzenkrankh. 12: 14-16, 1902.

71. Hall, Van C. Ber. d. Deutsch. bot. Ges. 1903, p. 2.

72. Smith, E. F., and Swingle. The dry rot of potatoes. Bur. of Plant Industry, U. S. Dept. Agr. Bul. 55, 1904.

73. Osterwalder, A., Dr. Uber eine buscher unbekannte Art. der kernobsfaule verursacht durch Fusarium putrefaciens Centbl. Bakt. 2 Abt. 207-213, 1904.

74. Owen, V. Uber ein Fusarium Krankheit der Tomaten. Landw. zahrb. p. $489,1905$.

75. Appel, O. und Schikarra, G. Arb. K. Biol. Inst. Land. U. Forstw. 5: 155-188, 1906.

76. Heald, F. D. Bud rot of earnations Abs. in Sci. n. ser 23: 620, 1906.

77. Hedgecock, G. G. Studies upon some chromogenic fungi which discolor wood. Mo. Bot. Garjen Rept. 17. III. 1906.

78. Chiffot, J. A. A study of disease of pelargonium Journ. Soe. Nat. Hort. France 9: 348-355, 1907. 
79. Burrill, T. J., and Barrett, J. T. Ear rots of corn. Illinois Sta. bul. $133,1909$. 1910.

80. Wolf, F. A. A Fusarium disease of the pansy. Mycologia 2: 19-22,

81. Smith, E. F. A Cuban banana disease. Abs. in Science N. ser 31: 754-755, 1910.

82. Cook, M. T. The double blossom. Abs. in Sci. N. ser 751, 1910.

83. Bubak, J. F., and Kosaroff, P. Some interesting plant diseases from Bulgaria, Centbl. Bakt. 2 abt. 31: 495-502, 1911.

84. Gifford, C. M. The damping off of coniferous seedlings. Vt. Sta. Bul. 156: 143-171, 1912.

85. Wollenweber, H. W. Studies on the Fusarium problem. Phytopathology 3: 24-50, 1913 .

86. Loc. cit. p. 29.

87. Marcinowski, Kati. Parasitisch und semi parasitsch an Pflanzen lebende nematoden Arbeiten aus der K. Biol. Anst. fur Land und Forstwirtschaft, Berlin 7 : 1-192. 1909.

88. Bessey, E. A. Root knot and its control. U. S. Dept. Agr., Bureau Pl. Industry., Bul. 217: 7-82, 1911.

89. Loc. cit. p. 32 .

90. Chittenden, F. J. Diseases of the sweet pea. Sweet Pea Annual, 14-24, 1912. England.

91. Coemans, M. E. Recherches sur la genese et les metamorphoses de la Peziza sclerotiorum Lib. Bul. l'acad. roy. des Sciences de Belgigue II, 9: 61, 1860 .

92. De Bary, A. Uber einige Sclerotinien und Sclerotinien Krankheiten Bot. Zeitz $44: 378,1886$.

93. Cohn, F. Illustr. landw. Ztg. 1887.

94. Smith, W. G. Gard. Chron. III, 8: 324, 1890.

95. Behrens, J. Uber das auftreten des Hanfkrebses in Elsass. Zeitschr der Pflanzen Krank 1: 208. 1891.

96. Humphrey, J. E. The rotting of lettuce. Rept. Mass. State Expt. Sta. 8: 219. 1892.

Humphrey, J. E. Disease of the cucumber plant. A sclerotium disease. Rept. Mass. Txpt. Sta. 10: 212, 1893.

97. Prillieux, M. M. et Delacroix, Maladie des branches des muriers de la Turquie d' Europe. Compt. Rend Acad. Sci., Paris. Vol. 124: 1168-1176, 1897.

98. Smith, Ralph E. Botrytis and Sclerotinia. Their relation to certain plant diseases and to each other. Bot. Gaz. $29: 369-406,1900$.

99. Hedgeock, G. G. A disease of eauliflower and eabbage. Mo. Bot. Gard. Ann. Rept. 16: 149-151, 1905.

100. Parisot, F. Maladie des Topinambours, Jour. Agr. Prot. N. Ser. 10: 369-371, 1905.

101. Appel, Otto, and Bruch, F. W. Sclerotinia libertiana Fckl. als Schadiger von Wurzel Fruehten Arb. K. Biol. anst. Land u. Forstw. 5: 189-263, 1906.

102. Masseron, P. Une nouvelle maladie des pois cultives. Semaine Agricole (Paris) 26. 270, 1907. 
103. Westerdijek. Zoha. Untersuchungen uber Sclerotinia libertiana Fckl. als Pflanzen parasit mended. Phyto, Lab. Willie Commelin Scholten. pp. 5-26. 1911.

104. Taubenhaus, J. J. Present knowledge of sweet pea diseases. Florist exchange $34: 108-110,1912$.

105. Loc. cit. p.

106. Massee, G. Fungoid diseases of the sweet pea: Sweet Pea annual, 20-21, 1906.

107. Stewart, F. C. Notes on New York plant diseases. New York (Geneva) Agr. Expt. Sta. Bul. 328: 394, 1910.

108. Sheldon, J. L. Concerning the identity of the fungi causing an anthracnose of the sweet pea and the bitter rot of the apple. Science, N. S. 22: 51-52. 1905.

109. Edgerton, C. W. Diseases of the fig and fruit. La. Agr. Exp. Sta. Bul. $126: 7.1911$.

110. Cook, M. T., and Taubenhaus, J. J. The relation of parasitic fungi to the contents of the cells of the host plants. Del. College Agr. Expt. Sta. Bul. 97 : 3-52. 1912 .

111. Mayer, Adolf. Landw. Versuchsstation, Vol. 32, 1886.

112. Land- und Forstwirthschaft, 1892. Cf. Berh. Z. Bot. CentralbI. Bd. 111, p. 266.

113. Comp. rendu hebd. des Seances de l'acad. des. Sc. CXVIII-XII, p. 668, 1894.

114. Revue mycologique XIX, 73, p. 13, 1897.

115. Loc. cit. p. 53.

116. Woods, A. F. Observations on mosaic diseases of tobacco. U. S. Dept. of Agr. Bur. of Pl. Indstry. Bul. No. 18, 1902.

117. Selby, A. D. Tobacco disease and tobaceo breeding. Ohio Agr. Expt. Sta. Bul. 156, 1904.

118. Allard, H. A. The mosaic diseases of tobacco. Science N. ser. Vol. XXXVI: 875-876, 1912.

119. Loc. cit. p. 10.

Exchange, 1912.

120. Loc. cit. p. 53.

121. Loc. cit. p. 53.

122. Conn. Agr. Expt. Sta. Rept. 1898.

123. Loc. cit. p. 54.

124. Bulletin of the College of Agr., Imp. Univ. Tokyo, IV, No. 3, 1900.

125. Massee, George. Fungoid diseases of the sweet pea. Sweet Pea Annual, 18-22, 1906.

126. Weston, T. A. Gardener, 1906.

127. Massee, George. The Sweet Pea Annual, 1909, England.

128. Chittenden, F. J. The Sweet Pea Annual, 14-24, 1912.

Chittenden, F. J. On some plant diseases new or little known in Britain. Jour. Royal Hort. Soc. 36: 545-550, 1912. 
129. Massee, George. A disease of sweet peas, asters, and other plants (Thielavia basicola Zopf.) Bul. of Miscl. Information: 44-52, 1912. Kew Bot. Garden, London.

130. Dyke, Van. Gard. Chron. 51: 36 ; 52-53; 84-85, 1912 . London.

131. Massee, George. Sweet Pea Annual, 1912.

132. Manns, T. F., and Taubenhaus, J. J. Streak a bacterial disease of the sweet pea and clovers. The Gard. Chron. (London), Apr. 5, 1913, pp. 215-216. 133. Rostrup, O. Report of the Danish seed control for 1896-97. pp. 37, 1898. Copenhagen (Review E. L. R. 10: 53-54.)

134. Todaro, F. Arzione dell' Acido solforico concentrato su alcuni semi, 2 in particolare sopra i semi duri delle Leguminose. Staz. Sper. Agr. Ital. 34: 613-689, 1911 (Review E. S. R. 13: 754-755.)

135. Thornber, J. J. Arizona Agr. Expt. Station, Rept. pp. 489-493, 1904.

136. Schneider-Orelli, O. The resistance of medicago seed to high temperatures. Flora 100: 305-311, 1910 (Review E. S. R. 24: 231.)

137. Bolley, H. L. The agricultural value of hard seeds in alfalfa and elover seeds. Paper read before the Association of O..cial Seed Analysis, 1910.

138. Love, Harry H., and Leighty, Clyde E. Germination of seeds as affected by sulphuric acid treatment. Cornell Univ. Agr. Expt. Sta. Bul. 312: 295-336, 1912.

139. Manns, T. F. The Fungi of flax sick soil and flax seed (unpublished) 1903, and later methods by the same author.

140. Bul. 107, Bur. of Chem.

141. Reddick, D., and Wallace, E., Science, n. ser. 31: 789, 1910.

142. Quoted from Gilbert, W. W. The root rot of tobacco eaused by Thielavia basicola. U. S. Dept. Agr., Bur. Pl. Industry., Bul. 158: p. 48, 1909. 


